Florida International University

FIU Digital Commons

FIU Electronic Theses and Dissertations

University Graduate School

$10-21-2019$

\title{
Incorporating Early Life History and Recruitment in Analysis of Population Dynamics of Wetland Fishes
}

John Vincent Gatto

Florida International University, jgatt006@fiu.edu

Follow this and additional works at: https://digitalcommons.fiu.edu/etd

Part of the Aquaculture and Fisheries Commons, and the Population Biology Commons

\section{Recommended Citation}

Gatto, John Vincent, "Incorporating Early Life History and Recruitment in Analysis of Population Dynamics of Wetland Fishes" (2019). FIU Electronic Theses and Dissertations. 4353.

https://digitalcommons.fiu.edu/etd/4353

This work is brought to you for free and open access by the University Graduate School at FIU Digital Commons. It has been accepted for inclusion in FIU Electronic Theses and Dissertations by an authorized administrator of FIU Digital Commons. For more information, please contact dcc@fiu.edu. 


\section{FLORIDA INTERNATIONAL UNIVERSITY}

Miami, Florida

INCORPORATING EARLY LIFE HISTORY AND RECRUITMENT IN THE ANALYSIS OF POPULATION DYNAMICS OF WETLAND FISHES

A dissertation submitted in partial fulfillment of

the requirements for the degree of

DOCTOR OF PHILOSOPHY

in

BIOLOGY

by

John Vincent Gatto

2019 
To: Dean Michael R. Heithaus

College of Arts, Sciences and Education

This dissertation, written by John Vincent Gatto, and entitled Incorporating Early Life History and Recruitment in the Analysis of Population Dynamics of Wetland Fishes, having been approved in respect to style and intellectual content, is referred to you for judgment.

We have read this dissertation and recommend that it be approved.

Ed Houde

Kevin Boswell

Gary Rand

Yuying Zhang

Yannis Papastamatiou

Joel C. Trexler, Major Professor

Date of Defense: October 21, 2019

The dissertation of John Vincent Gatto is approved.

Dean Michael R. Heithaus
College of Arts, Sciences and Education

College of Arts, Sciences and Education

Andrés G. Gil

Vice President for Research and Economic Development and Dean of the University Graduate School

Florida International University, 2019 


\section{DEDICATION}

This dissertation is dedicated to my family. My parents encouraged me to follow fish, not chemistry, in my quest to add another doctor to the Gatto name. And finally, Josephine Gustowski, who never made it to see my potential realized. 


\section{ACKNOWLEDGMENTS}

Several field technicians, graduate students, and professionals deserve credit for this dissertation. First, I would like to thank my advisor, Joel Trexler, who saw my potential as a student and guided me throughout all these difficult years. I would like to thank my committee members- Ed Houde, Yuying Zhang, Yannis Papastamatiou, Kevin Boswell, and Gary Rand-for helping me develop my dissertation and introducing me to a variety of topics and techniques. I wish to also thank Jeff Kline, Everglades National Park, and Joel Trexler again for granting me access to the large time series dataset used throughout the dissertation. I wish to thank the George Maier Fund for funding the research behind several Chapters. Funding from the Florida International University Dissertation Year Fellowship made writing this dissertation possible. Alan Katzenmeyer and Jan Hoover, United States Army Corps of Engineers (USACE), were generous for lending their Blazka-style swim chamber. Jessica Sanchez and Sarah Bornhoeft assisted in field sampling and feeding aquarium fish. Scientific discussions with Abe Smith improved my understanding of swimming performance methods and analyses. Finally, I would like to thank the hard-working Aquatic Ecology field technicians and lab managers. Aaron Zenone performed the tedious task of extracting numerous otoliths for a chapter of this dissertation. Sommer Smott assisted in updating the data files and the QA/QC of the time series dataset. Post-docs Alex Mercado, Joe Parkos, and Nathan Evans acted as great mentors throughout my time at FIU. Sofia Burgos, Bree Zenone, and James Herrin ordered and organized the tools and supplies needed to conduct this research. James Herrin provided additional advice on programming in SAS. Justin Dummit was 
instrumental in planning all the field work needed to collect specimens for each Chapter.

Without his assistance, no field collections would have been possible under the chaotic field sampling schedule of the lab. 


\title{
ABSTRACT OF THE DISSERTATION \\ INCORPORATING EARLY LIFE HISTORY AND RECRUITMENT IN THE ANALYSIS OF POPULATION DYNAMICS OF WETLAND FISHES
}

\author{
by \\ John Vincent Gatto \\ Florida International University, 2019 \\ Miami, Florida \\ Professor Joel C. Trexler, Major Professor
}

Hydrological variation is believed to be the major abiotic factor influencing fish recruitment in floodplain ecosystems. However, past studies fail to address the impact of hydrology on the three major drivers of recruitment: age-specific growth and mortality, and dispersal. I examined long-term recruitment dynamics for six fish species inhabiting the Everglades by addressing the impact of hydrology on these important characteristics. I then linked these changes to annual fluctuations in population size.

Before interpreting time-series data on recruitment, I evaluated the impact of sizeselective bias from sampling gear on our interpretation of hydrological drivers of recruitment. Analyses revealed that individuals under the size of maturation were under represented, but these individuals could be estimated using a stage-based model. Analyses of the corrected data revealed that recruitment primarily occurred in October for most species, driven by changes in water depth and the number of days post-drying.

Recruitment variability in fish stocks is commonly assumed to be controlled by density-dependent processes. I examined density-dependent feedback on recruitment by 
evaluating stock-recruitment models. I found strong evidence for density-dependence along a wide hydrological gradient. This feedback was driven by recruitment from the previous season and was strongest at short and long hydroperiods.

Immigration/emigration also explained residual variance in these models. To quantify dispersal, I evaluated the recolonization patterns following disturbance. The sequence of species arrival was highly repeatable. Interspecific differences in both speed and directedness estimated by swimming tests and field data best described arrival order of these species. Directedness was more strongly correlated with faster recolonization than speed. The transitional age when mortality equals weight-specific growth $\left(\mathrm{M}^{\prime} / \mathrm{G}^{\prime}=1\right)$ is an important indicator of recruitment success. Analyses revealed that the transitional age was correlated with annual changes in species abundance. The timing of the transitional age occurred later in life as disturbance frequency increased, with highly dispersing species unaffected.

My research has detailed how hydrology influences the three indicators of recruitment success. Interpretation of these results can only be accomplished after accounting for bias in sampling gear, identifying the source of density-dependent mortality, and accounting for movement from long-distance dispersal. 


\section{TABLE OF CONTENTS}

CHAPTER

PAGE

PREFACE

.1

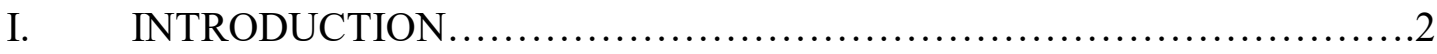

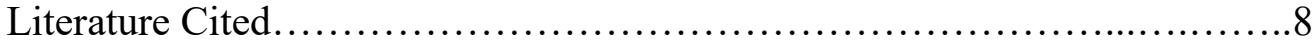

II. SEASONALITY OF FISH RECRUITMENT IN A PULSED

FLOODPLAIN ECOSYSTEM: ESTIMATION AND

HYDROLOGICAL CONTROLS........................................12

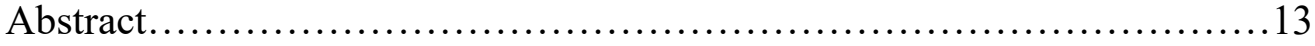

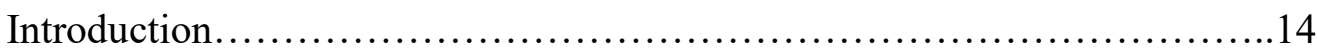

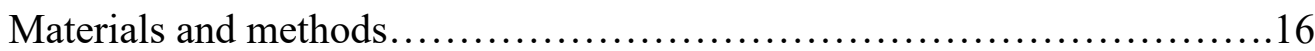

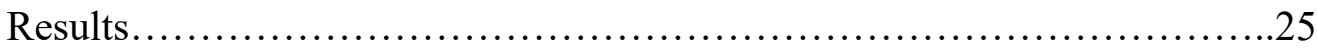

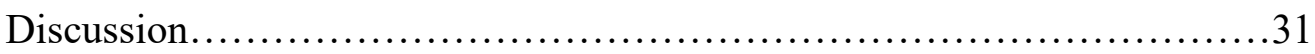

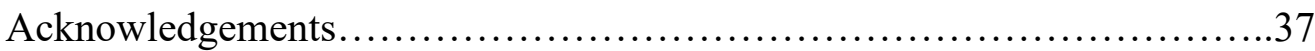

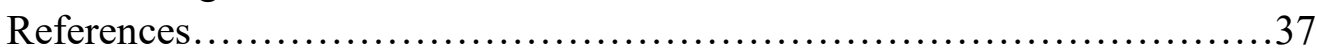

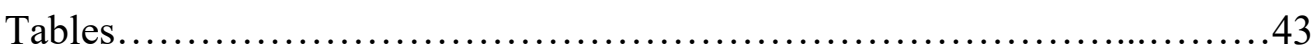

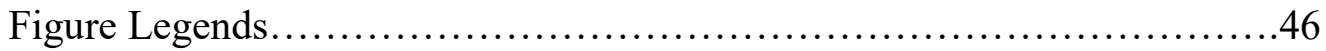

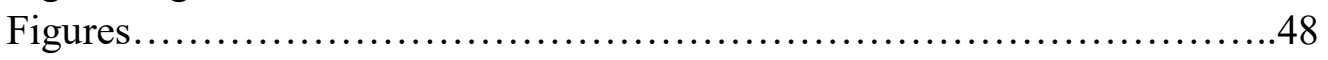

III. EVALUATING DENSITY-DEPENDENT RECRUITMENT IN A PULSED FLOODPLAIN ECOSYSTEM.................................56

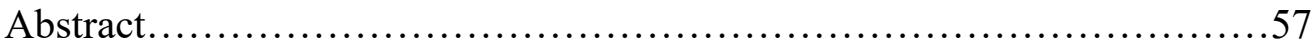

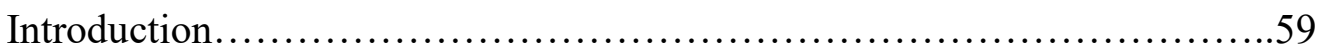

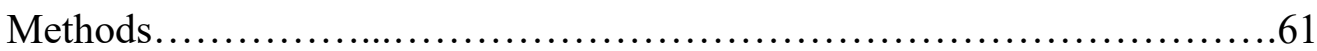

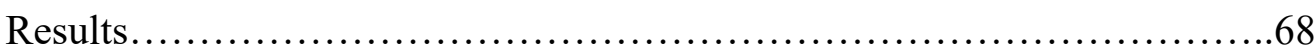

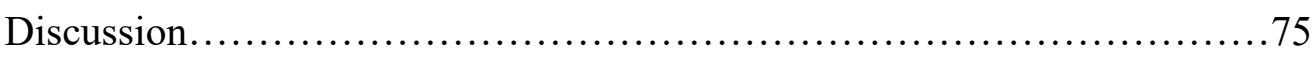

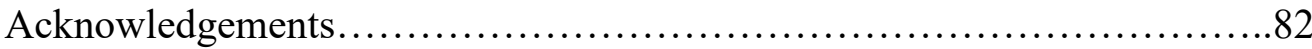

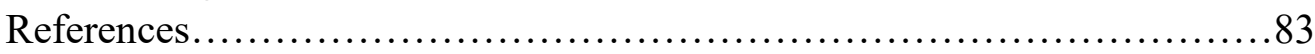

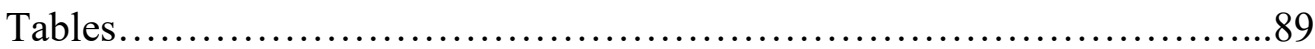

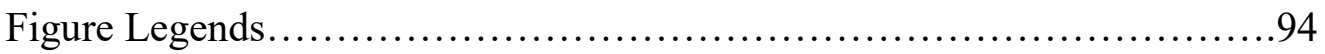

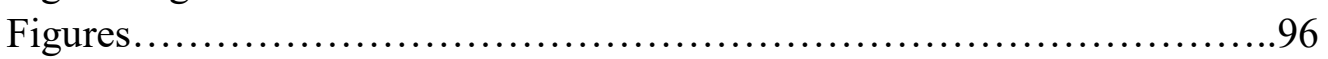

IV. SPEED AND DIRECTEDNESS PREDICT COLONIZATION

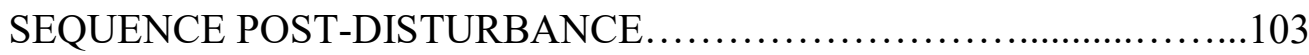

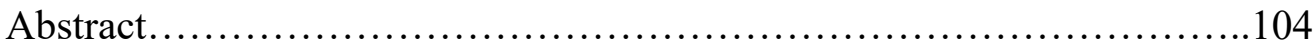

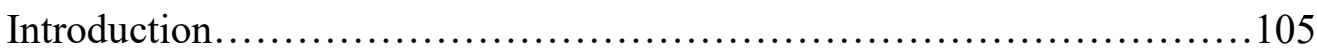

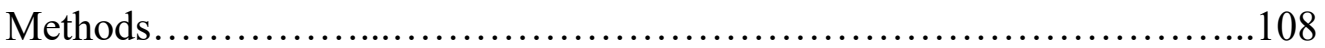

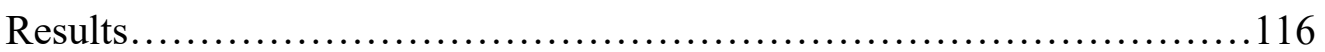




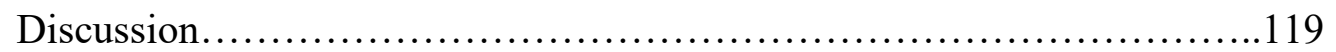

Acknowledgements................................................. 123

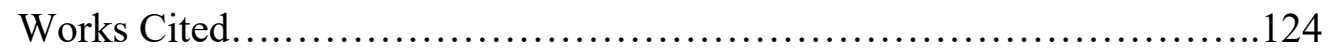

Tables............................................................. 131

Figure Legends................................................. 135

Figures........................................................ 136

V. LINKING AGE-SPECIFIC MORTLAITY AND GROWTH RATES TO ANNUAL CHANGES IN ABUNDANCE AND BIOMASS WITHIN A FLUCTUATING ENVIRONMENT .......................... 140

Abstract...........................................................141

Introduction....................................................... 142

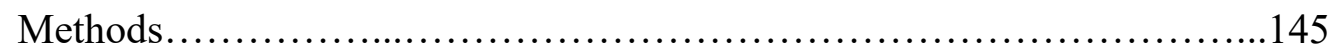

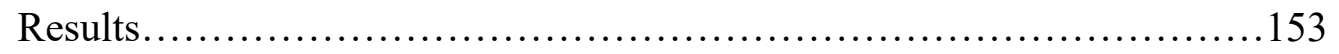

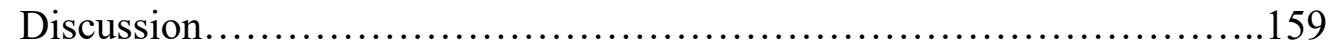

Acknowledgements................................................. 164

Works Cited ......................................................... 165

Tables.......................................................... 170

Figure Legends................................................ 173

Figures..................................................... 175

VI. CONCLUSIONS AND FUTURE DIRECTIONS ...................... 182

Literature Cited..................................................187

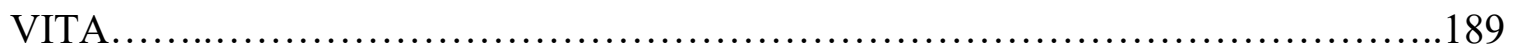




\section{LIST OF TABLES}

TABLE

PAGE

\section{CHAPTER II}

1 Assumptions made for the generalized linear models on the abundance-at-age data. Age and size at maturation is for females in species with sexual dimorphism.

2 Summary statistics of hydrological variables throughout the 20 years of the study by sites located in Shark River Slough, Taylor Slough, and Water Conservation Area at the date of sampling. Under Number of Drying Events, parentheses indicate individual plots

3 Mean $\left({ }^{+} /\right.$- SE) slope parameter estimate over the 17-year time series by site and species. The slope for each Generalized Linear Model is equivalent to the instantaneous mortality rate $\left(Z\right.$, individuals $\left.\mathrm{mm}^{-1}\right)$. Estimates for each individual year were used in our VPA to estimate recruit abundance...

\section{CHAPTER III}

1 Stock-recruitment models considered for our analysis. The seasonal and DSD models were added for comparison to standard S-R models (Iles 1994)....89

2 Population dynamics models that were considered for our analyses (Dennis and Taper 1994). The response variable was changed from Changes in population abundance $(\mathrm{Nt}+1 / \mathrm{Nt})$ to changes in recruit Abundance $(\mathrm{Rt}+1 / \mathrm{Rt})$. This represents changes in the recruitment rate

3 Estimates for the density-independent $(\alpha)$ and -dependent $(\beta)$ terms for our S-R models. Estimates of $\beta$ were set to zero if a density-independent model was selected.

4 Partial correlations for each parameter included in our Type III S-R regressions. Correlations were averaged based on disturbance intensity (Mean $+/-\mathrm{SE}$ ). Correlations for $\beta$ are missing if a density-independent model was selected.

$5 \quad$ Partial correlations for each parameter included in our Type III population models. Correlations were averaged based on disturbance intensity (Mean +/- SE)

\section{CHAPTER IV}

1 Restrictions and characteristics of the six virtual species (agents) used in the ABM's. Restrictions on orientation were used to produce varying levels of directedness 
2 The arrival probabilities for each species $(n=536)$ estimated from field data collected post-disturbance $\left({ }^{+} /-95 \% \mathrm{CI}\right)$. Some species arrived at the same sample event and were assigned the same ranks; probabilities were calculated by species, so columns but not rows sum to one..................132

3 Comparison of species dispersal characteristics from both laboratory and field studies. Direct estimates of speed were calculated following endurance tests $\left(\right.$ Mean $\left.{ }^{+} /-\mathrm{SE}\right)$. Field measures of speed $\left(\right.$ Mean $\left.{ }^{+} /-\mathrm{SE}\right)$ were estimated using encounter samplers (Bush 2017). Observed directedness was taken from Hoch et al (2015)...

$4 \quad$ Arrival probabilities for each species of simulated dispersal using ABM's and Kendall's Rank Correlation Coefficient $(\tau)$. Species are arranged left to right by decreasing levels of directedness. Some species arrived at the same sample event and were assigned the same ranks; therefore, only column values will sum to one. Kendall's Tau is calculated based on comparing values in the same row and columns (Arrival Order) from Table 2. Two asterisks (**) indicate significance at $\alpha=0.05$ and single asterisk (*) indicates significance at $\alpha=0.10$.

\section{CHAPTER V}

1 Estimates of the VBGF growth parameter K (mm day-1) and standard Error for all species collected between 2014 and 2016. Data for $F$. chrysotus and $H$. formosa in 2016 were not available.

2 Estimates of the age-based instantaneous mortality rate M (individuals day-1) and standard error for all species collected between 2014 and 2016. Estimates were standardized to daily mortality rates. Data for $F$. chrysotus and $H$. formosa in 2016 were not available...

3 The Coefficient of Variation (CV) of stage-specific mortality $\mathrm{M}$ and growth $\mathrm{G}$ for the early life stages (birth/hatch) of each species. $\mathrm{CV}$ percentages were calculated at $7 \mathrm{~mm}$ (F. chrysotus, G. holbrooki), $6 \mathrm{~mm}$ (H. Formosa, J. floridae, L. goodei) and 9mm (P. latipinna). The ratio of the CV's (M/G) was also calculated. All species, sites, and years per hydroperiod classification were averaged together to calculate the mean $\mathrm{CV}$ at each hydroperiod classification (+/- SE). Sample size vary by hydroperiod classification per species ( $n=4$ to 6 ). 


\section{LIST OF FIGURES}

FIGURE

PAGE

CHAPTER II

1 Map of the sites in this study.

2 Mean water depth with 95\% confidence interval at each sample event averaged across all sites within the hydroperiod classification (Long, Intermediate, and Short hydroperiods). Values underneath the dashed reference line $(5 \mathrm{~cm})$ are considered too dry for fish species. Vertical bars enclose one year of samples (5 samples per year) from February to December (D)

3 The unadjusted (filled circles) and adjusted (open circles) size-selectivity curves for each study species in 1-mm increments. The dashed line indicates the size of maturation for that species.

$4 \quad$ An example of average differences in density between VPA estimates and observed densities. Data for SRS Site 07 over the 20-year study for A) Golden Topminnow, B) Eastern Mosquitofish, C) Least Killifish, D) Flagfish, and E) Bluefin Killifish. Estimates reveal seasonal changes in peak recruitment following cohort analysis. ...

5 Partial regression plots describing changes in Bluefin Killifish recruit density at WCA 10 (Intermediate Hydroperiod). The three-parameter quadratic model (no intercept) was selected based on AIC values. $\mathrm{K}=3$,

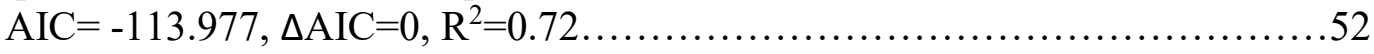

6 Scatter plot describing how recruit abundance increases with increasing water depth for Least Killifish at WCA 06 (Long Hydroperiod) based on the linear model (no intercept) selected by $\mathrm{AIC} . \mathrm{K}=1, \mathrm{AIC}=13.81, \triangle \mathrm{AIC}=0$, $\mathrm{R}^{2}=0.61$

7 A) Partial regression plots describing annual variability in peak recruit density driven by site hydroperiod for Golden Topminnow at TSL MDsh (Short Hydroperiod). B) Model predicted values of annual maximum recruitment versus the corresponding hydroperiod for each species....

8 A) Partial regression plots describing annual variability in total annual recruit density driven by site hydroperiod for Flagfish at TSL MDsh (Short Hydroperiod). B) Model predicted values of annual total recruitment versus the corresponding hydroperiod for each species. 


\section{CHAPTER III}

1 Boxplots describing the strength of evidence for each species across all 21 study sites. The strength of evidence was calculated by summing the Aikake weights $(\mathrm{AICw})$ for all density-independent and -dependent models respectively.

2 The $\log 10$-transformed evidence ratios (LER) for the stock-recruitment models. This includes the Random Walk (RW), density-independent (EX St), lagged density-independent (EX St-1), Seasonal models (SE), DSD models (HY), Cushing S-R models (CU), density-dependent S-R models (DD St), and lagged density-dependent models (DD St-1). B) LER's for the population dynamics models. This includes the densityindependent models (DI), days since last dry down (DSD), and density dependent models (DD). DD models are separated based on the independent variable used (Rt, Rt-1, St St-1).

$3 \quad$ Bar graph describing the significant parameters for our Type III stock-recruitment analysis. A) Density-independent models and B) Density-dependent models

$4 \quad$ Bar graph describing the significant parameters for our Type III population dynamics model.

5 A) Scatterplot showing the relationship between the CV of hydroperiod and the density-independent stock-recruitment parameter $(\alpha)$ for L. goodei. B) Scatterplot showing the relationship between the CV of hydroperiod and the steepness of the S-R relationship (h) for L. goodei. Estimates were calculated based on the best model at each site $(\triangle \mathrm{AIC}=0)$

6 A) Scatterplot showing the relationship between the CV of Hydroperiod and the strength of density-dependence for J. floridae. B) Model predicted values for the relationship between the $\mathrm{CV}$ of Hydroperiod and the strength of density-dependence. Estimates for $\beta$ were taken from the best model at each site $(\triangle \mathrm{AIC}=0)$

7 A) Scatterplot from our Type III regressions showing the relationship between the CV of Hydroperiod and the strength of density-dependence for F. chrysotus. B) Model predicted values for the relationship between the $\mathrm{CV}$ of Hydroperiod and the strength of density-dependence. Estimates for $\beta$ were taken from the best model at each site using Type III Sum of Squares $(\triangle \mathrm{AIC}=0)$ 


\section{CHAPTER IV}

1 A visual representation of the virtual world for ABM's created in Netlogo. The original habitat (striped region) is located $1000 \mathrm{~m}$ due south of refuge habitat (checkered region).

2 Results of ANOVA with Tukey's Pairwise Comparisons on interspecific variation in $\mathrm{U}_{\mathrm{CR} I T}$. Three distinct groups were detected (Fast, Intermediate, Slow) and are indicated by the enclosure of the means in ellipses.

3 Three-dimensional plot describing arrival probabilities based on speed/directedness combinations from the ABM's for A) Arriving First and B) Arriving Fourth. The horizontal axes for Figure 3B were rotated $180^{\circ}$ to highlight differences between fast/directed and slow/non-directed. Arrival probabilities were calculated based on arrival time at the end of each simulated run. C) Observed field probabilities of arriving first based on a species estimated $U_{\text {CRIT }}$ and observed directedness in the field. U $U_{\text {CRIT was }}$ calculated from endurance tests. Directed species were assigned a value of 1 and non-directed species a value of 0 . Observed field probabilities were calculated based on species' arrival times following re-inundation of the habitat (Table 2)

$4 \quad$ Probability plots of two metrics of recolonization potential: Speed and directedness. A) The probability of arriving first based on a species' level of directedness (independent of speed) and speed (independent of directedness). B) The proportion of each individual arriving at the refuge habitat after each run based on a species' level of directedness (independent of speed) and speed (independent of directedness).

\section{CHAPTER V}

1 Results from our general linear model (GLM) testing differences in the instantaneous mortality rates $\mathrm{M}$ among hydroperiod types for

A) Length-based methods and B) Age-based methods. Estimates for age-based methods were standardized to daily mortality rates

2 Average $\mathrm{M}^{\prime} / \mathrm{G}^{\prime}$ curves as a function of length $(\mathrm{mm})$ for short, intermediate, and long hydroperiod sites. Estimates for G. holbrooki and L. goodei were based on two sites per hydroperiod from 2014-2016 (n=6). Estimates for F. chrysotus and $\mathrm{H}$. formosa were based on two sites per hydroperiod from 2014-2015 $(\mathrm{n}=4)$. Shaded regions indicate $95 \%$ confidence intervals. Darkest areas indicate overlap in confidence intervals. Confidence intervals were excluded for intermediate hydroperiod sites because overlap with both long and short hydroperiod curves obscured patterns. Vertical reference lines indicating the size at the transition period were included for each hydroperiod

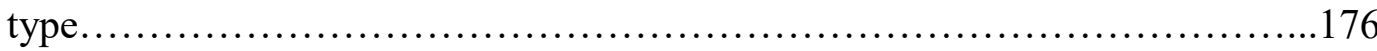


3 Relationship between the log-transformed transition age (days) and annual abundance for the pooled data of each species...............................177

$4 \quad$ Site-specific relationship between the log-transformed transition age (age $\mathrm{M}^{\prime} / \mathrm{G}^{\prime}=1$ ) and annual abundance for L. goodei. Two examples for each hydroperiod type are presented and selected based on sites used for the growth study

5 Results from our general linear model (GLM) testing differences in species A) Annual density, B) Biomass density, C) Age $\mathrm{M} / \mathrm{G}=1$, and D) Length $\mathrm{M} / \mathrm{G}=1$ among disturbance regimes

6 A) Scatter plot demonstrating the relationship between Annual Hydroperiod (disturbance intensity) and the transition age (age $\mathrm{M}^{\prime} / \mathrm{G}^{\prime}=1$ ). B) Scatter plot demonstrating the relationship between the CV of Hydroperiod (hydrological variability) and the CV of the transition period......180

$7 \quad$ Mean transition age $\left(\right.$ age $\left.\mathrm{M}^{\prime} / \mathrm{G}^{\prime}=1\right)$ at each site for each species. The transition period was averaged across 20 years for each site. Sites are arranged from least disturbed (right) to most disturbed (left) 


\section{PREFACE}

The following chapters will be submitted or have been accepted for publication and are formatted according to journal specifications:

\section{CHAPTER II}

Gatto, J. V. and J. C Trexler. 2019. Seasonality of Fish Recruitment in a Pulsed Wetland Ecosystem: Estimation and Hydrological Effects. Environmental Biology of Fishes. 102 (4): 595-613.

\section{CHAPTER III}

Gatto, J. V. and J. C Trexler. Evaluating Density-Dependent Recruitment in a Pulsed Floodplain Ecosystem. Canadian Journal of Fisheries and Aquatic Science.

\section{CHAPTER IV}

Gatto, J. V. and J. C Trexler. Speed and Directedness Predict Colonization Sequence Post-Disturbance. Journal of Animal Ecology. In review

\section{CHAPTER V}

Gatto, J. V. and J. C Trexler. Linking Age-Specific Mortality and Growth Rates to Annual Changes in Abundance and Biomass within a Fluctuation Environment. Canadian Journal of Fisheries and Aquatic Science. 


\section{CHAPTER I}

INTRODUCTION 
The process of fish being added to the exploitable stock each year due to growth and/or migration into the fishing area, known as recruitment, has become a central theme in fisheries biology (Blackhart et al. 2006). Hjort originally described the effects of early life history on recruitment dynamics with the Critical Period and the Aberrant Drift Hypotheses (Hjort 1914, Hjort 1926). Direct and indirect derivations of these have evolved, including the Match-Mismatch Hypothesis, the Lottery Hypothesis, the Stable Retention Hypothesis, the Optimal Environmental Window Hypothesis, and the Stable Ocean Hypothesis to further explain recruitment variability not explained by Hjort's original ideas (Lasker 1978, Sale 1978, Iles and Sinclair 1982, Sinclair and Tremblay 1984, Cushing 1990). Although these hypotheses incorporated prey availability, larval dispersal, and environmental conditions, each addresses some aspect of the biotic or abiotic factors influencing age-specific growth, mortality, and dispersal. Further work revealed that the ratio between age-specific somatic growth and mortality ( $\left.\mathrm{M}^{\prime} / \mathrm{G}^{\prime}\right)$ is critical to recruitment success. Often described as "the universal process", the timing of the "transition period" $\left(\mathrm{M}^{\prime} / \mathrm{G}^{\prime}=1\right)$ is critical to recruitment success and best summarizes the density-independent and -dependent factors altering recruitment (Houde 1987, Anderson 1988, Houde 1996).

Changes in hydrology are predicted to be the major environmental factor that influences fish recruitment in floodplain ecosystems (Arthington and Balcombe 2011). Environmental variability has the greatest impact on the early life stages and influences survival rates of the pre-recruit stages (Fogarty et al. 1991). Furthermore, habitat loss due to hydrological modification is believed to be the major source of reduced recruitment in modified rivers (Aarts et al. 2004). These habitats generate slack water 
areas that provide refuges from high flows, acting as spawning and nursery areas (Humphries et al. 1999, King et al. 2003). Species have adapted to exploit these pulses in primary productivity following inundation, but these adaptations are often life-history dependent (Agostinho et al. 2004, Winemiller 2004). The importance of flooding dynamics on recruitment success has been extensively evaluated; however, the impact of altered hydrology on age-specific mortality, growth and dispersal have yet to be explored.

The freshwater marshes of the Florida Everglades provide acts as an excellent system to study the effects of hydrology on age-specific mortality, growth, and dispersal in relation to successful fish recruitment. These marshes experience seasonal rainfall patterns with an annual dry (February-June) and wet (July-January) period (Ogden et al. 2005), with seasonal inundation a direct result of rainfall and drought being caused by evaporation of surface water (Fennema et al. 1994). Altered hydrology and seasonal patterns of disturbance are the major abiotic factors that controls population dynamics of marsh fish and invertebrates (Ruetz et al. 2005, Trexler et al. 2005, Parkos et al. 2011). The seasonal patterns of disturbance influence temporal shifts of fish densities, causing these organisms to immigrate in with flooding or emigrate out when drying or face desiccation (Trexler et al. 2011, Yurek et al. 2013). Small-bodied marsh fish make use of these shallow water habitats and escape predation from large bodied predators but are forced to move to riskier habitats during a dry-down. These patterns of response to disturbance may be linked to adaptive life history traits, such as rapid life cycles of Everglades fish, which have been shown to regulate recruitment in other floodplain systems (Haake and Dean 1983, Loftus and Eklund 1994, Bunn and Arthington 2002). Extensive work has been done to describe adult and juvenile fish movement and patterns 
of recolonization between long and short hydroperiod sites (DeAngelis et al. 2010, Obaza et al. 2011a, Goss et al. 2014b); however, very little information exists on the biotic and abiotic controls that regulate recruitment within this seasonally dynamic wetland.

The first chapter of this dissertation, titled "Seasonality of Fish Recruitment in a Pulsed Floodplain Ecosystem: Estimation and Hydrological Controls", evaluated how to correct for size-selective bias in sampling gear within a 20 -year time series data set. A series of generalized linear models were applied to the abundance-at-age data for six common marsh fish species. The estimated values of abundance were then compared to the observed estimates of abundance within the time series. The ratio of the observed versus estimated abundance was then used to calculate the size-selectivity curves for each species. Estimates of mortality derived from the generalized linear models were then applied to a series of cohort analyses. These cohort analyses were used to correct for size-selective bias within the time series. Finally, hydrological variables were then analyzed to assess how depth, seasonality, and days since dry (DSD) influenced the temporal dynamics of fish abundance.

The second chapter, titled "Evaluating Density-Dependent Recruitment in a Pulsed Floodplain Ecosystem", used Multimodel Inference to evaluate several densitydependent and independent recruitment models. I applied seven density-independent and four density-dependent stock-recruitment (S-R) models to each species at each site. These models were then evaluated using Aikake Information Criteria (AIC) to asses which model best described the data. This allowed me to determine the strength of support for either density-dependent or -independent recruitment across a hydrological 
gradient. I also applied population dynamics models to determine the source of densitydependence, if present. This approach evaluated both spawning stock abundance and recruit abundance as possible sources of density-dependent mortality. Finally, I compared the strength of density-dependence from these models to annual hydroperiod. This allowed me to determine whether the strength of density-dependence was influenced by hydrological disturbance.

The third chapter, titled "Speed and Directedness Predict Colonization Sequence Post-Disturbance", identified two key traits associated with movement and quantified how these traits related to species arrival order following disturbance. The colonization patterns for six common marsh fish species was analyzed using a 20-year, multi-site time series data set to determine the colonization sequence post-disturbance. The Critical Swimming Speed (U $\mathrm{URIT}_{\mathrm{CR}}$ ) for each species was then estimated using a Blazka-style swim tunnel to quantify each species' colonization potential. The second trait, directedness, was programmed into a series of Agent Based Models (ABM's) to incorporate indirect estimates of directedness with the speed data. These ABM's tested several speed/directedness combinations and valuated the relative importance of each parameter to a species' arrival sequence. The arrival probabilities from these ABM's were then compare to the arrival probabilities from the field data to evaluate the model's ability to predict colonization order.

My final chapter, titled "Linking Age-Specific Mortality and Growth Rates $\left(\mathrm{M}^{\prime} / \mathrm{G}^{\prime}\right)$ to Annual Changes in Abundance and Biomass Within a Fluctuating Environment", compiled data on species mortality and growth rates to evaluate how the 
age-specific mortality to growth ratio ( $\left.\mathrm{M}^{\prime} / \mathrm{G}^{\prime}\right)$ influences changes in species abundance over time. Fish were collected using a dip net at two short hydroperiod (TSL MDsh, WCA 03), two intermediate hydroperiod (SRS 7, WCA 02) and two long hydroperiod (WCA 4 and 5) sites between 2014 and 2016. Otoliths were extracted from 24 individuals of each species, site, and year which allowed me to age them using growth rings. Growth curves were then applied to the length-at-age data to calculate age-specific growth rates. Mortality rates were then estimated using the generalized linear models described in Chapter 1. I then calculated the $\mathrm{M}^{\prime} / \mathrm{G}^{\prime}$ ratio and back-calculated when this ratio equaled one to estimate the transition period. Finally, I used both the age and length of the transition period to evaluate how the timing of this life history trait influenced annual abundance and biomass.

My dissertation builds upon a large body of work which aims to understand the biotic and abiotic controls of recruitment within marine (Hjort 1914, Sinclair and Tremblay 1984), estuarine (Boehlert and Mundy 1988, Rothlisberg et al. 1995), and freshwater fishes (Maceina and Bettoli 1998, Vandenbos et al. 2006). I was able to evaluate the contribution of age-specific growth, mortality, and dispersal on recruitment by using data available within a 20 -year time series for a collection of six coexisting species. This dataset allowed me to track several cohorts throughout time and space to evaluate how spatial-temporal variations in site hydrology influenced recruit abundance. The time series permitted the use of a variety of quantitative techniques and simulations to link experimental data to observed field patterns. I was able to study fish populations along a wide hydrological gradient which provided insight on how site-specific hydrology altered species growth and mortality rates. This dissertation provides a 
thorough examination of how hydrology influences age-specific growth, mortality, and dispersal within a seasonally variable environment.

\section{Literature Cited}

Aarts, B. G., F. W. Van Den Brink, and P. H. Nienhuis. 2004. Habitat loss as the main cause of the slow recovery of fish faunas of regulated large rivers in Europe: the transversal floodplain gradient. River Research and Applications 20:3-23.

Agostinho, A. A., L. C. Gomes, S. Veríssimo, and E. K. Okada. 2004. Flood regime, dam regulation and fish in the Upper Paraná River: effects on assemblage attributes, reproduction and recruitment. Reviews in Fish Biology and Fisheries 14:11-19.

Anderson, J. T. 1988. A review of size dependent survival during pre-recruit stages of fishes in relation to recruitment. Journal of Northwest Atlantic Fishery Science 8:55-66.

Arthington, A. H., and S. R. Balcombe. 2011. Extreme flow variability and the 'boom and bust'ecology of fish in arid-zone floodplain rivers: a case history with implications for environmental flows, conservation and management. Ecohydrology 4:708-720.

Blackhart, K., D. G. Stanton, and A. Shimada. 2006. NOAA Fisheries Glossary. United States Department of Commerce, National Oceanic and Atmospheric Administration.

Boehlert, G. W., and B. C. Mundy. 1988. Roles of behavioral and physical factors in larval and juvenile fish recruitment to estuarine nursery areas. Pages 1-67 in American Fisheries Society Symposium.

Bunn, S. E., and A. H. Arthington. 2002. Basic principles and ecological consequences of altered flow regimes for aquatic biodiversity. Environmental Management 30:492-507.

Cushing, D. 1990. Plankton production and year-class strength in fish populations: an update of the match/mismatch hypothesis. Advances in marine biology 26:249293.

DeAngelis, D. L., J. C. Trexler, C. Cosner, A. Obaza, and F. Jopp. 2010. Fish population dynamics in a seasonally varying wetland. Ecological modelling 221:1131-1137. 
Fennema, R. J., C. J. Neidrauer, R. A. Johnson, T. K. MacVicar, and W. A. Perkins. 1994. A computer model to simulate natural Everglades hydrology. Everglades: the ecosystem and its restoration:249-289.

Fogarty, M. J., M. P. Sissenwine, and E. B. Cohen. 1991. Recruitment variability and the dynamics of exploited marine populations. Trends in Ecology \& Evolution 6:241246.

Goss, C. W., W. F. Loftus, and J. C. Trexler. 2014. Seasonal fish dispersal in ephemeral wetlands of the Florida Everglades. Wetlands:1-11.

Haake, P. W., and J. M. Dean. 1983. Age and growth of four Everglades fishes using otolith techniques. National Park Service, South Florida Research Center, Everglades National Park.

Hjort, J. 1914. Fluctuations in the Great Fisheries of Northern Europe, Viewed in the Light of Biological Research. Andr. Fred. Høst \& Fils.

Hjort, J. 1926. Fluctuations in the year classes of important food fishes. Journal Du Conseil 1:5-38.

Houde, E. 1996. Evaluating stage-specific survival during the early life of fish. Survival strategies in early life stages of marine resources:51-56.

Houde, E. D. 1987. Fish early life dynamics and recruitment variability. Pages 17-29 in Am. Fish. Soc. Symp.

Humphries, P., A. J. King, and J. D. Koehn. 1999. Fish, flows and flood plains: links between freshwater fishes and their environment in the Murray-Darling River system, Australia. Environmental Biology of Fishes 56:129-151.

Iles, T. D., and M. Sinclair. 1982. Atlantic herring: stock discreteness and abundance. Science 215:627-633.

King, A., P. Humphries, and P. Lake. 2003. Fish recruitment on floodplains: the roles of patterns of flooding and life history characteristics. Canadian Journal of Fisheries and Aquatic Sciences 60:773-786.

Lasker, R. 1978. The relations between oceanographic conditions and larval anchovy food in the California Current: identification of factors contributing to recruitment failure. Rapports et Proces-verbaux des Reunions 173.

Loftus, W. F., and A.-M. Eklund. 1994. Long-term dynamics of an Everglades small-fish assemblage. Everglades: the Ecosystem and Its Restoration. St. Lucie Press, Delray Beach, FL, USA:461-484. 
Maceina, M. J., and P. W. Bettoli. 1998. Variation in largemouth bass recruitment in four mainstream impoundments of the Tennessee River. North American Journal of Fisheries Management 18:998-1003.

Obaza, A., D. DeAngelis, and J. C. Trexler. 2011. Using data from an encounter sampler to model fish dispersal. J Fish Biol 78:495-513.

Ogden, J. C., S. M. Davis, K. J. Jacobs, T. Barnes, and H. E. Fling. 2005. The use of conceptual ecological models to guide ecosystem restoration in South Florida. Wetlands 25:795-809.

Parkos, J. J., C. R. Ruetz, and J. C. Trexler. 2011. Disturbance regime and limits on benefits of refuge use for fishes in a fluctuating hydroscape. Oikos 120:15191530 .

Rothlisberg, P., J. Church, and C. Fandry. 1995. A mechanism for near-shore concentration and estuarine recruitment of post-larval Penaeus plebejushess (Decapoda, Penaeidae). Estuarine, Coastal and Shelf Science 40:115-138.

Ruetz, C. R., J. C. Trexler, F. Jordan, W. F. Loftus, and S. A. Perry. 2005. Population dynamics of wetland fishes: spatio-temporal patterns synchronized by hydrological disturbance? Journal of Animal Ecology 74:322-332.

Sale, P. F. 1978. Chance patterns of demographic change in populations of territorial fish in coral rubble patches at heron reef. Journal of Experimental Marine Biology and Ecology 34:233-243.

Sinclair, M., and M. Tremblay. 1984. Timing of spawning of Atlantic herring (Clupea harengus harengus) populations and the match-mismatch theory. Canadian Journal of Fisheries and Aquatic Sciences 41:1055-1065.

Trexler, J. C., D. L. DeAngelis, and J. Jiang. 2011. Ecology and evolution of poeciliid fishes Pages 95-108 in J. P. Evans, A. Pilastro, and I. Schlupp, editors. Community assembly and mode of reproduction: predicting the distribution of livebearing fishes. The University of Chicago Press, Chicago, IL [etc.].

Trexler, J. C., W. F. Loftus, and S. Perry. 2005. Disturbance frequency and community structure in a twenty-five year intervention study. Oecologia 145:140-152.

Vandenbos, R. E., W. M. Tonn, and S. M. Boss. 2006. Cascading life-history interactions: alternative density-dependent pathways drive recruitment dynamics in a freshwater fish. Oecologia 148:573-582.

Winemiller, K. O. 2004. Floodplain river food webs: generalizations and implications for fisheries management. Pages 285-309 in Proceedings of the second international symposium on the management of large rivers for fisheries. Food and Agriculture Organization \& Mekong River Commission, FAO Regional .... 
Yurek, S., D. L. DeAngelis, J. C. Trexler, F. Jopp, and D. D. Donalson. 2013. Simulating mechanisms for dispersal, production and stranding of small forage fish in temporary wetland habitats. Ecological modelling 250:391-401. 
CHAPTER II

SEASONALITY OF FISH RECRUITMENT IN A PULSED FLOODPLAIN ECOSYSTEM: ESTIMATION AND HYDROLOGICAL CONTROLS 


\section{Abstract}

Hydrological variation is believed to be the main density-independent factor that controls fish recruitment in floodplain ecosystems. However, our ability to fully understand these controls is greatly impeded by the size-selective nature of sampling gear. To illustrate the benefits of estimating the effects of size-selective bias on population parameters, we used a cohort analysis to reconstruct a 20 -year time series of larval/neonate abundance for five species in the Order Cyprinodontiformes along a hydrological gradient in the Florida Everglades. We applied generalized linear models to estimate recruit density and analyze size-selectivity for our sampling gear. The adjusted data resulted in a 7 to 40 -fold increase in estimated recruit density, which varied seasonally at regional and local spatial scales and was greatest at the end of the wet season (October, December) for most species; no consistent seasonality in recruitment of any species was apparent in the raw data. Using the adjusted data, we detected a positive relationship between recruit density and recovery time following marsh drying events at short and intermediate-hydroperiod sites for all species. However, depth was the major hydrological driver of recruitment at long-hydroperiod sites. Within sites, we observed interspecific variation in species responses to changes in annual hydroperiod. We suggest that fisheries models can be applied to data from any meshed sampling gear to improve abundance estimates and reveal seasonal recruitment dynamics. Our use of such models revealed seasonal recruitment dynamics there were previously undetected, with implications for planning of restoration and management of the Everglades.

Key words: cohort analysis, recruitment, floodplains, size bias 


\section{Introduction}

Fish recruitment may be tightly linked to hydrological cycles in seasonally pulsed freshwater ecosystems (Agostinho et al. 2004, Arthington and Balcombe 2011, Godfrey et al. 2017). Variations in hydrology are predicted to be the major environmental factor that influences fish recruitment in floodplain ecosystems. These are often life-history dependent with the dependence on floods highest for migratory species and lowest for sedentary species with parental care (Agostinho et al. 2004, Winemiller 2004). Furthermore, habitat loss due to hydrological regime modification is believed to be the major source of reduced recruitment in regulated rivers (Aarts et al. 2004). Fish species have adapted to hydrologically dynamic environments by evolved reproductive strategies and life histories that exploit pulses in primary production within newly inundated habitats (King et al. 2003, Zeug and Winemiller 2008, Furness 2015). These adaptations may buffer some species against anthropogenic modification of the hydrological landscape. Understanding the factors that control fish recruitment is crucial to determining the influence of hydrological regime on population dynamics in seasonally pulsed systems.

However, our ability to fully understand these controls is often greatly impeded by biased estimates of early life history stages associated with size-selective sampling gear. Differences among gear type have impeded quantification of age and size-structured processes in fisheries (Ghulam Kibria and Ahmed 2005). For example, several studies have shown that mesh size and shape severely impact the quantity and composition of the total catch, often selecting for larger individuals (Rudstam et al. 1984, MacLennan 1992, Millar and Fryer 1999). Organism morphology (length, width, and height) can be used to 
understand the magnitude of selection associated with equipment type and use (Reis and Pawson 1999, Gabr et al. 2007, Bolat et al. 2010). Other sampling methods used to study recruitment also suffer from inherent bias. Sweep net electrofishing (SNE), for example, selectively captures species based on the voltage and mesh size used (King and Crook 2002). Therefore, understanding the size-selective nature of sampling gear is crucial to assure accurate quantitative estimates of key parameters shaping recruitment and evaluate their links to environmental gradients in dynamic ecosystems.

Cohort analyses have become a popular method to reconstruct fish populations and indirectly estimate recruitment (Cadrin and Vaughan 1997, Porch et al. 2001). Two types of cohort analyses have been developed for fisheries stock assessment, the backward projection model (e.g., Virtual Population Analysis (VPA)) and forward projection model (e.g., Statistical Catch-at-Age Analysis (SCAA)). Backward projection models follow adult cohorts backward through time to estimate the abundance of younger fish and have become a useful tool in estimating the abundance of larval and juvenile recruits (Livingston and Jurado-Molina 2000, Coggins Jr et al. 2006). Estimates of fishing and natural mortality obtained from both fisheries-dependent and -independent data are used to estimate the historical recruitment that would support the current population. Although these methods do not directly estimate recruitment, these cohort analyses are useful in estimating current and future stocks of commercially exploited species.

Though widely adopted in stock assessment protocols and management practices (Lassen and Medley 2001, Jurado-Molina et al. 2016), cohort analyses have not been 
applied to support field studies of fish recruitment using meshed sampling gear. This technique has the potential to improve biomass estimates and our understanding of recruitment dynamics in any ecosystem. Currently, little is known about the impact of size-selective bias on our understanding of seasonal recruitment dynamics for small fish species inhabiting floodplains and wetlands. In this paper, we illustrate the use of a backwards projection cohort analysis in a study of fish population dynamics from a seasonally pulsed floodplain wetland. The Florida Everglades is an excellent system to explore the effects of hydrology on fish recruitment because it supports a diverse gradient of hydrological disturbance (short to long hydroperiods). In this paper, we demonstrate how to correct density estimates derived from meshed sampling gear in a long-term dataset and improve our understanding of recruitment dynamics of fishes in hydrologically pulsed wetlands. This information can improve our understanding of links between hydrological modification of ecosystems and recruitment, and ultimately fish population dynamics, to improve restoration approaches following anthroprogenic modification of rivers and floodplains by providing more accurate information on recruit abundance and temporal patterns of recruitment along environmental gradients

\section{Materials and methods}

\section{Study Sites and Species}

Between 1996 and 2016, fish were collected using a 1- $\mathrm{m}^{2}, 2-\mathrm{mm}$ mesh, throw trap using a standard protocol (Jordan et al. 1997) at 21 monitoring sites in the Everglades, Florida, U. S. A. These sites were distributed in Shark River Slough (SRS), Taylor Slough (TSL), and Water Conservation Areas (WCA) 3A and 3B (Fig. 1). Samples were 
collected in five months of each year (July, October, December, February, and April), with water-year sampling starting in July (early in South Florida wet season) and ending in April of the following year (late in South Florida dry season, Fig. 2). Three or five plots were selected at each site, and five (WCA 3A and 3B) or seven (SRS, TSL) throwtrap samples were collected within a plot. Sites located in WCA 3A and 3B yielded 75 samples per year (3 plots x 5 throws $x 5$ sample events), while sites in SRS and TSL yielded 105 samples per water-year ( 3 plots x 7 throws per plot x 5 sample events); in dry years requiring helicopter access, 5 throws were taken per plot. The location of each throw within each plot was determined using a random number table. Plot sizes varied from $10,000 \mathrm{~m}^{2}(100 \mathrm{~m} \times 100 \mathrm{~m})$ to $2,100 \mathrm{~m}^{2}(70 \mathrm{~m} \times 30 \mathrm{~m})$, depending on surrounding vegetation and availability of sampleable habitat (Trexler et al. 2002, Trexler et al. 2003). After securing the trap, floating mat volume (submerged aquatic vascular plants, periphyton, etc), water depth, and emergent plant stem counts (by species) were recorded before fish and macroinvertebrates were removed following a standardized protocol of sweeps with a bar seine and dip nets (Jordan et al. 1997). We used data from the Everglades Depth Estimation Network (EDEN) to provide stage data for each site that were used to estimate days since a site was last dry prior to sampling (DSD), number of days the site was inundated greater than $5 \mathrm{~cm}$ in the preceding 365 , and depth at the time of sampling (Telis 2006, Liu et al. 2009). Long-term monitoring at these sites from July, 1996, to April, 2016, (20 water years) yielding over 20,000 community samples with over 400,000 fish and invertebrates. There is no evidence of visitor impact on these longterm study sites, possibly because randomization makes revisiting same sampling points 
unlikely, marsh plants re-grow quickly, and periodic marsh drying overwhelms sampler impacts on vegetation and soil (Wolski et al. 2004).

To assure adequate sample sizes for this study, only the six most common fish species were used. These species were Bluefin Killifish Lucania goodei, Least Killifish Heterandria formosa, Flagfish Jordanella floridae, Sailfin Molly Poecilia latipinna, Eastern Mosquitofish Gambusia holbrooki, and Golden Topminnow Fundulus chrysotus. Age estimates from otolith analyses suggest that the typical lifespan of these species is much less than one year in the Everglades (Haake and Dean 1983, Konnert 2002). The age at sexual maturity for these species is between 30 and 90 days, less than or similar to the time between sequential samples. Thus, the 100 sequential samples in this study (20 years x 5 samples per year) represent between 34 and 51 generations for each species.

Recruitment is the process of new individuals entering an existing population, which for fisheries is often the exploitable stock (Blackhart et al. 2006). In practice, fisheries scientists have used a variety of working definitions of recruitment and recruits to facilitate study (Miller and Kendall 2009), often focusing on the life history transition from larva to juvenile that may be accompanied by a transition of habitat-use or 'settlement' (Kaufman et al. 1992). This study includes species with (Fundulidae: Golden Topminnows, Bluefin Killifish; Cyprinodontidae: Flagfish) and without (Poeciliidae: Eastern Mosquitofish, Least Killifish, Sailfin Molly) a larval stage, complicating use of a developmentally-based recruitment criterion. Therefore, we define recruits as any individual below the size of sexual maturation (Table 1; cf. Anderson 
1988). Thus, age (days since hatching or parturition) of fishes considered to be recruits in this study would be from hatch/birth up to 60-163 days depending on the species.

\section{Population-Based Models}

We used age-structured models to estimate population growth. Horizontal life tables for each species suggested senescing populations because of low density of early age/size classes, though long-term observation indicated that the populations were persistent over time and space (unpublished data). A graphical representation of survivorship curves produced an inverse parabola, with an inflection point near the size of maturation for each species $(\sim 15-18 \mathrm{~mm})$. We assumed that individuals at lengths to the left of the inflection point were under-represented by our sampling gear. In all cases where multiple inflection points were noted, the inflection point representing the shortest length was selected as the minimum size collected efficiently. These multiple inflection points were noted at all study sites for each of the species, suggesting that movement (e.g., immigration, emigration) of early life stages, could not alone explain their absence. We hypothesized that the missing early age classes resulted from un-sampled juvenile fishes. Accordingly, we used model-based projections of survivorship curves to estimate their abundance and evaluate this hypothesis.

We applied a generalized linear model to the adult cohorts within the abundanceat-age data for each species. This equation linearized the discrete-time model:

$$
N_{t}=N_{0}^{-M t}
$$

where $\mathrm{N}_{\mathrm{t}}$ is the population size at time $t, \mathrm{~N}_{0}$ is the initial population size, and $M$ is the instantaneous mortality rate (proportion of individuals which recruit to next size class 
(individuals $\left.\mathrm{mm}^{-1}\right)$ ). Several assumptions about the population structure for each species were necessary to apply this model (Table 1). We fit a negative binomial error distribution because the response variable (cohort density) was estimated as integers (counts). To account for the annual lifespan of these species ( $<300$ days), every wateryear was treated separately by producing a single model for each site by water-year (JulyApril), creating a maximum of 440 (22 sites x 20 water-years) cohort models for each species. Following model approximation, we tested their fit by comparing the observed abundance and the model-predicted values using ordinary least-squares regression. We then calculated the number of individuals that were missing in our data by comparing the model predicted values to the observed abundance for each length class and converted it into a density $(\beta)$ as follows:

$$
\beta=\sum_{0}^{l} \frac{N_{e s t}-N_{o b s}}{n}
$$

where $l$ is length class (in $1 \mathrm{~mm}$ increments), $l_{0}$ is the length at birth/hatch, $N_{\text {est }}$ is the model predicted value, $N_{o b s}$ is the observed count per cohort, and $n$ is the number of samples collected.

\section{Estimating Size-Selectivity Curves}

Following the estimation of abundance per cohort, we then estimated sizeselectivity of the sampling gear for each species. First, we estimated the probability of catching a fish based on its size by:

$$
\hat{P}_{\text {catch }}=\frac{N_{\text {obs }}}{N_{\text {est }}}
$$


where $N_{o b s}$ is the observed count per cohort and $N_{\text {est }}$ is the model-predicted value. We then fit a nonlinear model using non-linear least squares (NLS) to our probability estimates using the size-selectivity equation:

$$
P_{\text {catch }}=\frac{1}{1+e^{-r(L-L 50)}}
$$

where $r$ is a constant that controls the shape of the curve, $L$ is fish standard length, and $\mathrm{L}_{50}$ is the length at which the probability of catch is $50 \%$ (Millar and Fryer 1999). Each model was run for a maximum of 1,000 iterations against the response variable $\hat{P}_{\text {catch }}$ to best estimate model parameters $r$ and $L_{50}$. Following model approximation, we tested the fit of these models by using the same methods as the age-structured models. Once all values of $P_{\text {catch }}$ were calculated, we averaged the estimates for all sites and water-years by length class to generate the size-selectivity curve for each species. The final estimates of selectivity were multiplied by 0.63 to account for both the clearing (probability of removal if present, $\sim 0.83$ ) and capture efficiencies (probability of fish escaping before enclosure, $\sim 0.20$ ) derived from previous studies (Jordan et al. 1997). This produced sizeselectivity curves that account for the size-selective nature of the throw trap and the clearing efficiency of the sampling methods.

\section{Cohort Analysis}

Although we estimated spatial differences in neonate/larval abundance, we were ultimately interested in documenting temporal or seasonal patterns of juvenile density. We applied the generalized linear models to our time series to obtain an estimate of the instantaneous mortality rate $(M)$ for every water-year, site, and species. Our estimates of 
mortality were then applied to a cohort analysis across 21 sites and 20 years for all species except the Sailfin Molly. We considered the data for Sailfin Molly to be too over-dispersed and the species was not abundant enough at each site to provide a robust cohort analysis. The same assumptions were made on population structure for each site (Table 1) and we conducted a backward projection cohort analysis to our catch-at-age data. Further, evidence suggests that our survey has no significant influence on population size (Wolski et al. 2004). This allowed us to set the catch equation of Pope's Approximation (Pope 1972) equal to zero and conducted a length-based cohort analysis based on the following equation:

$$
N_{l, t}=N_{l+1, t+t} e^{M}
$$

where $\mathrm{N}_{l, t}$ is the number of individuals of length $l$ at time $t$, and $\mathrm{N}_{l+1, t+1}$ is the number of individuals surveyed of length $l+1$ at time $t+1$.

To account for the rapid life histories of our study species, we conducted our cohort analysis using a seasonal time cycle. Each year was analyzed individually using a six-season time step. The cohort analysis started in February and followed a cohort backward to April of the previous year. This timing was selected based on adult density in the time series and a 12/12 photoperiod corresponding to the onset of the reproductive cycle for these species. We assumed cohort duration to be one water year, permitting creation of a time step between February and April $(\mathrm{T}=6)$ and assumed that all but one individual of the cohort died in that period $\left(\mathrm{N}_{\mathrm{a}, 6}=1\right)$. This satisfies the assumption of backward projection models describing mortality of all individuals within a cohort past a certain time. We then started our backward projection in February with 


$$
\mathrm{N}_{1,5}=e^{M}
$$

where $\mathrm{N}_{1,5}$ is the number of individuals of length $l$ in February $(\mathrm{T}=5)$. To account for 60 90 days between sample periods, we used published age-at-length curves to account for growth between sample periods (Haake and Dean 1983). Our calculations of cohort abundance were projected backward in time to December ( $\mathrm{T}=4,60$ days), October $(\mathrm{T}=3$, 60 days), July ( $\mathrm{T}=2,90$ days), and ended in April ( $\mathrm{T}=1,90$ days).

Although we originally assumed that these study sites were closed systems, evidence suggests that these sites are not closed (Goss et al. 2013, Hoch et al. 2015). Furthermore, some level of reproduction and recruitment occur year-round for the study species in the Everglades (Haake and Dean 1983). We accounted for both immigration and continual reproduction by using a series of two condition statements in real time:

$$
\begin{aligned}
& \text { If } \mathrm{N}_{l+1, t+1} e^{\mathrm{M}} \mathrm{N}_{\text {obs }} \text { then } \mathrm{N}_{\mathrm{a}, \mathrm{t}}=\mathrm{N}_{l+1, t+1} e^{\mathrm{M}} \\
& \text { If } \mathrm{N}_{l+1, t+1} e^{\mathrm{M}} \leq \mathrm{N}_{\text {obs }} \text { then } \mathrm{N}_{l, t}=\mathrm{N}_{\text {obs }}
\end{aligned}
$$

which compares our calculated values of $\mathrm{N}_{l, t}$ with the observed value in our time series. The larger of the two values was retained for any given length. Finally, we adjusted our estimates based on hydrology data collected from nearby monitoring gauges. Since our initial analysis was conducted independently of hydrology data, dry sites at the time of sampling were originally ignored. We corrected for this by setting all $\mathrm{N}_{\mathrm{a}, \mathrm{t}}=0$ when dry sample-periods were identified $(\operatorname{depth}<5 \mathrm{~cm}, \mathrm{DSD}=0)$ for all three plots. 


\section{Seasonal and Hydrological Effects}

We used a general linear model to examine how recruitment of juveniles for five species varied by season, year, hydrological region, and among sites within regions. The response variable was log-transformed density of recruits (number of fish per sample) estimated by our cohort analysis. Recruit density was calculated for the three plots combined $(\mathrm{n}=15-21)$ and was log-transformed to meet the assumptions of normality and homoscedasticity for both the original and reconstructed time series. To determine the effect of hydrology on recruit density, we used hydrological variables derived from EDEN gauges. We calculated the number of days following a major drying event (DSD), a squared DSD term (DSD ${ }^{2}$ ) and water depth at date of sampling. Our linear models used the main effects of season, water-year, site, species, DSD, $\mathrm{DSD}^{2}$, and depth. To determine if there were changes in seasonality of recruitment between our original and reconstructed time series, we developed a separate series of linear models with the season of peak recruitment as the response variable. This tested the main effects of site, wateryear, species, and density type (observed vs estimated).

We used multi-model inference (MMI) based on Information Theory (Akaike Information criterion) to evaluate the effects of hydrological drivers on recruitment (Burnham and Anderson 2004). We considered the variables DSD, DSD 2 , depth, and the combination of these variables (with and without intercepts) as linear predictors of logtransformed recruit density. To determine the effect of annual variation of hydroperiod (a metric of annual disturbance intensity), we evaluated whether changes in annual hydroperiod would result in lower or higher maximum recruitment at each study site. Overall recruitment (total number of recruits throughout the year) was also evaluated to 
determine if changes in annual hydroperiod reflected changes in total recruitment. However, these models were not applied to long-hydroperiod sites because they lacked variability of the independent variables ( $>360$ days annually). We then selected the best model $(\triangle \mathrm{AIC}=0)$ and used an Analysis of Covariance (ANCOVA) to the test the interaction between species and annual hydroperiod within a site on both annual recruitment and maximum recruit density as individual response variables. Although there were additional models that were equally valid $(\triangle \mathrm{AIC}<3)$, we wanted to limit this analysis to a single model and considered the best model $(\triangle \mathrm{AIC}=0)$ the most parsimonious explanation of recruitment for our ANCOVA models.

\section{Results}

\section{Site Descriptions and Hydrological Context}

Hydroperiod ranged from 172 to 366 days at the 21 study sites (Table 2). We classified each site into one of three different disturbance regimes (short, intermediate, and long) based on the number of drying events (depth $<5 \mathrm{~cm}$ ) each site experienced during the study (20 years). Long-hydroperiod sites experienced zero to three drying events over the 20 water years of the study, four to twelve for intermediate hydroperiods, and $>12$ drying events in 20 years for short-hydroperiod sites. All six long-hydroperiod sites were located within WCA (sites 4-8). Three of these sites (WCA 4, 5, and 8) experienced zero or one drying event per plot over the duration of our study. Ten intermediate-hydroperiod and five short-hydroperiod sites were identified, primarily located within SRS and TSL. Both these regions included the most frequently disturbed sites in the study; WCA had only one short-hydroperiod site (WCA 3). Three sites 
located within SRS and TSL dried annually over the course of the study (TSL MDsh, SRS 37, and SRS 50).

\section{Size-Selective Nature of Throw Traps}

Observed adult density for each species closely matched model-predicted values and provided a good basis to back-calculate larval/neonate density. On average, our generalized linear models explained $>63 \%$ of the variation observed for adult density. Model fit was weakest for the Bluefin Killifish (Mean $\mathrm{R}^{2}=0.63^{+} /-0.01$ ) and strongest for the Least Killifish (Mean $\left.\mathrm{R}^{2}=0.95^{+} /-0.004\right)$. We observed no significant lack-of-fit for $>75 \%$ of all site, water year, and species combinations. Our analyses revealed that the number of larvae and juveniles ( $<7 \mathrm{~mm}$ to $\sim 15 \mathrm{~mm}$ for all species) captured was low compared to model-predicted values (observed was $<10 \%$ of predicted) across all sites and water years. Unlike juveniles, the model predictions for adults (individuals $>18 \mathrm{~mm}$ SL except for Least Killifish) were well-matched to observed values (observed abundance was $>80 \%$ of predicted) with little spatial-temporal variability in predictability. Therefore, selectivity was generally high ( $>80 \%$ theoretical selectivity) at size of maturation for five of the six species (Table 1) due to strong model fit of the estimated adult densities prior to accounting for clearing and enclosure efficiency for four

of the six species (Fig. 3). These models achieved 100\% theoretical selectivity for five of the six species ( $>20 \mathrm{~mm}$ SL for Eastern Mosquitofish, Bluefin Killifish, $>25 \mathrm{~mm}$ SL for Flagfish, and $>30 \mathrm{~mm}$ SL for Sailfin Molly). Although the Least Killifish achieved 100\% selectivity for mature individuals $>14 \mathrm{~mm}$ SL, selectivity was generally low $(<40 \%)$ for both juveniles and small adults at and above the size of maturation $(<=11 \mathrm{~mm} \mathrm{SL})$. In 
contrast to the other species, capture efficiency was lowest for the Golden Topminnow and only achieved $95 \%$ selectivity $(>80 \%$ for mature adults $>22 \mathrm{~mm} \mathrm{SL})$.

\section{Cohort Analysis}

Prior to cohort analysis to correct for size-biased sampling, our data did not reveal seasonal recruitment that was consistent among years for any species. However, after cohort analyses, peaks of recruitment were present on a consistent seasonal pattern at 15 of our 21 study sites and for 4 of the 5 species. This noticeable change in estimated recruitment was clearest at short-hydroperiod sites and occurred at all five shorthydroperiod sites. Unlike short-hydroperiod sites, accounting for under-sampling juveniles revealed seasonal recruitment for $70 \%$ and $50 \%$ of intermediate and longhydroperiod sites respectively. Seasonal dynamics of recruitment seem most prominent at short hydroperiod sites and disappear as the environment becomes more stable. Longhydroperiod sites experience annual peaks in recruitment; however, the timing of these peaks varied from year to year and failed to occur on a consistent seasonal basis.

On average, estimated recruitment was 7 to 40 -fold greater in our corrected data than in the raw data at times of highest recruitment; however, this difference was negligible at times of little to no recruitment. Though the mean relative difference was great, the absolute increases in recruit density attributable to corrections were often modest; large differences between the corrected and uncorrected data were most prevalent for Least Killifish. We attribute this to the small body size of both adults and juveniles, which resulted in larger under-sampling of both age classes. Further, higher mortality rates (steeper slope) were estimated for this species when compared to the other 
four analyzed (Table 3). Our cohort analysis added more recruits for the Least Killifish since observed recruitment was significantly lower to support estimates of population size at $\mathrm{N}_{\mathrm{t}+1}$ than for all other species.

Our analyses detected interspecific variation in the timing of recruitment along a hydrological gradient. We found that October through December were the primary months for peak recruitment of Bluefin Killifish, Eastern Mosquitofish, and Least Killifish (Fig. 4 A-C). In contrast, July through October had peak recruitment for Flagfish and December through February for Golden Topminnows (Fig. 4 D-E). Most seasonal shifts predicted by our models were directed toward a later sample period (e. g., July to October, October to December), with few changes to earlier sample periods (e. g., October to July). On average, peak recruitment occurred 1-3 months later in the water year than observed in the raw data, shifting the estimated time from the dry to wet season in some cases. Flagfish displayed the largest change in the timing of estimated recruitment, with peak recruitment approximately seven months later than observed in the raw data (in July rather than February). This shifts the Flagfish peak from early wet season to early dry season and was consistent across hydroperiods. Our analyses also revealed a three-month change from early in the dry season (February) to late in the dry season (April) at some sites for Flagfish. Dry-season recruitment was indicative for the Golden Topminnow in both our cohort analysis and our unadjusted data. Overall, the Least Killifish, Bluefin Killifish, Flagfish and Eastern Mosquitofish were recruiting during the peak of the wet season; whereas, the Golden Topminnow recruits during the transition period between the wet and dry seasons at intermediate and short hydroperiods. 
Using the model-estimated density data, we found that hydrological differences among sites played an important role in fish recruitment. Recruitment varied among regions, sites within regions, seasons, years, and species $\left(F_{47,10499}=158.49 ; p<0.001\right)$. Inter-season variation was primarily driven by fluctuations in water depth and proximity to a drying event at short and intermediate hydroperiod sites. Partial residual plots revealed that recruit abundance increased parabolically as a function of DSD and water depth at short and intermediate hydroperiod sites for all species (e.g., Bluefin Killifish, Fig. 5). MMI included DSD ( $>66 \%$ of sites on average) and $\mathrm{DSD}^{2}(>63 \%$ of sites on average) as predictors of recruit density for both short and intermediate hydroperiod sites $(\triangle \mathrm{AIC}<3)$. This suggests that recruitment at both short and intermediate hydroperiod sites increased rapidly following re-inundation of a habitat, but declined over time. Further, MMI included depth as an important predictor of recruitment for the majority of our models regardless of hydroperiod ( $>88 \%$ on average). This occurred most commonly for models that described recruitment at long-hydroperiod sites ( $>85 \%$ for all species at long hydroperiods). DSD and $\mathrm{DSD}^{2}$ were less likely to explain recruitment variability at long-hydroperiod sites and were included in $<57 \%$ of models, suggesting that depth acts as the primary hydrological driver of recruitment at long-hydroperiod sites (e. g., Least Killifish, Fig. 6).

Within a site, interannual variation in hydroperiod drove changes in both annual and maximum recruitment rates. Results from our ANCOVA suggest that the interaction between species and annual hydroperiod is different for each species; hydroperiod and maximum recruitment were either negatively correlated, positively correlated, or respond 
parabolically to hydroperiod (e.g., TSL MDsh, Fig. 7). Maximum recruitment rates for both the Eastern Mosquitofish and Flagfish displayed linear correlations with hydroperiod more frequently than any other species ( 9 of 16, 56.3\% of models selected each) and were negatively correlated with hydroperiod for $33 \%$ of those models. Regardless of the relationship, annual hydroperiod significantly influenced maximum recruitment rates at all sites except four of the shortest hydroperiod sites (SRS 37; TSL CP, MDsh, TSsh). MMI revealed that quadratic models (Hydroperiod and Hydroperiod ${ }^{2}$ ) best explained maximum recruitment at both intermediate and short-hydroperiod sites; however, parameter estimates for the squared term were not significantly different from zero for the majority of cases. Contrary to maximum recruitment rates, MMI revealed annual recruitment was positively correlated with hydroperiod for the majority of the cases (e.g., TSL MDsh, Fig. 8). The squared term, Hydroperiod², was not significantly different from zero in cases when the quadratic model was selected. Although each species reacted differently to changes in annual hydroperiod, each species responded differently across sites and no species-specific pattern was detected.

Recruit density was most variable, and often highest, at intermediate hydroperiod sites. We detected no difference in maximum recruit density based on hydroperiod class for Golden Topminnows $\left(F_{2,57}=0.47, p=0.63\right)$, Least Killifish $\left(F_{2,57}=2.16, p=0.13\right)$, and Flagfish $\left(\mathrm{F}_{2,57}=1,72, \mathrm{p}=0.1875\right)$. However, there were noticeable differences in maximum recruitment for Eastern Mosquitofish $\left(\mathrm{F}_{2,57}=6.94, \mathrm{p}<0.05\right)$ and Bluefin Killifish $\left(\mathrm{F}_{2,57}=17.71, \mathrm{p}<0.05\right)$. On average, the density at maximum recruitment was greater at intermediate-hydroperiod sites when compared to short-hydroperiod sites for 
Flagfish (Mean Difference: $+9.51^{+} /-5.58$ recruits $/ \mathrm{m}^{2}$ ), Eastern Mosquitofish (Mean Difference: $+7.74^{+} /-2.10$ recruits $/ \mathrm{m}^{2}$ ), Bluefin Killifish (Mean Difference: $+10.18^{+} /-$ 1.44 recruits $/ \mathrm{m}^{2}$ ), and Least Killifish (Mean Difference: $+9.78^{+} /-2.67$ recruits $/ \mathrm{m}^{2}$ ), but this difference was negligible for the Golden Topminnow $\left(-0.36^{+} /-0.32\right.$ recruits $\left./ \mathrm{m}^{2}\right)$. We also observed increased recruitment at intermediate versus long-hydroperiod sites for Bluefin Killifish $\left(+7.23^{+} /-1.40\right.$ recruits $\left./ \mathrm{m}^{2}\right)$ and Least Killifish $\left(+3.92^{+} /-3.04\right.$ recruits $/ \mathrm{m}^{2}$ ). However, the difference between long and intermediate hydroperiods was negligible for Golden Topminnows $\left(-0.26^{+} /-0.42\right.$ recruits $\left./ \mathrm{m}^{2}\right)$, Flagfish $\left(+6.48^{+} /-6.72\right.$ recruits $\left./ \mathrm{m}^{2}\right)$, and Eastern Mosquitofish $\left(-0.09^{+} /-2.72\right.$ recruits $\left./ \mathrm{m}^{2}\right)$. On average, intermediate- hydroperiod sites experienced higher recruitment annually compared to annual recruitment at short and long-hydroperiod sites.

\section{Discussion}

Our study has demonstrated that hydrology is a major abiotic control of fish recruitment in the Everglades, similar to other floodplain ecosystems (King et al. 2003, Agostinho et al. 2004, Balcombe et al. 2006). For six species examined, a site-by-site analysis of the hydrological drivers of recruitment revealed DSD to be a major driver of recruitment dynamics along a hydrological gradient. Our analyses also revealed that seasonal variation in recruitment was weakest for short-hydroperiod sites and driven by the number of days post-disturbance. Seasonal inundation creates optimal environmental conditions for reproduction and recruitment (Humphries et al. 1999, Agostinho et al. 2004, Balcombe et al. 2007). Other studies have demonstrated that inundation of the floodplain creates new habitats, refuge from piscivorous predatory fish, and newly 
available food sources generated from the pulses in primary production (Junk et al. 1989, Lake 2011, Bolland et al. 2015). Species at our sites exploit these features and may be dependent on adult dispersal into newly inundated habitats for reproduction because none are known to produce eggs tolerant of drying (Furness 2015). In contrast to shorter hydroperiods, annual variation in the seasonal timing of recruitment was greatest for long and intermediate-hydroperiod sites. Species located at these sites may respond to other environmental cues (e. g., temperature, photoperiod, light penetration) which may be less important drivers of recruitment in strongly pulsed habitats. Furthermore, depth was correlated with variation in estimated recruit density at long-hydroperiod sites. Pulsed ecosystems experience a wide range of water depths between seasons. Consequently, shallow-water stress (elevated temperature, risk of desiccation, risk of invertebrate predators) during the dry season may result in drastic changes in recruitment.

Hydrology induced immigration and emigration (Obaza et al. 2011b, Goss et al. 2014b) may have influenced the abundance-at-age data and resulting model-predicted values. Although such dispersal would violate one of our underlying assumptions (no dispersal), an analysis of model residuals suggested that both immigration and emigration did occur. These inferred movement rates were not equivalent (i.e., emigration $\neq$ immigration), which made accounting for individual movement difficult since no discernable pattern was observed. Our cohort analysis attempted to account for these movement patterns by retaining observed values that exceeded model predicted estimates (See Equations 7 and 8) to account for immigrants arriving between sample events. Although we assumed that missing cohorts were caused by sampling gear, these missing 
individuals may be emigrants that left to avoid stress associated with hydrological disturbance. We accounted for these individuals through our cohort analysis via the addition of missing individuals. Therefore, the assumptions made to the fitted models were robust, regardless of hydrologically induced movement.

Jordan et al. (1997) estimated the magnitude of two sources of sampling bias for a throw trap: clearing efficiency and escape probabilities. Although clearing efficiency and escape probabilities have been estimated at $83 \%$ and $20 \%$ respectively, these estimates do not account for the size-selective nature of mesh size. Our analyses calculated the sizeselective nature of a 2-mm mesh and compared it to the other forms of bias associated with this gear. Size-selectivity seems to be the most variable form of gear limitation since it is both species and size-specific. Therefore, we suggest fitting catch curves to abundance-at-age data to describe size-selective bias in any sampling method (Schlechte et al. 2016). The combination of size-selectivity, recovery probabilities, and clearing efficiency can provide valuable information on how density estimates are influenced by sampling gear limitations.

Changes in recruitment can be masked by gear selectivity favoring large individuals (Frusher et al. 2003). These results indicate that under-estimates of population density are not uniform across the year and vary among species; when present, underestimated densities were greatest in times of high recruitment (primarily October through December in the data used) and least in times of limited reproduction (April through July in the data used). Although some of these changes were minor (e.g., Eastern Mosquitofish), our analyses did reveal some drastic changes for some species. For 
example, our analyses indicated that seasonal recruitment of Flagfish occurred during the late wet to early dry season (December to February). Our observed data indicated that this occurred predominantly in the early wet season (July), resulting in a 7-10 month difference between our observed and estimated values. This also indicates that this species recruits during a period that is more unpredictable and environmentally unfavorable (transition from wet to dry) in contrast to other species which favor more stable environments (peak of wet season). This has large implications for management purposes, and the practical uses of cohort analyses can prevent errors in the estimation of seasonal recruitment. Furthermore, we were also able to estimate instantaneous mortality rates and apply these estimates to a cohort analysis specifically designed for annual species.

In contrast to other cohort analyses, which is conducted on an annual (year to year) time step, we used a seasonal time step because of the short life cycles of the species examined. This shift in temporal scale was both appropriate and necessary for a seasonally dynamic annual species. This approach allowed for estimation of temporal shifts in density by specifically targeting inter-season variation in catch data.

Furthermore, species used in our analyses are born small, rapidly reach sexually maturity, and reproduce throughout much of the year (Haake and Dean 1983). These life history characteristics make typical use of popular cohort analyses (e. g., VPA, SCAA) both impractical and inaccurate. Our work illustrated how subtle differences in life history characteristics (e. g., growth, development) have large implications for larval mortality and recruitment (Houde 1989). These small differences in mortality may have contributed to high estimates and uncertainty for Least Killifish. This species grows 
rapidly and reaches sexual maturity at a small size $(\sim 10-12 \mathrm{~mm}$ in length) compared to the five other study species $(\sim 18-22 \mathrm{~mm})$. Because of its small terminal size, Least Killifish were the most under-sampled of those considered (a larger portion of its life cycle was under-represented in collections) and provide a good example for the need to incorporate life history differences when conducting cohort analyses.

Uncertainties in the estimate of age-specific mortality $(M)$ continue to be a major problem for cohort analyses (Lapointe et al. 1992, Maunder and Punt 2013). These concerns are often associated with guessing the relative contribution of natural and fishing mortality to total mortality. There is no fishing mortality in this study, but low population size may have caused unstable estimates of age structure in some populations for some years, violating one of the underlying assumptions of our models. This may have caused under- or overestimation of mortality needed for our backward projection models. We were unable to calculate daily or seasonal changes in mortality. Instead, we estimated annual changes in the instantaneous mortality rate $(M)$ by fitting models to adult cohorts. Seasonal differences in mortality, which are likely present, may influence our results and future studies on seasonal sensitivity are needed. This would require an age-based model that follows a cohort month to month. Such an approach is beyond the scope of the present study. We believe that our study has addressed the major sources of error in cohort analyses, validating the use of our cohort analysis to predict larval and juvenile abundance in the Everglades.

We have provided a comprehensive survey of the size-selective nature of the 1$\mathrm{m}^{2}, 2-\mathrm{mm}$ mesh, throw trap. Our findings are consistent with previous studies that 
suggest capture probabilities vary across sizes and between species (Sistiaga et al. 2011). Differences in selectivity not only reflect organism morphology, but were also influenced by the size of maturation. Approximately, 63\% efficiency (after correcting for clearing and enclosure efficiency) was achieved at or around the size of maturation for each species. Contrary to studies that use organism morphology to describe selectivity (Herrmann et al. 2012), minimum size at peak collection efficiency from our selectivity curves did not match sizes calculated from the morphometric analyses (Golden Topminnow: $11.09 \mathrm{~mm}$ (Morphometric) vs $18.00 \mathrm{~mm}$ (Selectivity); Eastern Mosquitofish: $14.56 \mathrm{~mm}$ (Morphometric) vs $17.00 \mathrm{~mm}$ (Selectivity); Flagfish: $7.91 \mathrm{~mm}$ (Morphometric) vs $20.00 \mathrm{~mm}$ (Selectivity); Bluefin Killifish: $9.75 \mathrm{~mm}$ (Morphometric) vs $18.00 \mathrm{~mm}$ (Selectivity); Least Killifish $10.20 \mathrm{~mm}$ (Morphometric) vs $12.00 \mathrm{~mm}$ (Selectivity)). This suggests that morphometric data alone cannot accurately represent the size-selective nature of quantitative equipment. For our Everglades data collected using a 2-mm mesh throw trap, we determined that information collected on all species of fish examined $<17 \mathrm{~mm}$ SL must be interpreted with caution. Juvenile individuals are best sampled using other quantitative methods that specifically target larval and early juvenile stages (Neal et al. 2012, Habtes et al. 2014). Furthermore, the efficiency of sampling gear can be improved by incorporating selectivity with clearing efficiency (Jordan et al. 1997) and recovery probabilities to fully understand the limitations of any sampling gear. Furthermore, these estimates can be used to back-calculate species density by dividing the observed density by the respective capture efficiency value (clearing efficiency $\mathrm{X}$ selectivity). The resulting estimates could be combined with a modified VPA to improve 
future density estimates, detect seasonality of recruitment, and determine the abiotic controls of recruitment in pulsed ecosystems.

\section{Acknowledgements}

We thank the many technicians, both past and present, who worked tirelessly in the field to collect the data used in this analysis. We are grateful to Dr. Yuying Zhang for introducing the concepts and equations needed to conduct the cohort analyses. Two anonymous reviewers provided helpful comments on a penultimate version of this paper that improved the final version. We also thank Jeff Kline, Everglades National Park, for making available data from sites 6,23 , and 50 , and for his support of this project. This work was funded by a number of Cooperative Agreements between Everglades National Park and FIU (most recently by Critical Ecosystem Science Initiative Task Agreement P06AC00043). All animal use was approved by the FIU Institutional Animal Care and Use Committee (IACUC-16-34). This material was developed in collaboration with the Florida Coastal Everglades Long-Term Ecological Research program under National Science Foundation Grant No. DEB-1237517. This is contribution No. XXX from the Southeastern Environmental Research Center of FIU.

\section{References}

Aarts BG, Van Den Brink FW, Nienhuis PH (2004) Habitat loss as the main cause of the slow recovery of fish faunas of regulated large rivers in Europe: the transversal floodplain gradient River Research and Applications 20:3-23

Agostinho AA, Gomes LC, Veríssimo S, Okada EK (2004) Flood regime, dam regulation and fish in the Upper Paraná River: effects on assemblage attributes, reproduction and recruitment Reviews in Fish Biology and Fisheries 14:11-19 
Ala-Honkola O, Friman E, Lindstrom K (2011) Costs and benefits of polyandry in a placental poeciliid fish Heterandria formosa are in accordance with the parentoffspring conflict theory of placentation Journal of Evolutionary Biology 24:2600-2610 doi:10.1111/j.1420-9101.2011.02383.x

Anderson JT (1988) A review of size dependent survival during pre-recruit stages of fishes in relation to recruitment Journal of Northwest Atlantic Fishery Science $8: 55-66$

Arthington AH, Balcombe SR (2011) Extreme flow variability and the 'boom and bust' ecology of fish in arid-zone floodplain rivers: a case history with implications for environmental flows, conservation and management Ecohydrology 4:708-720

Balcombe S, Bunn S, Arthington A, Fawcett J, McKenzie-Smith F, Wright A (2007) Fish larvae, growth and biomass relationships in an Australian arid zone river: links between floodplains and waterholes Freshwater Biology 52:2385-2398

Balcombe SR, Arthington AH, Foster ND, Thoms MC, Wilson GG, Bunn SE (2006) Fish assemblages of an Australian dryland river: abundance, assemblage structure and recruitment patterns in the Warrego River, Murray-Darling Basin Marine and Freshwater Research 57:619-633

Beyger L, Orrego R, Guchardi J, Holdway D (2012) The acute and chronic effects of endosulfan pulse-exposure on Jordanella floridae (Florida flagfish) over one complete life-cycle Ecotoxicology and Environmental Safety 76:71-78 doi:http://dx.doi.org/10.1016/j.ecoenv.2011.09.015

Blackhart K, Stanton DG, Shimada A (2006) NOAA Fisheries Glossary. United States Department of Commerce, National Oceanic and Atmospheric Administration,

Bolat Y, Demirci A, Mazlum Y (2010) Size Selectivity of Traps (Fyke-Nets) of Different Mesh Size on the Narrow-Clawed Crayfish, Astacus Leptodactylus (Eschscholtz, 1823)(Decapoda, Astacidae) in Eschscholtz Lake, Turkey Crustaceana 83:13491361 doi:10.1163/001121610x536969

Bolland J, Nunn A, Lucas M, Cowx I (2015) The habitat use of young-of-the-year fishes during and after floods of varying timing and magnitude in a constrained lowland river Ecological Engineering 75:434-440

Burnham KP, Anderson DR (2004) Multimodel inference: understanding AIC and BIC in model selection Sociological methods \& research 33:261-304

Cadrin SX, Vaughan DS (1997) Retrospective analysis of virtual population estimates for Atlantic menhaden stock assessment Oceanographic Literature Review 12:1553 
Coggins Jr LG, Pine III WE, Walters CJ, Martell SJ (2006) Age-structured markrecapture analysis: a virtual-population-analysis-based model for analyzing agestructured capture-recapture data North American Journal of Fisheries Management 26:201-205

Conrow R, Zale AV (1985) Early life history stages of fishes of Orange Lake, Florida: an illustrated identification manual

Frusher S, Hoenig J, Gardner C (2003) Have changes in selectivity masked recruitment declines in crustacean trap fisheries? Fisheries Research 65:467-474

Furness AI (2015) The evolution of an annual life cycle in killifish: adaptation to ephemeral aquatic environments through embryonic diapause Biological Reviews

Gabr M, Fujimori Y, Shimizu S, Miura T (2007) Behaviour analysis of undersized fish escaping through square meshes and separating grids in simulated trawling experiment Fisheries Research 85:112-121 doi:10.1016/j.fishres.2007.01.006

Ghulam Kibria M, Ahmed K (2005) Diversity of selective and non-selective fishing gear and their impact on inland fisheries in Bangladesh Naga, Worldfish Center Quarterly 28:43-48

Godfrey PC, Arthington AH, Pearson RG, Karim F, Wallace J (2017) Fish larvae and recruitment patterns in floodplain lagoons of the Australian Wet Tropics Marine and Freshwater Research 68:964-979

Goss C, Loftus W, Trexler J (2013) Seasonal Fish Dispersal in Ephemeral Wetlands of the Florida Everglades Wetlands:1-11 doi:10.1007/s13157-013-0375-3

Goss CW, Loftus WF, Trexler JC (2014) Seasonal fish dispersal in ephemeral wetlands of the Florida Everglades Wetlands:1-11

Haake PW, Dean JM (1983) Age and growth of four Everglades fishes using otolith techniques. National Park Service, South Florida Research Center, Everglades National Park,

Habtes S, Muller-Karger FE, Roffer MA, Lamkin JT, Muhling BA (2014) A comparison of sampling methods for larvae of medium and large epipelagic fish species during spring SEAMAP ichthyoplankton surveys in the Gulf of Mexico Limnology and Oceanography: Methods 12:86-101

Herrmann B, Sistiaga MB, Nielsen KN, Larsen RB (2012) Understanding the size selectivity of redfish (Sebastes spp.) in North Atlantic trawl codends 
Hoch JM, Sokol ER, Parker AD, Trexler JC (2015) Migration Strategies Vary in Space, Time, and Among Species in the Small-fish Metacommunity of the Everglades Copeia 2015:157-169

Houde E (1989) Subtleties and episodes in the early life of fishes J Fish Biol 35:29-38

Humphries P, King AJ, Koehn JD (1999) Fish, flows and flood plains: links between freshwater fishes and their environment in the Murray-Darling River system, Australia Environmental Biology of Fishes 56:129-151

Jordan F, Coyne S, Trexler JC (1997) Sampling fishes in vegetated habitats: Effects of habitat structure on sampling characteristics of the 1-m(2) throw trap Transactions of the American Fisheries Society 126:1012-1020 doi:10.1577/15488659(1997)126<1012:sfivhe $>2.3 . c 0 ; 2$

Junk WJ, Bayley PB, Sparks RE (1989) The flood pulse concept in river-floodplain systems Canadian Special Publication of Fisheries and Aquatic Sciences 106:110127

Jurado-Molina J, Gatica C, Arancibia H, Neira S, Alarcón R (2016) A Multispecies Virtual Population Analysis for the Southern Chilean Demersal Fishery Marine and coastal fisheries 8:350-360

Kaufman L, Ebersole J, Beets J, McIvor CC (1992) A key phase in the recruitment dynamics of coral reef fishes: post-settlement transition Environmental Biology of Fishes 34:109-118

King A, Crook D (2002) Evaluation of a sweep net electrofishing method for the collection of small fish and shrimp in lotic freshwater environments Hydrobiologia 472:223-233

King A, Humphries P, Lake P (2003) Fish recruitment on floodplains: the roles of patterns of flooding and life history characteristics Canadian Journal of Fisheries and Aquatic Sciences 60:773-786

Konnert TJ (2002) The effects of hydroperiod on the life history parameters of Poecilia latipinna and Heterandria formosa (Poechiliidae) in the Florida Everglades. Master's Thesis, Florida International University

Lake PS (2011) Drought and aquatic ecosystems: effects and responses. John Wiley \& Sons,

Lapointe MF, Peterman RM, Rothschild BJ (1992) Variable natural mortality rates inflate variance of recruitments estimated from virtual population analysis (VPA)

Canadian Journal of Fisheries and Aquatic Sciences 49:2020-2027 
Lassen H, Medley P (2001) Virtual population analysis: a practical manual for stock assessment. vol 400. Food \& Agriculture Org.,

Liu Z, Volin JC, Dianne Owen V, Pearlstine LG, Allen JR, Mazzotti FJ, Higer AL (2009) Validation and ecosystem applications of the EDEN water-surface model for the Florida Everglades Ecohydrology 2:182-194

Livingston PA, Jurado-Molina J (2000) A multispecies virtual population analysis of the eastern Bering Sea ICES Journal of Marine Science: Journal du Conseil 57:294299

MacLennan DN (1992) Fishing gear selectivity: an overview Fisheries Research 13:201204

Maunder MN, Punt AE (2013) A review of integrated analysis in fisheries stock assessment Fisheries Research 142:61-74

Millar RB, Fryer RJ (1999) Estimating the size-selection curves of towed gears, traps, nets and hooks Reviews in Fish Biology and Fisheries 9:89-116

Miller B, Kendall AW (2009) Early life history of marine fishes. University of California Press,

Neal JW, Adelsberger CM, Lochmann SE (2012) A comparison of larval fish sampling methods for tropical streams Marine and Coastal Fisheries 4:23-29

Nordlie FG (2000) Patterns of reproduction and development of selected resident teleosts of Florida salt marshes Hydrobiologia 434:165-182

doi:10.1023/a:1004073125007

Obaza A, DeAngelis DL, Trexler JC (2011) Using data from an encounter sampler to model fish dispersal J Fish Biol 78:495-513 doi:10.1111/j.1095-

8649.2010.02867.x

Pope J (1972) An investigation of the accuracy of virtual population analysis using cohort analysis ICNAF Research Bulletin 9:65-74

Porch CE, Turner SC, Powers JE (2001) Virtual population analyses of Atlantic bluefin tuna with alternative models of transatlantic migration: 1970-1997 Col Vol Sci Pap ICCAT 52:1022-1045

Reis EG, Pawson MG (1999) Fish morphology and estimating selectivity by gillnets Fisheries Research 39:263-273 doi:http://dx.doi.org/10.1016/S01657836(98)00199-4 
Rudstam LG, Magnuson JJ, Tonn WM (1984) Size selectivity of passive fishing gear: a correction for encounter probability applied to gill nets Canadian Journal of Fisheries and Aquatic Sciences 41:1252-1255

Schlechte JW, Bodine KA, Daugherty DJ, Binion GR (2016) Size selectivity of multifilament gill nets for sampling Alligator Gar: modeling the effects on population metrics North American Journal of Fisheries Management 36:630-638

Sistiaga M, Herrmann B, Nielsen KN, Larsen RB (2011) Understanding limits to cod and haddock separation using size selectivity in a multispecies trawl fishery: an application of FISHSELECT Canadian Journal of Fisheries and Aquatic Sciences 68:927

Telis PA (2006) The Everglades Depth Estimation Network (EDEN) for support of ecological and biological assessments. Geological Survey (US),

Trexler JC, Loftus WF, Chick JH (2003) Setting and monitoring restoration goals in the absence of historical data: the case of fishes in the Florida Everglades Monitoring ecosystems: interdisciplinary approaches for evaluating ecoregional initiatives Island Press, Washington, DC:351-376

Trexler JC, Loftus WF, Jordan F, Chick JH, Kandl KL, McElroy TC, Bass O (2002) Ecological scale and its implications for freshwater fishes in the Florida Everglades The Everglades, Florida Bay, and Coral Reefs of the Florida Keys: An Ecosystem Sourcebook CRC Press, Boca Raton, FL:153-181

Winemiller KO Floodplain river food webs: generalizations and implications for fisheries management. In: Proceedings of the second international symposium on the management of large rivers for fisheries, 2004. Food and Agriculture Organization \& Mekong River Commission, FAO Regional ..., pp 285-309

Wolski LF, Trexler JC, Nelson EB, Philippi T, Perry SA (2004) Assessing researcher impacts from a long-term sampling program of wetland communities in the Everglades National Park, Florida, USA Freshwater Biology 49:1381-1390 doi:10.1111/j.1365-2427.2004.01256.x

Zeug S, Winemiller K (2008) Relationships between hydrology, spatial heterogeneity, and fish recruitment dynamics in a temperate floodplain river River Research and Applications 24:90-102 
Table 1: Assumptions made for the generalized linear models on the abundance-at-age data. Age and size at maturation is for females in species with sexual dimorphism.

\begin{tabular}{|c|c|c|}
\hline Topic & Assumption & Justification \\
\hline Immigration/Emigration & $\begin{array}{l}\text { Closed populations; No emigration } \\
\text { or immigration across sites }\end{array}$ & $\begin{array}{l}\text { Sites spatially isolated; } \\
\text { located }>15 \mathrm{~km} \text { from each } \\
\text { other }\end{array}$ \\
\hline Population Structure & $\begin{array}{l}\text { Populations exhibit age structured } \\
\text { growth }\end{array}$ & $\begin{array}{l}\text { Life tables reveal stable } \\
\text { age structure of adults; } \\
\text { Sample bias possible for } \\
\text { smaller individuals }\end{array}$ \\
\hline Population growth rate & $\begin{array}{l}\text { Population is in stable equilibrium; } \\
\text { neither increasing or decreasing in } \\
\text { size }\end{array}$ & $\begin{array}{l}\text { Tests on density } \\
\text { dependence reveals } \\
\text { intrinsic rate of growth } \sim 0 \text { ) }\end{array}$ \\
\hline \multirow[t]{4}{*}{ Size at birth/hatch } & $\begin{array}{l}\text { Eastern Mosquitofish }(<7 \mathrm{~mm}) \text { and } \\
\text { Sailfin Molly }(<9 \mathrm{~mm})\end{array}$ & $\begin{array}{l}\text { (Conrow and Zale 1985, } \\
\text { Nordlie 2000, Ala- } \\
\text { Honkola et al. 2011, }\end{array}$ \\
\hline & $\begin{array}{l}\text { Golden Topminnow }(<7 \mathrm{~mm}) \text { and } \\
\text { Bluefin Killifish }(<6 \mathrm{~mm})\end{array}$ & Beyger et al. 2012) \\
\hline & Least Killifish $(<6 \mathrm{~mm})$ & \\
\hline & Flagfish $(<6 \mathrm{~mm})$ & \\
\hline \multirow[t]{6}{*}{ Age/Size at Maturation } & $\begin{array}{l}\text { Eastern Mosquitofish (17mm, 84 } \\
\text { days) }\end{array}$ & \\
\hline & Bluefin Killifish (18mm, 71 days) & \\
\hline & Sailfin Molly (18mm, $\sim 112$ days) & \\
\hline & Least Killifish (10mm, $\sim 65$ days) & \\
\hline & $\begin{array}{l}\text { Golden Topminnow }(22 \mathrm{~mm}, \sim 54 \\
\text { days) }\end{array}$ & \\
\hline & Flagfish (20mm, $\sim 164$ days) & \\
\hline Mortality & $Z=M$ & $\begin{array}{l}\text { Throw trap removal of } \\
\text { species (fishing mortality } \\
F \text { ) is negligible }\end{array}$ \\
\hline
\end{tabular}


Table 2: Summary statistics of hydrological variables throughout the 20 years of the study by sites located in Shark River Slough, Taylor Slough, and Water Conservation Area at the date of sampling. Under Number of Drying Events, parentheses indicate individual plots.

\begin{tabular}{|c|c|c|c|c|c|}
\hline Region & Site & $\begin{array}{c}\text { Average Annual Minimum } \\
\text { Depth }(\mathrm{cm})\end{array}$ & $\begin{array}{c}\text { Average Annual Maximum } \\
\text { Depth }(\mathrm{cm})\end{array}$ & $\begin{array}{c}\text { Mean Hydroperiod } \\
\text { (Days) }\end{array}$ & Number of Drying Events \\
\hline SRS & 06 & $26.29(2.80)$ & $73.84(2.19)$ & $356.77(4.14)$ & $3(\mathrm{~A}), 3(\mathrm{~B}), 8(\mathrm{C})$ \\
\hline SRS & 07 & $19.24(2.76)$ & $62.61(2.21)$ & $348.73(5.01)$ & $11(\mathrm{~A}), 11(\mathrm{~B}), 12(\mathrm{C})$ \\
\hline SRS & 08 & $16.30(2.60)$ & $61.32(2.36)$ & $331.22(7.75)$ & $13(\mathrm{~A}), 11(\mathrm{~B}), 13(\mathrm{C})$ \\
\hline SRS & 23 & $15.00(2.71)$ & $59.66(2.12)$ & $322.60(11.00)$ & 7 (A), 11 (B), 7 (C) \\
\hline SRS & 37 & $9.54(2.07)$ & $54.25(2.61)$ & $316.68(9.64)$ & $17(\mathrm{~A}), 18(\mathrm{~B}), 16(\mathrm{C})$ \\
\hline SRS & 50 & $7.29(1.94)$ & $54.04(2.87)$ & $299.50(9.54)$ & 17 (A), 17 (B), 17 (C) \\
\hline TSL & $\mathrm{CP}$ & $19.81(2.72)$ & $62.19(1.53)$ & $343.21(7.75)$ & 9 (A), 9 (B), 12 (C) \\
\hline TSL & MD & $20.76(3.25)$ & $62.49(1.68)$ & $344.81(4.77)$ & $13(\mathrm{~A}), 13(\mathrm{~B}), 13(\mathrm{C})$ \\
\hline TSL & MDsh & $4.26(1.79)$ & $42.00(1.61)$ & $263.77(10.14)$ & 18 (B), 19 (E) \\
\hline TSL & TS & $16.98(2.52)$ & $54.10(1.45)$ & $341.32(6.37)$ & $13(\mathrm{~A}), 13(\mathrm{~B}), 13(\mathrm{C})$ \\
\hline TSL & TSsh & $12.53(2.46)$ & $47.05(1.51)$ & $332.00(6.83)$ & 14 (D), 16 (E) \\
\hline WCA & 01 & $41.00(2.34)$ & $89.80(3.55)$ & $362.63(1.73)$ & $1(\mathrm{~A}), 1(\mathrm{~B}), 1(\mathrm{C})$ \\
\hline WCA & 02 & $30.08(3.13)$ & $79.29(3.31)$ & $354.95(4.94)$ & $5(\mathrm{~A}), 5(\mathrm{~B}), 5(\mathrm{C})$ \\
\hline WCA & 03 & $14.73(2.70)$ & $60.58(3.19)$ & $319.63(10.10)$ & $15(\mathrm{~A}), 14(\mathrm{~B}), 14(\mathrm{C})$ \\
\hline WCA & 04 & $51.51(2.71)$ & $103.77(3.81)$ & 365 & $0(\mathrm{~A}), 0(\mathrm{~B}), 0(\mathrm{C})$ \\
\hline WCA & 05 & $41.01(3.13)$ & 95.37 (3.99) & 365 & $0(\mathrm{~A}), 0(\mathrm{~B}), 0(\mathrm{C})$ \\
\hline WCA & 06 & $42.93(4.11)$ & $109.14(4.59)$ & $361.75(2.59)$ & $2(\mathrm{~A}), 2$ (B), $3(\mathrm{C})$ \\
\hline WCA & 07 & $24.57(2.74)$ & $60.27(2.24)$ & $353.55(5.82)$ & $4(\mathrm{~A}), 3(\mathrm{~B}), 3(\mathrm{C})$ \\
\hline WCA & 08 & $24.57(2.35)$ & $61.83(2.36)$ & $359.18(4.30)$ & $0(\mathrm{~A}), 1(\mathrm{~B}), 2(\mathrm{C})$ \\
\hline WCA & 09 & $16.14(2.59)$ & $60.18(3.40)$ & $333.95(8.41)$ & $10(\mathrm{~A}), 10(\mathrm{~B}), 10(\mathrm{C})$ \\
\hline WCA & 10 & $10.80(2.20)$ & $65.76(4.13)$ & $308.32(12.00)$ & 13 (A), 13 (B), 13 (C) \\
\hline
\end{tabular}


Table 3: Mean $(+/$ SE) slope parameter estimate over the 17 -year time series by site and species. The slope for each Generalized Linear Model is equivalent to the instantaneous mortality rate $\left(Z\right.$, individuals $\left.\mathrm{mm}^{-1}\right)$. Estimates for each individual year were used in our VPA to estimate recruit abundance.

\begin{tabular}{|c|c|c|c|c|c|c|}
\hline \multicolumn{7}{|c|}{ Estimated Mean Instantaneous Mortality Rates $(Z)$} \\
\hline Region & Site & $\begin{array}{c}\text { Golden } \\
\text { Topminnow }\end{array}$ & $\begin{array}{c}\text { Eastern } \\
\text { Mosquitofish }\end{array}$ & Flagfish & $\begin{array}{c}\text { Least } \\
\text { Killifish }\end{array}$ & $\begin{array}{l}\text { Bluefin } \\
\text { Killifish }\end{array}$ \\
\hline SRS & 06 & $0.12(0.01)$ & $0.37(0.04)$ & $0.27(0.03)$ & $0.74(0.03)$ & $0.33(0.02)$ \\
\hline SRS & 07 & $0.11(0.01)$ & $0.27(0.02)$ & $0.24(0.02)$ & $0.67(0.04)$ & $0.29(0.02)$ \\
\hline SRS & 08 & $0.11(0.01)$ & $0.31(0.01)$ & $0.30(0.03)$ & $0.62(0.05)$ & $0.30(0.02)$ \\
\hline SRS & 23 & $0.14(0.02)$ & $0.31(0.02)$ & $0.33(0.06)$ & $0.60(0.05)$ & $0.34(0.02)$ \\
\hline SRS & 37 & $0.09(<0.01)$ & $0.26(0.02)$ & $0.27(0.02)$ & $0.63(0.02)$ & $0.24(0.02)$ \\
\hline SRS & 50 & $0.18(0.03)$ & $0.26(0.02)$ & $0.42(0.06)$ & $0.52(0.05)$ & $0.25(0.03)$ \\
\hline TSL & $\mathrm{CP}$ & $0.14(0.02)$ & $0.19(0.02)$ & $0.42(0.05)$ & $0.52(0.05)$ & $0.28(0.02)$ \\
\hline TSL & MD & $0.11(0.01)$ & $0.25(0.02)$ & $0.35(0.02)$ & $0.56(0.05)$ & $0.26(0.02)$ \\
\hline TSL & MDsh & $0.10(0.01)$ & $0.26(0.03)$ & $0.21(0.03)$ & $0.48(0.06)$ & $0.25(0.02)$ \\
\hline TSL & TS & $0.11(0.01)$ & $0.25(0.02)$ & $0.37(0.05)$ & $0.54(0.06)$ & $0.25(0.02)$ \\
\hline TSL & TSsh & $0.04(0.02)$ & $0.22(0.02)$ & $0.36(0.07)$ & $0.56(0.07)$ & $0.21(0.02)$ \\
\hline WCA & 01 & $0.15(0.02)$ & $0.32(0.02)$ & $0.34(0.06)$ & $0.70(0.04)$ & $0.34(0.02)$ \\
\hline WCA & 02 & $0.12(0.01)$ & $0.31(0.02)$ & $0.29(0.02)$ & $0.73(0.05)$ & $0.33(0.01)$ \\
\hline WCA & 03 & $0.09(<0.01)$ & $0.29(0.04)$ & $0.22(0.02)$ & $0.50(0.05)$ & $0.23(0.01)$ \\
\hline WCA & 04 & $0.13(0.01)$ & $0.31(0.02)$ & $0.26(0.06)$ & $0.64(0.05)$ & $0.36(0.02)$ \\
\hline WCA & 05 & $0.12(0.01)$ & $0.34(0.01)$ & $0.28(0.04)$ & $0.71(0.03)$ & $0.32(0.01)$ \\
\hline WCA & 06 & $0.12(0.01)$ & $0.34(0.02)$ & $0.32(0.04)$ & $0.63(0.03)$ & $0.30(0.02)$ \\
\hline WCA & 07 & $0.11(0.01)$ & $0.29(0.01)$ & $0.24(0.03)$ & $0.70(0.03)$ & $0.30(0.01)$ \\
\hline WCA & 08 & $0.11(0.01)$ & $0.30(0.01)$ & $0.23(0.03)$ & $0.64(0.03)$ & $0.29(0.02)$ \\
\hline WCA & 09 & $0.08(0.01)$ & $0.25(0.02)$ & $0.15(0.02)$ & $0.49(0.04)$ & $0.21(0.01)$ \\
\hline WCA & 10 & $0.10(0.01)$ & $0.26(0.01)$ & $0.18(0.02)$ & $0.50(0.03)$ & $0.23(0.02)$ \\
\hline
\end{tabular}


Fig. 1. Map of the sites in this study.

Fig. 2. Mean water depth with $95 \%$ confidence interval at each sample event averaged across all sites within the hydroperiod classification (Long, Intermediate, and Short hydroperiods). Values underneath the dashed reference line $(5 \mathrm{~cm})$ are considered too dry for fish species. Vertical bars enclose one year of samples (5 samples per year) from February to December (D).

Fig. 3. The unadjusted (filled circles) and adjusted (open circles) size-selectivity curves for each study species in 1-mm increments. The dashed line indicates the size of maturation for that species.

Fig. 4. An example of average differences in density between VPA estimates and observed densities. Data for SRS Site 07 over the 20-year study for A) Golden Topminnow, B) Eastern Mosquitofish, C) Least Killifish, D) Flagfish, and E) Bluefin Killifish. Estimates reveal seasonal changes in peak recruitment following cohort analysis.

Fig. 5. Partial regression plots describing changes in Bluefin Killifish recruit density at WCA 10 (Intermediate Hydroperiod). The three-parameter quadratic model (no intercept) was selected based on $\mathrm{AIC}$ values. $\mathrm{K}=3, \mathrm{AIC}=-113.977, \Delta \mathrm{AIC}=0, \mathrm{R}^{2}=0.72$.

Fig. 6. Scatter plot describing how recruit abundance increases with increasing water depth for Least Killifish at WCA 06 (Long Hydroperiod) based on the linear model (no intercept) selected by $\mathrm{AIC} . \mathrm{K}=1, \mathrm{AIC}=13.81, \Delta \mathrm{AIC}=0, \mathrm{R}^{2}=0.61$. 
Fig. 7. A) Partial regression plots describing annual variability in peak recruit density driven by site hydroperiod for Golden Topminnow at TSL MDsh (Short Hydroperiod). B) Model predicted values of annual maximum recruitment versus the corresponding hydroperiod for each species.

Fig. 8. A) Partial regression plots describing annual variability in total annual recruit density driven by site hydroperiod for Flagfish at TSL MDsh (Short Hydroperiod). B) Model predicted values of annual total recruitment versus the corresponding hydroperiod for each species. 
Fig. 1

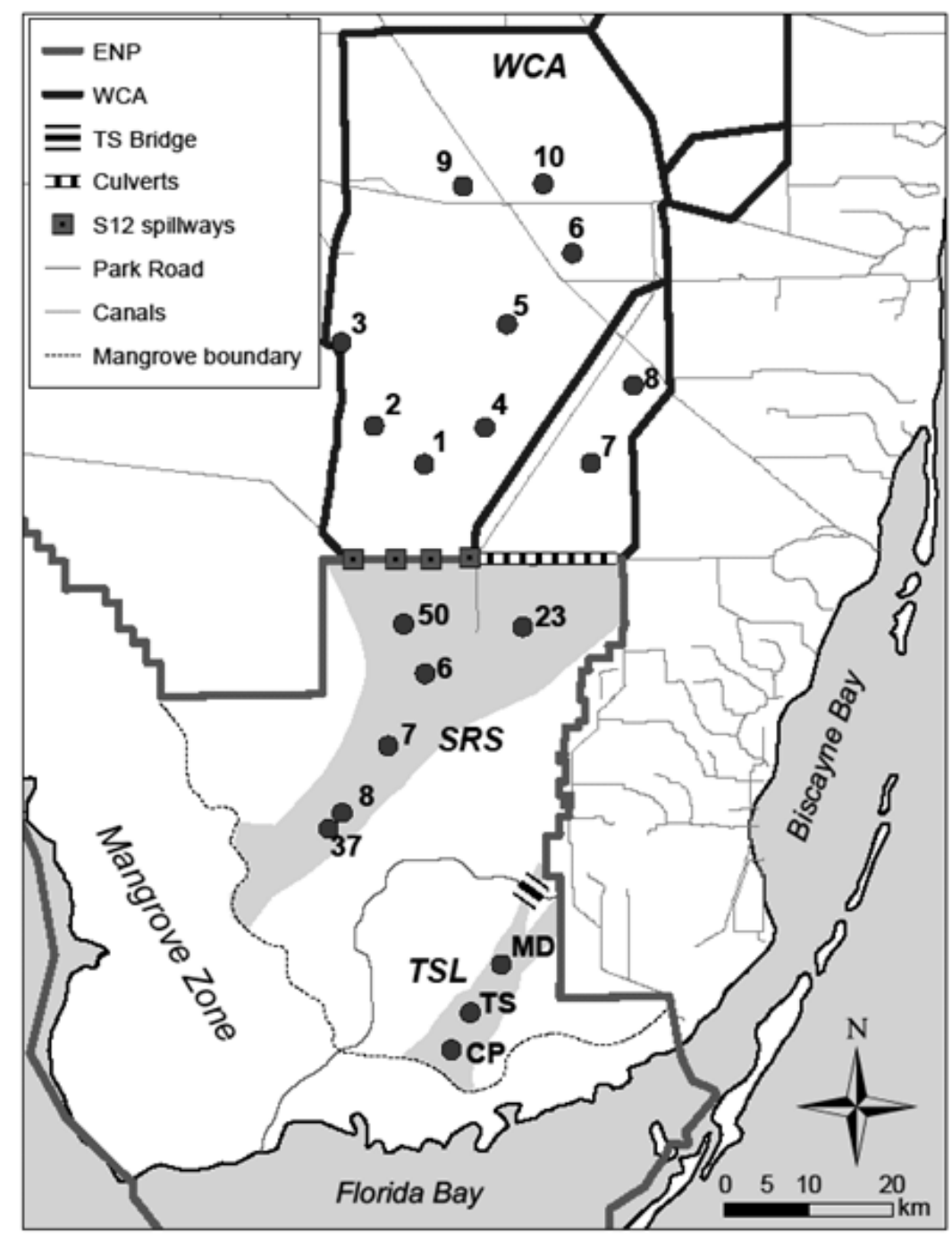


Fig. 2
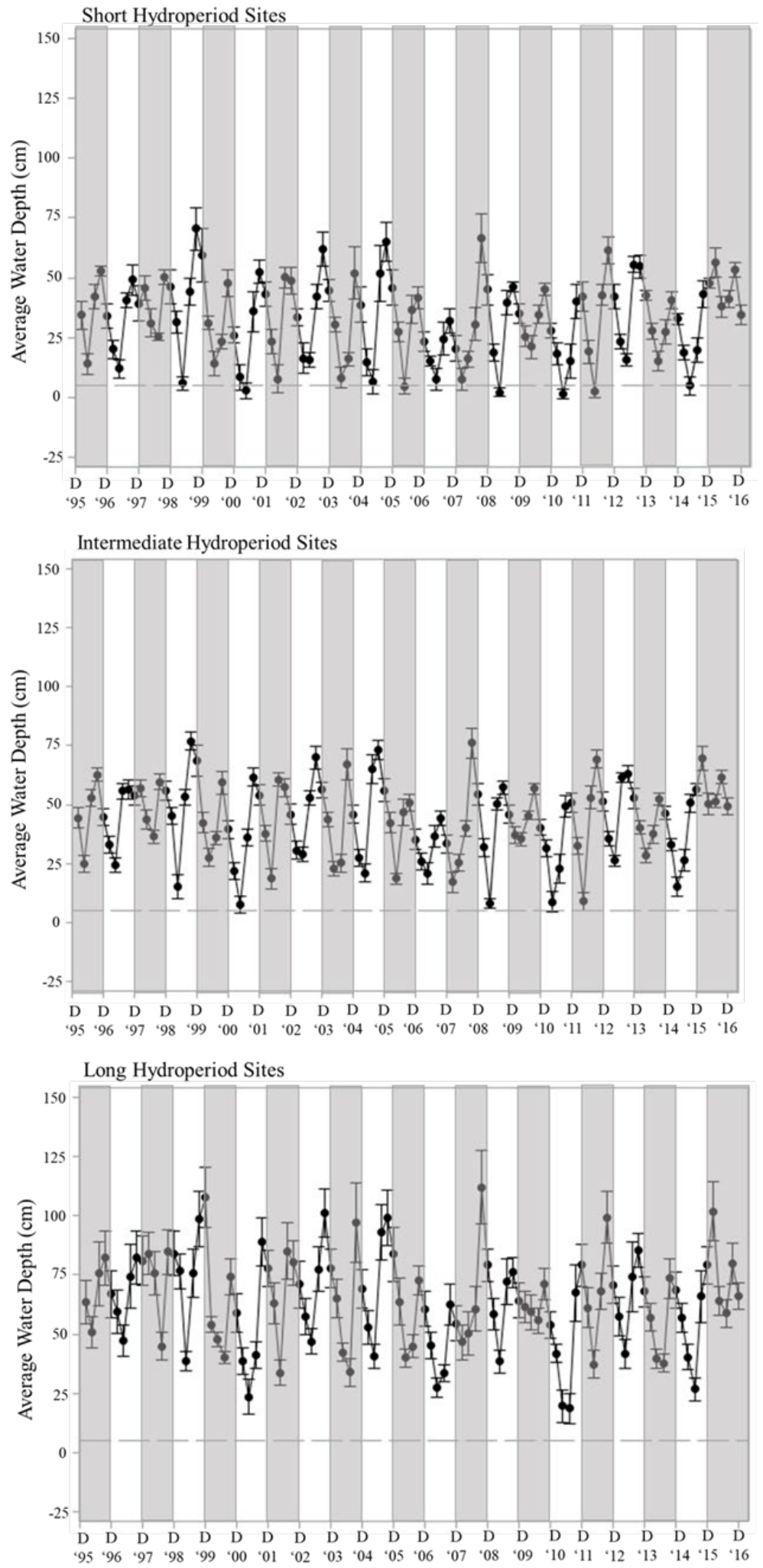
Fig. 3
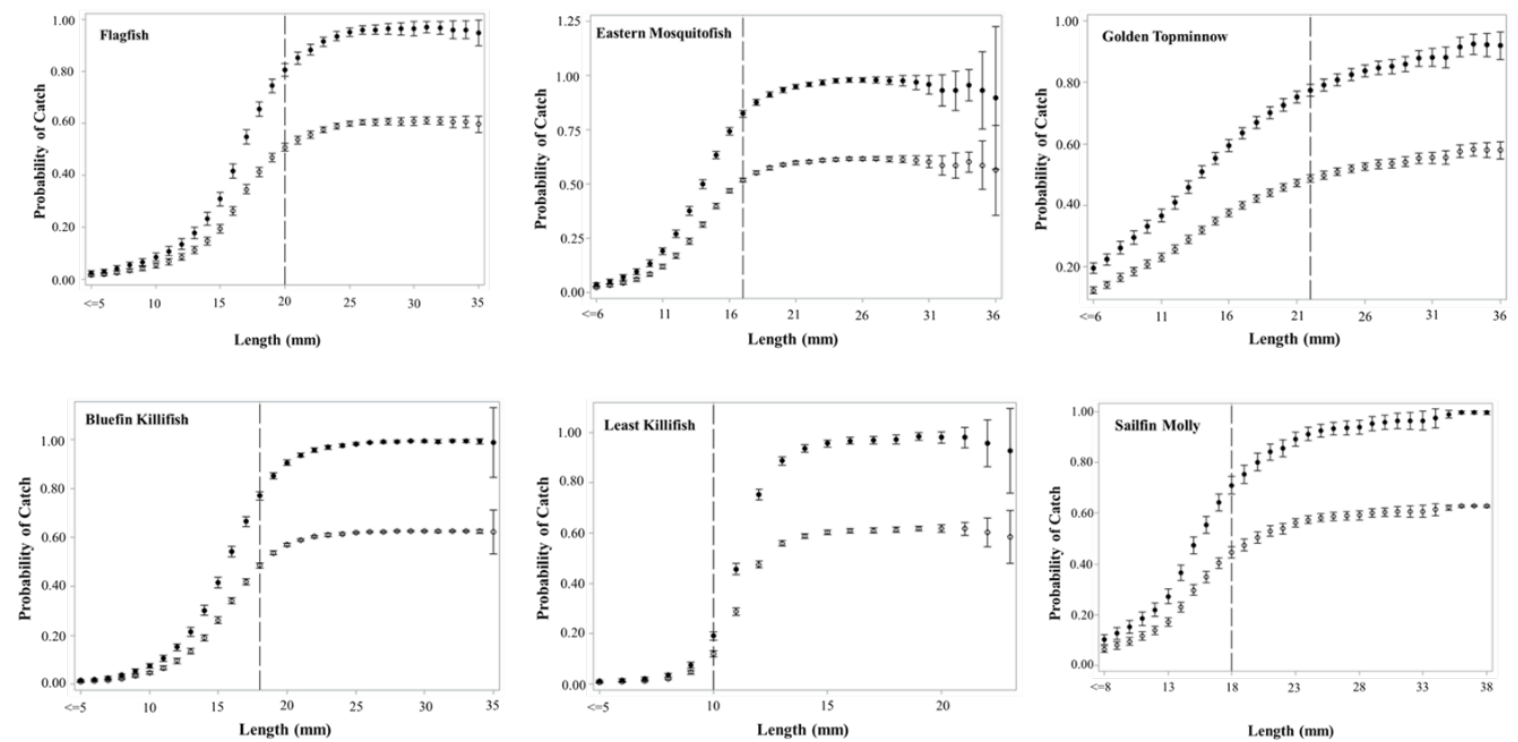
Fig. 4

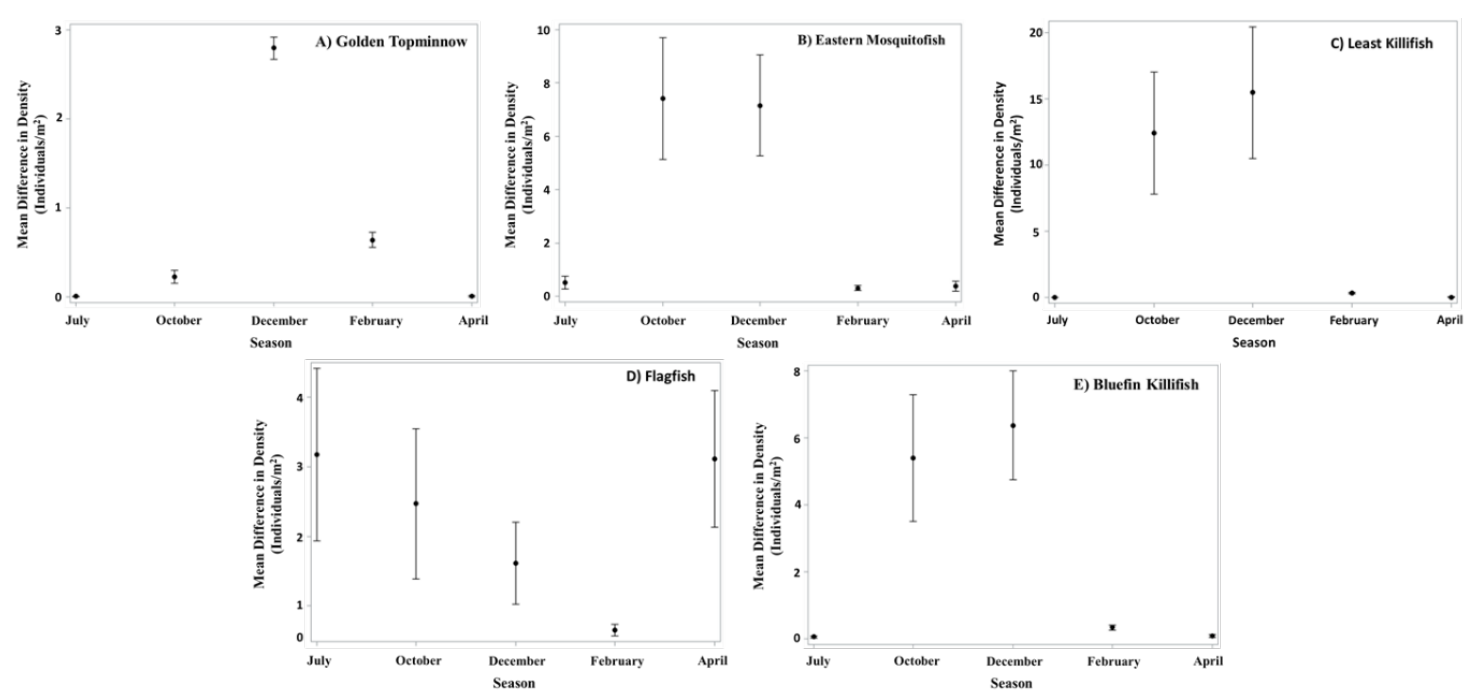


Fig. 5

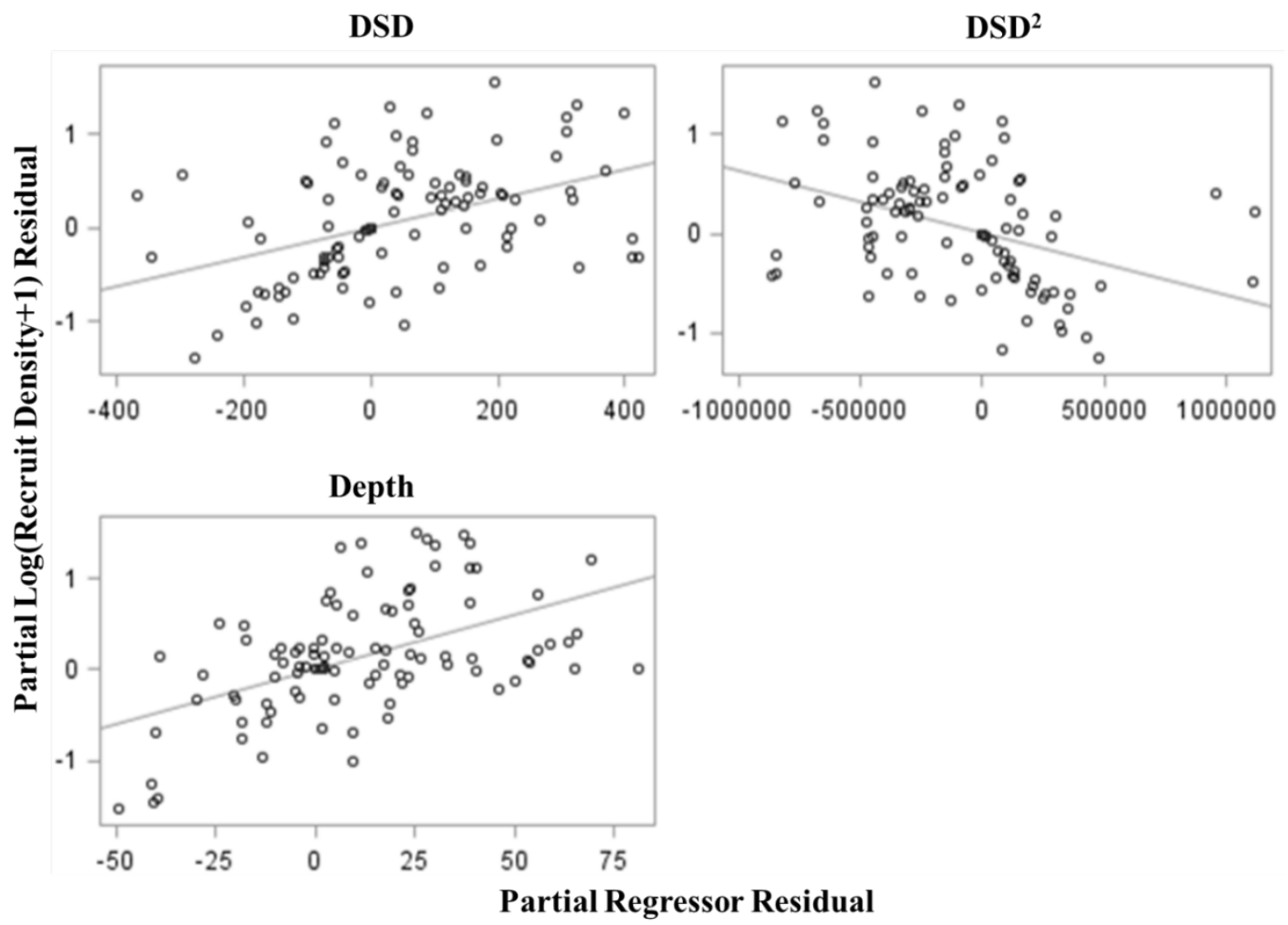


Fig. 6

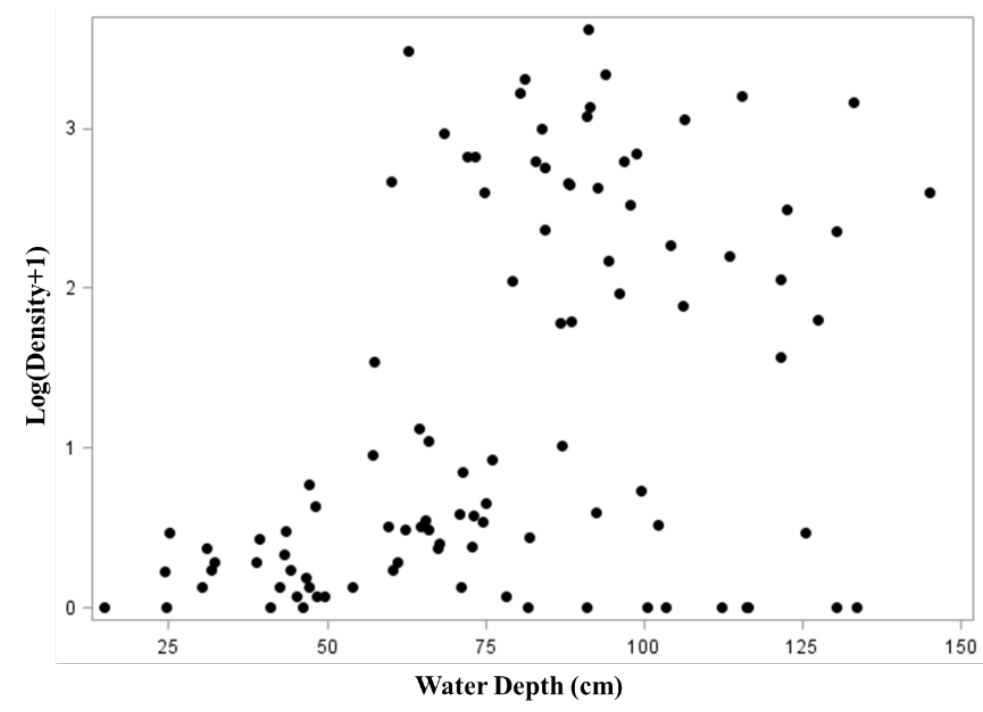


Fig. 7

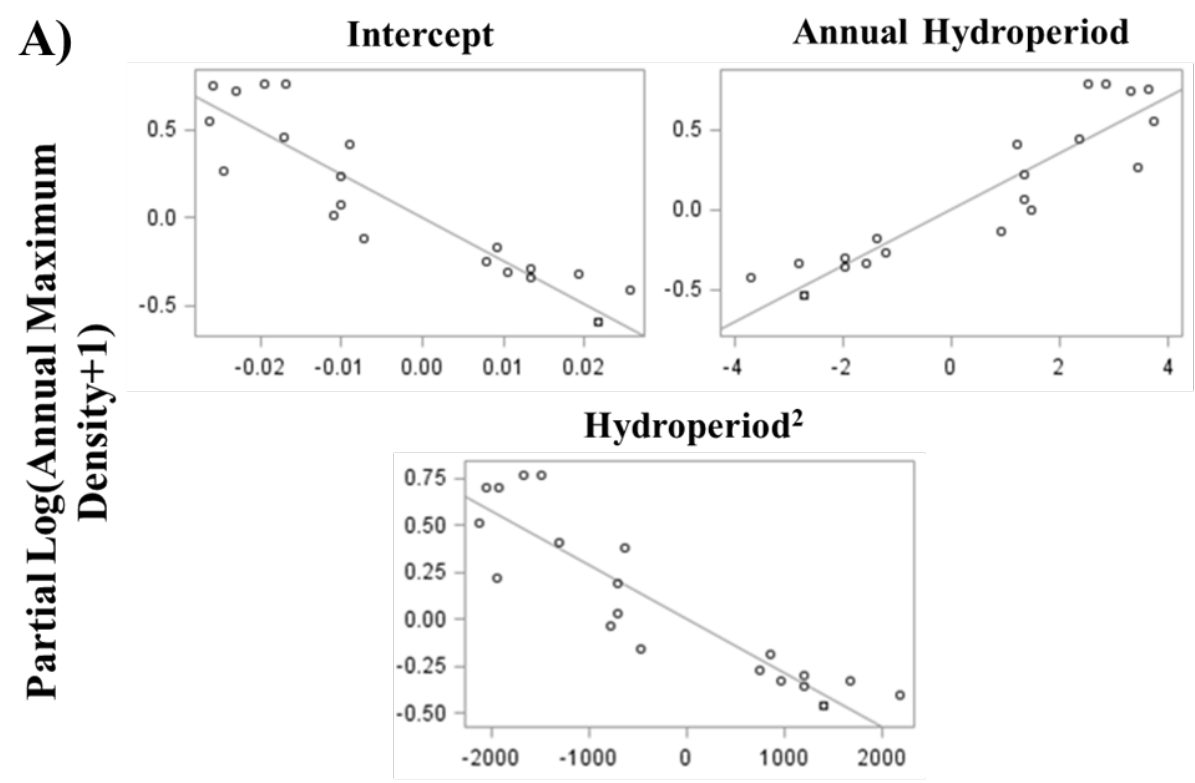

\section{Partial Regressor Residual}

B)

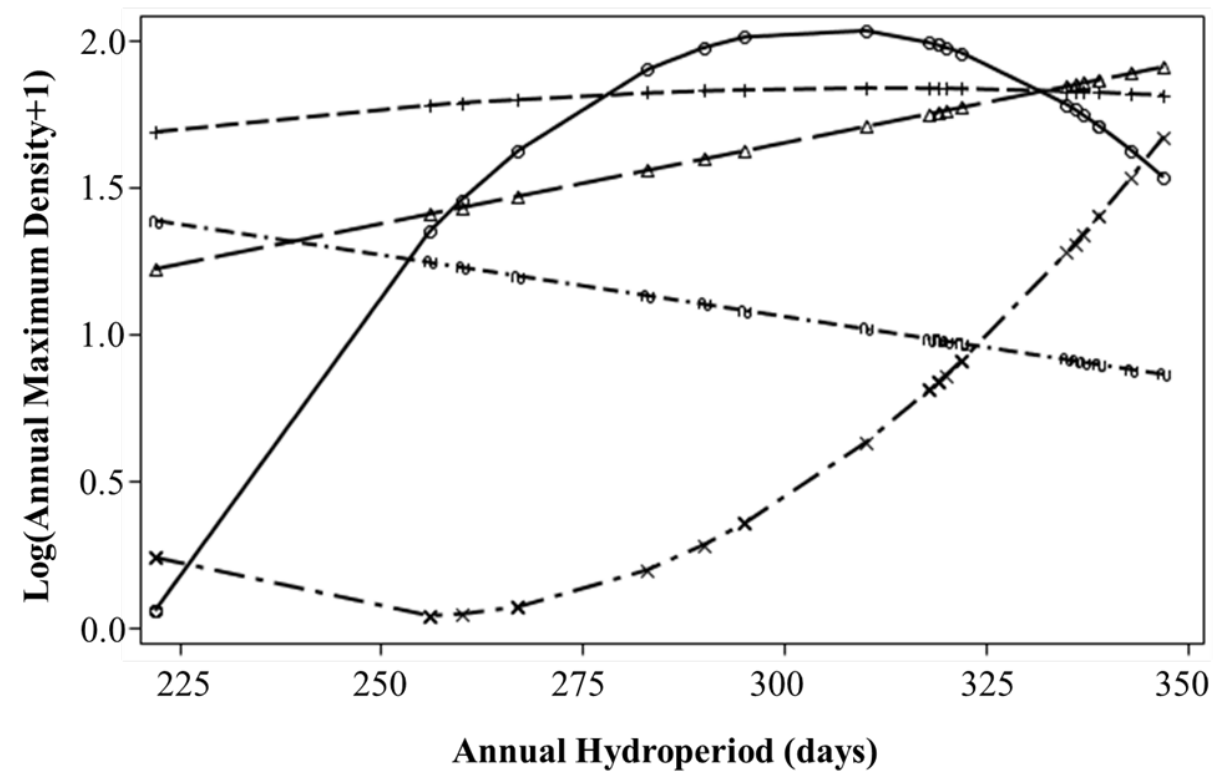

\begin{tabular}{|ll|}
\hline & Species \\
\hline Golden Topminnow & --- Eastern Mosquitofish $-\cdots$ \\
- Flagfish & $--\cdot-$ Bluefin Killifish \\
\hline
\end{tabular}


Fig. 8

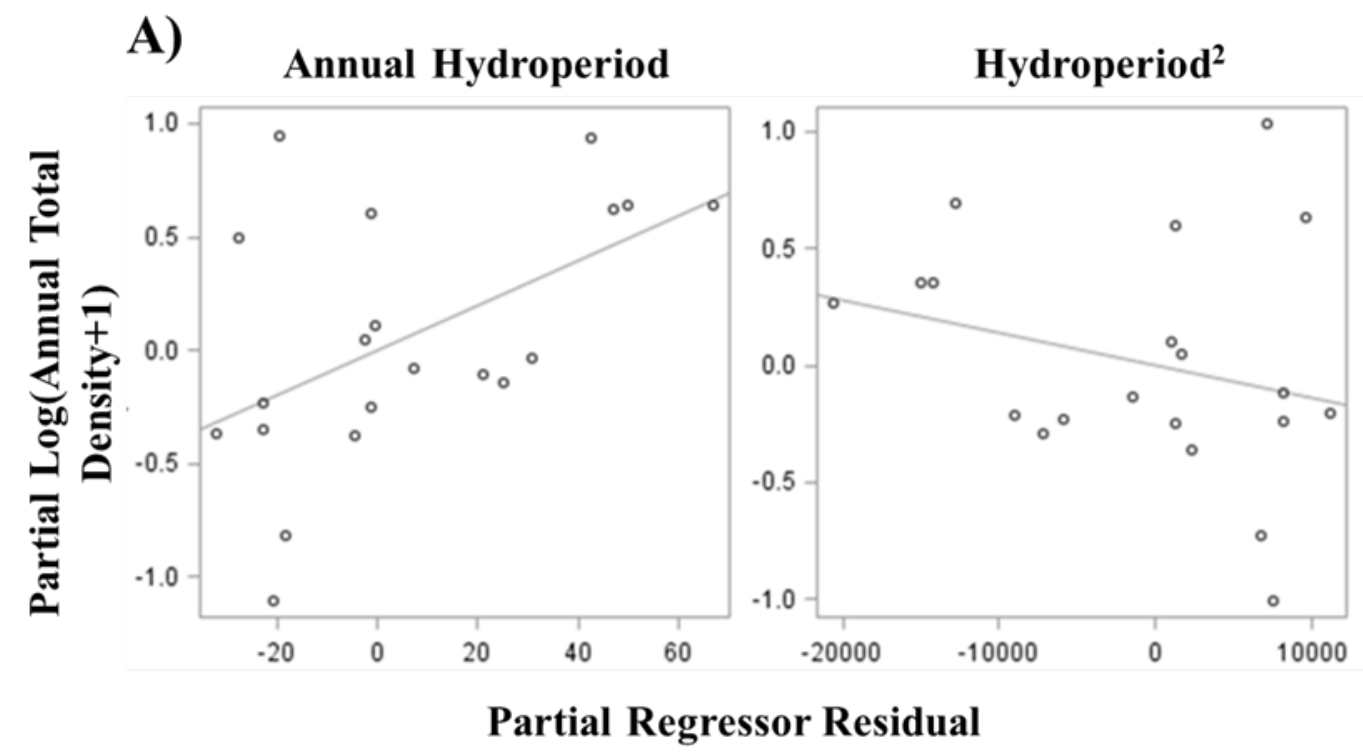

B)

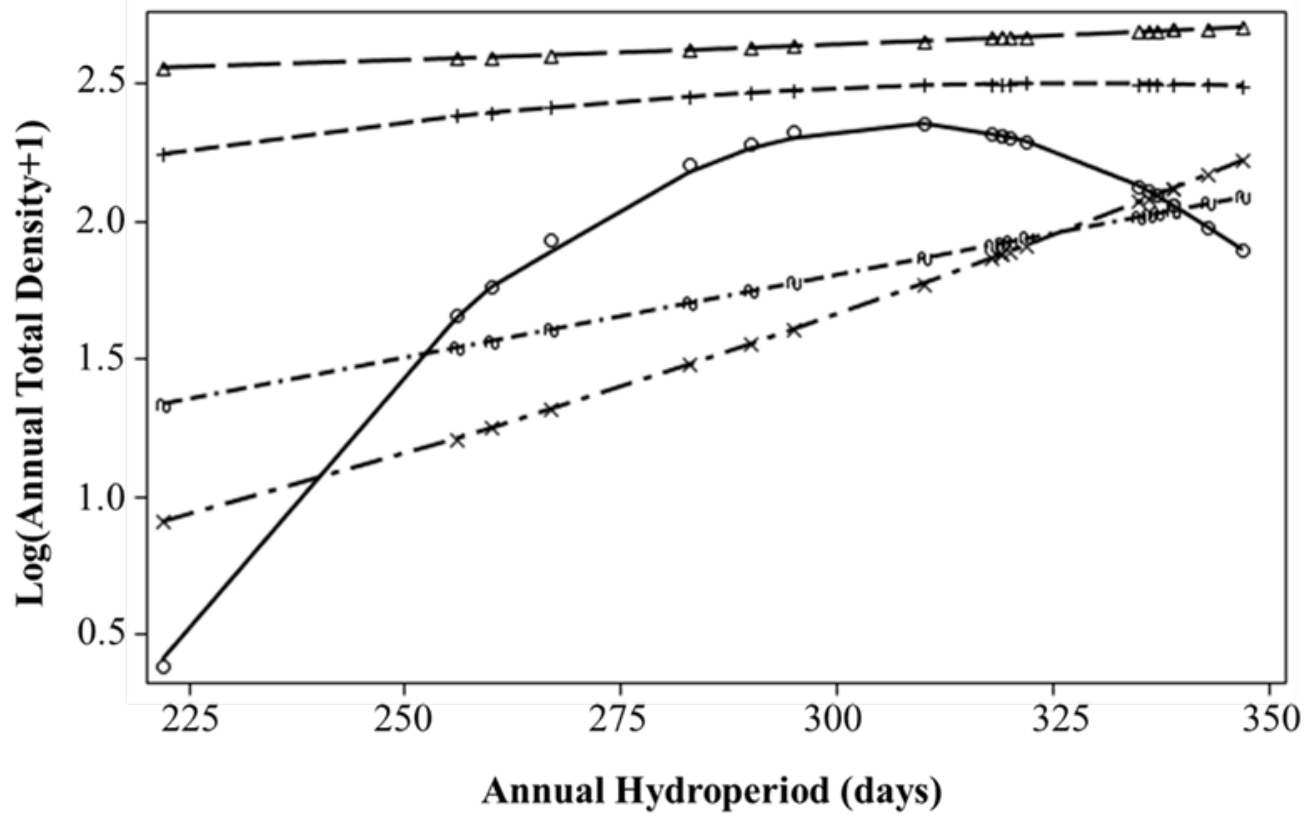

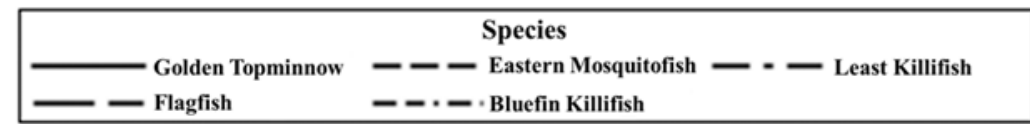




\section{CHAPTER III}

EVALUATING DENSITY-DEPENDENT RECRUITMENT IN A PULSED

FLOODPLAIN ECOSYSTEM 


\begin{abstract}
Recruitment is often assumed to be inhibited by the abundance of spawning stock (adults) leading to density-dependent (DD) regulation. In floodplains and wetlands, hydrology is believed to be the strong driver of abundance and acts as a density-independent (DI) factor that obscures DD signals and stock-recruitment (S-R) relationships. We used multimodel Inference (MMI) to determine if DD signals were present in a 20 -year time series of density of six marsh fish species in a hydrologically dynamic ecosystem. We investigated how hydrological variability influenced productivity $(\alpha)$, the strength of DD $(\beta)$, and the steepness $(h)$ of our S-R curves and population growth models. Both the S-R relationship and population dynamics were evaluated to differentiate stock-dependence and density-dependent feedback on recruits. Analyses revealed that DD feedback was selected in $35.7 \%(\triangle \mathrm{AIC}=0)$ and $63.1 \%(\triangle \mathrm{AIC}<3)$ of cases. Our population growth models revealed unanimous support for DD. The strength of evidence for DD based on Aikake Weights $\left(\mathrm{AIC}_{\mathrm{w}}\right)$ from our $\mathrm{S}-\mathrm{R}$ curves varied greatly among species and ranged from $<1 \%(H$. formosa $)$ to $66.4 \%^{+} /-8.0$ (L. goodei). However, the strength of evidence from our population growth models was $>98 \%$ for all species. Modeled outcomes revealed a lack of stock-dependence and increased evidence for density-dependence via competition among recruits. The inclusion of seasonal terms improved model fit for all species, and we determined that both $\beta$ and the interaction of season with $\beta$ significantly regulate recruitment. We detected evidence that the strength of density-dependence $(\beta)$ either decreased or increased with increased hydrological variability, depending on the species. This relationship was linearly correlated for $J$. floridae, indicating stronger negative DD as the environment became less stable. A parabolic relationship between $\beta$
\end{abstract}


and hydrological variability was detected for the remaining five species of the study. Analyses also revealed that, for $L$. goodie, both $h$ and $\alpha$ were correlated with the Coefficient of Variation of hydroperiod $\left(\mathrm{R}^{2}=0.43\right.$ and 0.40 , respectively). Overall, hydrology caused the strength of density-dependence on recruits to decrease under conditions of short to intermediate hydroperiods but to increase under longer hydroperiods as the environment became more stable for all species except $J$. floridae and P. latipinna.

Key words: density-dependence, stock-recruitment, hydrology, seasonality

\section{Introduction}

Attempts to understand the density-dependent (intrinsic) and density-independent (extrinsic) factors leading to recruitment variability have a long history in both fisheries and population biology (Anderson 1988; Cushing 1973; Fogarty et al. 1991). However, extrinsic and intrinsic processes act differently throughout life-history, with environmental variability acting strongly on the earliest life stages (DingsØr et al. 2007; Fogarty 1993). This either directly enhances recruitment through physical processes (e.g., hydrology) or indirectly by altering the strength of density-dependent mechanisms such as mortality from predation (Dorn and Cook 2015; Lasker 1981; Menge and Sutherland 1987). Furthermore, density-dependent (DD) and -independent (DI) processes may vary considerably among years or between seasons, altering the strength of these complex processes on recruitment (Stenseth et al. 2002). 
The most common measure for density-dependence in fish stocks is the stockrecruitment (S-R) relationship. Spawning stock both produces recruits (densityindependent, $\alpha$ ) and inhibits recruitment via density-dependent $(\beta)$ feedback (Beverton and Holt 1957; Ricker 1954). Mechanisms for density-dependent recruitment can either be "stock-dependent" (i.e. competition between adults and pre-recruits) or "densitydependent" via competition for limited prey among larvae and juveniles (Heath and Gallego 2000). Environmental variables (e.g., temperature, salinity) have been used to improve models of this highly variable relationship; however, many of these models ultimately fail due to environmental changes, for example in temperature or salinity (Myers 1998). In floodplain ecosystems, seasonal changes in hydrology may drastically impact the biological community and have major implications for density-dependent recruitment in these inherently variable environments (Bozelli et al. 2015; Dutterer et al. 2013).

Seasonal pulses in hydrology are believed to be the major abiotic factor influencing fish recruitment in floodplain ecosystems (Agostinho et al. 2004; Arthington and Balcombe 2011; Godfrey et al. 2017). Recruitment variability in freshwater systems often reflects local-scale environmental conditions and life history strategies have evolved to take advantage of local flood dynamics (Agostinho et al. 2004; Winemiller 2004). Inundation of the floodplain induces primary and secondary production, providing additional habitat and increased food sources for recruits (Geddes and Puckridge 1989; Junk et al. 1989; Schiller and Harris 2001). Age-specific differences in the use of the floodplain can lead to spatial-temporal differences in both recruit and stock 
abundance (Scharbert and Borcherding 2013). The early life stages may also saturate the carrying capacity of nursery habitats during times of low adult stock or when habitats are not limiting to adult stocks (Beverton 1995). This has the potential to alter or disrupt the stock-recruitment relationship and density-dependent feedback on recruitment.

The freshwater marshes of the Florida Everglades provide an excellent system for testing the effects of hydrology on the strength of density-dependent recruitment in floodplain ecosystems. These marshes experience seasonal rainfall patterns with an annual dry (February-June) and wet (July-January) period (Ogden et al. 2005), with seasonal inundation a direct result of rainfall and drought being caused by evaporation of surface water (Fennema et al. 1994). Small-bodied marsh fish make use of these shallow habitats to escape predation from large bodied predators, but are forced to move to riskier habitats during a dry-down (Parkos III et al. 2011). We investigate whether seasonal changes in hydrology influences the strength of density-dependent recruitment. Multimodel Inference (MMI) was applied to a series of density-independent and dependent stock-recruitment and population growth models to determine the presence of density-dependence along a hydrological gradient. This two-model approach evaluated whether fluctuations in recruitment were either stock-dependent via production (S-R) or density-dependent (population dynamics models). Furthermore, the population dynamics models evaluated whether the source of density-dependence was from either recruits or spawning stock. Seasonal components were introduced into our models to determine the influence of seasonal pulses in recruitment and spawning stock on density-dependence. We then evaluated how hydrological variability altered productivity, the strength of 
density-dependence, and the ability of populations to recover at low fish stocks for several marsh fish species.

\section{Methods}

Study Site and Species

From 1996 to 2016, fish were collected using a 1-m², 2-mm mesh, throw trap under a standard protocol (Jordan et al. 1997) at 21 monitoring sites in the Everglades, Florida, U. S. A. Six sites were located in Shark River Slough (SRS), five in Taylor Slough (TSL), and 10 in Water Conservation Areas (WCA) 3A and 3B. Samples were collected at each site in five months of each year (July, October, December, February, and April). Each site consisted of three plots, except TSL MDsh and TSsh that consisted of two plots each. Five (WCA 3A and 3B) or seven (SRS, TSL) throw trap samples were collected within each plot; five samples were taken in SRS and TSL in years when lowwater conditions required access by helicopter, most commonly in February and April in TSL. Sites located in WCA 3A and 3B yielded 75 samples per year (3 plots $\mathrm{x} 5$ throws $\mathrm{x}$ 5 sample events), while sites in SRS and TSL yielded 105 samples per water-year (3 plots $\mathrm{x} 7$ throws per plot $\mathrm{x} 5$ sample events) in most years. Missing samples were uncommon but occurred because water was too deep to sample effectively (most likely in WCA 3A) or too shallow or dry (most likely in TSL). Sample locations within each plot were determined using a random number table. After securing the trap, floating vegetation (non-rooted vascular plants and periphyton mat) was cleared before fish were removed following a standardized protocol of sweeps with a bar seine and dip nets. Vertebrate organisms were euthanized using a solution of MS-222 and ambient marsh water 
(Nickum et al. 2004). There is no evidence of visitor impact on these long-term study sites, possibly because marsh plants re-grow quickly and periodic marsh drying overwhelms sampler impacts on vegetation and soil (Wolski et al. 2004). Additional information on the study sites and sampling design are described in detail within other publications (Trexler et al. 2003; Trexler et al. 2005).

We focus on the six most common species in our data to minimize impacts of excessive zero samples on our model results (Martin et al. 2005). Three of the study species were oviparous Fundulus chrysotus (Golden Topminnow), Lucania goodei (Bluefin Killifish), and Jordanella floridae (Flagfish), and three were viviparous Gambusia holbrooki (Eastern Mosquitofish), Heterandria formosa (Least Killifish), Poecilia latipinna (Sailfin Molly). We define recruitment as the process of new individuals entering the population susceptible to capture by our throw traps (Blackhart et al. 2006). For all but one species, the minimum size/age captured efficiently included specimens in the juvenile life stage; only H. formosa matured at a size at or below effective capture (Gatto and Trexler 2019). We differentiated spawning stock $(S)$ and recruits $(R)$ by the size of maturation using the following criteria: H. formosa $(R<10 \mathrm{~mm}$, $S \geq 10 \mathrm{~mm}), G$. holbrooki $(R<17 \mathrm{~mm}, S \geq 17 \mathrm{~mm})$, P. latipinna and L. goodei $(R<18 \mathrm{~mm}, S$ $\geq 18 \mathrm{~mm}), F$. chrysotus $(R<22 \mathrm{~mm}, S \geq 22 \mathrm{~mm})$, and $J$. floridae $(R<20 \mathrm{~mm}, S \geq 20 \mathrm{~mm})$. Stock-Recruitment Analysis

We investigated the stock-recruitment relationships for six species across 21 sites by applying a series of models to our 20-year time series. Both spawning stock and recruit abundance were calculated by summing the total number of individuals of a species collected at each sample event $\left(\mathrm{n}_{\max }=107\right)$. We followed the recommendation of 
Turchin (2003) by adjusting zero values to equal one divided by the maximum number of samples $(1 / 21 \approx 0.048)$ for each observation (Turchin 2003). To account for unequal sample sizes collected throughout the year $(\mathrm{n}=15-21)$, we calculated the density of each species based on the number of throw trap samples taken. We considered two densityindependent (random walk, density-independent) and five density-dependent stockrecruitment models (Cushing, Salia-Lorda, Beverton-Holt, Ricker, Shepherd) that have been widely used in stock assessment (Table 1). We regressed the response variable (log-transformed recruit abundance) against spawning stock abundance $\left(\mathrm{S}_{\mathrm{t}}\right)$ or $\log$ transformed abundance, depending on the model. This independent variable was selected over Spawning Stock Biomass (SSB) since individual adults are small and overall biomass was low. Preliminary analysis determined that model fit was poor and parameter estimates were quite small using SSB. Results using SSB as the independent variable for all analyses are included in Supplemental Appendix A. We also considered a lag in the stock-recruitment relationship by independently testing spawning stock abundance from the previous time step $\left(\mathrm{S}_{\mathrm{t}-1}\right)$.

A series of linear and non-linear models were used to calculate classic stockrecruitment curves. The log-linear transformation of the random walk, exponential growth, Ricker, Saila-Lorda, and Cushing models permitted Ordinary Least Squares (OLS) regression. The Beverton-Holt and Shepherd models do not have a log-linear transformation and were fitted using non-linear least squares (NLS) with the Marquardt optimization method. We used the log-transformed response variable for all stockrecruitment models to permit comparison of fit of all models using Information 
Theoretical methods (Burnham and Anderson 2004). We did not restrict these models to non-negative terms and negative values may have been considered by the optimization procedure to produce a converging model. This, and all other analyses, were conducted using SAS 9.4 (Insititute 2012).

Although recruitment occurs year-round, evidence suggests that there are seasonal pulses in stock and recruit abundance (Gatto and Trexler 2019). We considered seasonal variability in recruit abundance by adding an additional three models to consider along with the stock-recruitment curves. We evaluated seasonality by introducing two models that regressed log-transformed recruit abundance against Season and Season ${ }^{2}$ (Table 1). We assigned numeric values to the month of sampling based on the south Florida water year (wet season to dry season: July=1, October=2, December=3, February=4, April=5). The remaining seasonal model considered an environmental variable previously described as an indicator of seasonal changes in hydrology. This count variable, days since last dry $\left(\mathrm{DSD}_{t}\right)$ was calculated using data extracted from the Everglades Depth Estimation Network (EDEN). EDEN uses water-surface models and water depths from a network of monitored gauges to estimate daily water depth at our study sites (Liu et al. 2009; Telis 2006). DSD records the cumulative number of days since gauges recorded a water depth $<5 \mathrm{~cm}$ for each sampling event. At $5 \mathrm{~cm}$, only a slurry of organic matter remains, and fish generally suffocate in the low oxygen conditions and organic matter blocking their gills. These models were used to compare seasonal effects on recruitment (density independent) to those of the stock-recruitment relationship.

Population Growth Models 
We used a series of population growth models and analyzed changes in recruitment as a phenomenological time series. Following the methods of Brook and Bradshaw (2006), we applied a set of four models commonly used to describe phenomenological time series data by replacing changes in population size with changes in recruitment. We investigated three density-independent (random walk, exponential growth, $\mathrm{DSD}_{\mathrm{t}}$ ) and two density-dependent models (Ricker- and Gompertz population growth) to test for density-dependent recruitment in our times series data (Table 2). The $\theta$-logistic model was excluded because simulations have suggested that parameter estimates for $r_{\max }$ and $\theta$ tend to be extreme and ecologically implausible (Clark et al. 2010). Four independent variables were considered for each of the four models $\left(R_{t}, R_{t-1}\right.$, $\left.\mathrm{S}_{t}, \mathrm{~S}_{\mathrm{t}-1}\right)$ against the response variable $\mathrm{r} 0$ or recruitment rate $\left(\ln \left(\mathrm{R}_{\mathrm{t}+1} / \mathrm{R}_{\mathrm{t}}\right)\right)$. This accounts for both lagged responses to changes in recruitment via stock-dependent or densitydependent effects. The random walk, exponential growth, Ricker-, and Gompertzpopulation growth models were all calculated using OLS.

\section{Strength of Density Dependence}

Following model approximation, we used MMI to determine which S-R and population growth model best fit our data. The validity of each stock-recruitment model was evaluated based on parameter estimates (Iles 1994). Stock-recruitment models were considered inadmissible when any parameters were negative $(a, \beta, y<0)$. We excluded these models and those remaining were considered valid for further analyses. MMI based on Information Theory was used to evaluate the density-dependent and -independent drivers on recruitment (Burnham and Anderson 2004). To determine the model that best fit our data, we calculated both the AIC and AICc values using the Sum of Square Errors 
(SSE). The model with the lowest AICc value ( $\mathrm{AIC}_{\mathrm{MIN}}$ ) had the highest support and models $\triangle \mathrm{AIC}<3$ were considered equally valid. The Aikake Weights $\left(\mathrm{AIC}_{\mathrm{w}}\right)$, an indicator of the model strength, were then calculated using $\triangle \mathrm{AIC}$ values (AICc-AIC $\mathrm{MIN}_{\text {) }}$ and used to determine the strength of support for each model. Given that the complexity of each model varied, we used $\log _{10}$-transformed information-theoretic evidence ratios (LER) to compare each model to the best model to quantify the relative support for each. We then evaluated the coefficient of determination $\left(\mathrm{R}^{2}\right)$ for each model to illustrate the goodness-of-fit. The strength of evidence for either DD or DI was calculated by summing the estimated $\mathrm{AIC}_{\mathrm{w}}$ by model type (DD vs DI) at each site (Brook and Bradshaw 2006).

\section{Seasonality and Density-Dependence}

Density-dependence via the stock-recruitment relationship may be obscured by seasonal stochasticity leading to a spatial-temporal mismatch in recruit and stock abundance. We addressed this by introducing three new parameters to the densityindependent, Cushing, Ricker, and Saila-Lorda equations. Two terms, Season and Season $^{2}$, were added to incorporate seasonality into the stock-recruitment curves. We then included the interaction between the independent variable stock abundance $\left(\mathrm{S}_{\mathrm{t}}, \mathrm{S}_{\mathrm{t}-1}\right)$ and the seasonal term. These models were then re-evaluated using a Type III Sum of Squares to determine the individual effects of seasonality and density-dependence (Chao et al. 2008). Given the complexity of the Beverton-Holt and Shepherd equations, we excluded these models from this analysis. For our population growth models, we 
incorporated both the seasonal and interaction terms into the Gompertz and Ricker models. These models were evaluated using MMI by adding the additional three parameters to the AIC calculation. Partial correlation coefficients $(r)$ were calculated for each parameter included in the model to determine the contribution of seasonal components, density-dependence (if present), and the interaction between the source of density-dependence and season.

Hydrology on Productivity, Density-Dependence, and Steepness

Following an analysis of the stock-recruitment relationship for our study species, we investigated the effect of hydrology on both the strength of density-dependence $(\beta)$, the estimated recruits-per-spawner $(\alpha)$, and the steepness of the S-R curves $(h)$. Steepness, a measure of a fish stock's ability to recover from low stock abundance (Mangel et al. 2013), was used to determine each species' ability to recover from environmental stress. First, we considered the best model selected using MMI for all sites and species. The strength of density-dependence, $\beta$, was retained for the Ricker, Beverton-Holt, and Saila-Lorda models based on their respective $\Delta$ AIC values. We retained $\beta$ for the Shepherd model when it was estimated as a density-dependent model $(\mathrm{c} \geq 1)$. The same methods were applied to the population dynamics models by retaining the slope for the Ricker and Gompertz models. The strength of density dependence was set to zero for all density-independent models, including the Shepherd model $(\mathrm{c}<1)$.

To test the effects of hydrology on the density-independent parameter $(\alpha)$, we retained the estimated recruit-per-spawner from the best model at each site for further analysis. Steepness was calculated based on one individual at each site and adjusted based on the number of samples taken ( $\sim 0.048$ for SRS and TSL, $\sim 0.066$ for WCA). We 
then used the Coefficient of Variation of Hydroperiod ( $\left.\mathrm{CV}_{\mathrm{Hydro}}\right)$, a metric of hydrological variability within a site, to test the effects of hydrology on the strength of densitydependence, productivity, and the steepness for each model. Parameters from the best model (response variable) were regressed against $\mathrm{CV}_{\text {Hydro }}$ using OLS. A separate quadratic model was assessed using a squared $\mathrm{CV}_{\text {Hydro }}$ term and compared to the linear model using MMI. We then used a generalized linear model (GLM) to determine if parameter estimates were different among disturbance intensities. These models tested the main effect of disturbance intensity (short, intermediate, long hydroperiods) against the response variable $(\alpha, \beta)$. Long hydroperiod sites were defined as experiencing $<4$ drying events in 20 years, intermediate hydroperiod sites as 4-12 drying events in 20 years, and short hydroperiod sites as experiencing $>12$ drying events in 20 years.

\section{Results}

\section{Evidence for Density-Dependence}

Our analyses produced 17 models for each species at each site to describe densityindependent and -dependent recruitment. Of these models, 461 were considered inadmissible because of negative parameter estimates. This consisted primarily of lagged independent variables $(72.0 \%)$ and MMI revealed no evidence for a lagged stockrecruitment model. Stock-recruitment dynamics were best described by the Cushing S-R model which was selected as the best model $(\triangle \mathrm{AIC}=0)$ in 68 of the 126 species/site combinations (54.0\%). This was followed by the Beverton-Holt (19.8\%), Saila-Lorda (5.6\%), Ricker (5.6\%), Shepherd (4.8\%), and density-independent models (4.0\%).

Furthermore, MMI revealed some of our seasonal models to be the best descriptors of 
recruitment at some sites. At one of the most disturbed sites in the time series (TSL MDsh), the linear season model described recruitment for $J$. floridae. The quadratic seasonal model also described recruitment at some of our frequently disturbed sites for $J$. floridae (WCA 03, SRS 50, SRS 08) and F. chrystous (SRS 50). For P. latipinna, proximity to a drying event (DSD) drove recruit abundance at TSL MD and WCA 03. These models were highly variable between sites for $F$. chrysotus (Mean $\mathrm{R}^{2}=0.33^{+} /-0.03$, 0.13-0.57), G. holbrooki (Mean $\left.\mathrm{R}^{2}=0.66^{+} /-0.04,0.28-0.92\right)$, H. formosa (Mean $\left.\mathrm{R}^{2}=0.55^{+} /-0.03,0.22-0.83\right)$, J. floridae $\left(\right.$ Mean $\left.\mathrm{R}^{2}=0.33^{+} /-0.02,0.17-0.59\right)$, L. goodei (Mean $\left.\mathrm{R}^{2}=0.73^{+} /-0.02,0.40-0.88\right)$, and P. latipinna $\left(\right.$ Mean $\left.\mathrm{R}^{2}=0.35^{+} /-0.03,0.06-0.67\right)$. Estimates for both the spawner-per-recruit $(\alpha)$ and density-dependence $(\beta)$ also varied considerably among species and sites (Table 3).

Our population dynamics models provided lower success in describing changes in recruitment over time. MMI revealed high support for the Gompertz population model for all sites and species. Model fit was predominantly driven by recruit density $(98.4 \%$ of species/sites); however, there was some support for spawning stock density ( $G$. holbrooki, SRS 37) and a lagged response to spawning stock density (L. goodei, TSL $\mathrm{CP})$. There was little support for other population models and no evidence for densityindependence after considering all valid models $(\triangle \mathrm{AIC}<3)$. Population dynamic models were less variable among sites when compared to S-R models for all species. On average, model fit was weak to moderate for $F$. chrysotus $\left(\right.$ Mean $\mathrm{R}^{2}=0.35^{+} /-0.01,0.24$ 0.47), G. holbrooki (Mean $\left.\mathrm{R}^{2}=0.35^{+} /-0.02,0.12-0.49\right)$, H. formosa $\left(\right.$ Mean $\mathrm{R}^{2}=0.31^{+} /-0.02$, $0.15-0.46)$, J. floridae $\left(\right.$ Mean $\left.\mathrm{R}^{2}=0.33^{+} /-0.02,0.20-0.47\right)$, L. goodei $\left(\right.$ Mean $\mathrm{R}^{2}=0.29^{+} /-$ $0.02,0.09-0.46$ ), and P. latipinna (Mean $\left.\mathrm{R}^{2}=0.33^{+} /-0.02,0.20-0.54\right)$. 
The strength of evidence for density-dependence based on stock-recruitment analysis revealed strong evidence for density-dependent feedback on recruitment for all species. A DD model was selected as the best model in $89.7 \%$ of cases overall. Support for DD was highest for G. holbrooki and H. formosa (95.2\% of sites) and lowest for $J$. floridae (81\%). High support for DD resulted predominantly from selection of the Cushing S-R model. Support for DD increased to $92.8 \%$ when considering all models with $\triangle \mathrm{AIC}<3$. On average, the strength of evidence for DD based on Akaike weights (sum of Akaike weights for DD models) using S-R models was $88.3 \%^{+} /-6.4$ for $F$. chrysotus, $96.2 \%^{+} /-1.6$ for G. holbrooki, $94.8 \%^{+} /-3.4$ for $H$. formosa, $77.2 \%{ }^{+} /-8.4$ for $J$. floridae, $92.6 \%^{+} /-2.7$ for $L$. goodei, and $89.1 \%^{+} /-6.4$ for P. latipinna (Figure 1). Logtransformed evidence ratios (LER's) also revealed substantial support for DD S-R models (Figure 2A). We found no evidence to suggest that a DI model was favored over a DD model based on disturbance intensity for our S-R curves. Furthermore, MMI revealed overwhelming support for DD using population growth models. A DD model was selected in $100 \%$ of the cases and the strength of evidence for DD was $>99 \%$ across all sites and species. We also found $100 \%$ selection of a DD model and significant evidence for DD when considering all valid models ( $\triangle \mathrm{AIC}<3$ ). LER's revealed substantial support for DD based on recruitment from the previous time step (Figure 2B). Seasonality and Density-Dependence

Our Type III analysis of the S-R relationship revealed results that differed from those lacking seasonal terms. MMI revealed the highest support for the densityindependent model, which was selected in $46.8 \%$ of cases. This was followed by the Cushing (39.7\%), Saila-Lorda (7.1\%), and Ricker (5.6\%) S-R models. The DSD model 
was also considered the best model describing recruitment for $P$. latipinna at TSL MD. Of the equally valid models, there was relatively high support for the Cushing (46.0\%) and density-independent (31.9\%) S-R models, but less for Saila-Lorda (13.3\%) and Ricker $(6.9 \%)$. The inclusion of the seasonal and interaction terms improved the S-R models for F. chrysotus (Mean $\left.\mathrm{R}^{2}=0.48^{+} /-0.02,0.28-0.67\right)$, G. holbrooki (Mean $\left.\mathrm{R}^{2}=0.73^{+} /-0.03,0.39-0.96\right)$, H. formosa $\left(\right.$ Mean $\left.\mathrm{R}^{2}=0.65^{+} /-0.03,0.32-0.89\right)$, J. floridae (Mean $\left.\mathrm{R}^{2}=0.47^{+} /-0.02,0.29-0.66\right)$, L. goodei $\left(\right.$ Mean $\left.\mathrm{R}^{2}=0.75^{+} /-0.02,0.53-0.88\right)$, and $P$. latipinna (Mean $\mathrm{R}^{2}=0.45^{+} /-0.04,0.08-0.77$ ). The inclusion of the seasonal terms improved model fit for the DI models; however, these terms were not significant for most models. The log-transformed recruit-per-spawner term and the interaction between spawning stock abundance and season were significant for most of the DI models selected (Figure 3A). Seasonal terms were also not significant drivers of recruitment for most of the DD models selected but mixed for the six species. Both the densitydependent term and interaction between density-dependence and season were important drivers of recruit abundance when DD was selected by MMI (Figure 3B). Partial correlations also support this and revealed that both the source of density-dependence $(\beta)$ and the interaction term were more highly correlated than the seasonal terms for each species (Table 4).

Our Type III analysis revealed that the Gompertz population model best described changes in recruitment over time driven by recruit density $(99.2 \%)$. There was also evidence that a lagged response to adult density drove recruit density for L. goodei at TSL CP. We found no evidence for density-independent feedback on recruitment after considering all valid models $(\triangle \mathrm{AIC}<3)$. The inclusion of the seasonal and interaction 
terms also improved the population models for $F$. chrysotus $\left(\right.$ Mean $\mathrm{R}^{2}=0.48^{+} /-0.02,0.25$ 0.64), G. holbrooki (Mean $\left.\mathrm{R}^{2}=0.45^{+} /-0.03,0.14-0.62\right)$, H. formosa $\left(\right.$ Mean $\mathrm{R}^{2}=0.42^{+} /-0.03$, $0.18-0.70)$, J. floridae $\left(\right.$ Mean $\left.\mathrm{R}^{2}=0.49^{+} /-0.03,0.24-0.67\right)$, L. goodei $\left(\right.$ Mean $\mathrm{R}^{2}=0.40^{+} /-$ 0.02, 0.20-0.56), and P. latipinna (Mean $\left.\mathrm{R}^{2}=0.41^{+} /-0.02,0.25-0.60\right)$. Although the inclusion of the seasonal terms improved model fit, the seasonal terms were not significant for most of the models. Furthermore, both the density-dependent terms and interaction between density-dependence and season were significant drivers of recruit abundance (Figure 4). The partial correlation for density-dependence was higher than the seasonal terms for all species, with Season and Season ${ }^{2}$ often being weakly correlated with recruit abundance $(r<0.05$, Table 5).

The strength of evidence for density-dependence based on Type III stockrecruitment analysis was mixed for all species. Support for DD was mixed considering a DD model was only selected as the best model in $57.9 \%$ of cases. This was highest for $J$. floridae and G. holbrooki (71.4\%) and lowest for H. formosa (2.4\%). Support for DD increased when considering all plausible models (66.4\%). On average, our Type III S-R analysis determined that the strength of evidence using $\mathrm{AIC}_{\mathrm{w}}$ for DD was $67.3 \%{ }^{+} /-6.5$ for F. chrysotus, $73.7 \%^{+} /-6.2$ for G. holbrooki, $44.1 \%{ }^{+} /-6.1$ for $H$. formosa, $69.0 \%^{+} /-$ 5.9 for J. floridae, $68.6 \%^{+} /-6.3$ for $L$. goodei, and $46.7 \%^{+} /-5.8$ for P. latipinna. LER's also determined that there was considerable support for both the density-independent models (stock-production model) and DD models when seasonal variables were included for our S-R models. However, there was unanimous support for DD using our population dynamic models. The strength of evidence based on $\mathrm{AIC}_{\mathrm{w}}$ revealed considerable support for DD ( $>98 \%)$ across all species and sites. LER's also determined that there was 
significant support for density-dependence based on recruit abundance using these models.

Hydrology on Strength of Density Dependence, Productivity, and Steepness

Analyses of the density-dependent terms in our stock-recruitment models revealed no changes in the strength of density-dependence based on site hydrology. These models explained $<3 \%$ of the variability in DD across each species. Our ANOVA's also revealed no differences in the strength of DD based on disturbance intensity (e.g., $G$. holbrooki, $F_{2,18}=0.71, \mathrm{p}=0.50$ ). Hydrological variability did not influence the recruit-perspawner term for 5 of the 6 species in our study. The recruit-per-spawner term was weakly correlated with site hydroperiod, and we did not detect any significant slopes. However, we did detect a significant negative correlation between hydrological variability and the number of recruits-per-spawner for $L$. goodei (Figure 5A). We also found significant differences in the number of recruits-per-spawner based on disturbance intensity for this species $\left(F_{2,18}=5.32, \mathrm{p}=0.02\right)$. Analyses also determined that the steepness of $L$. goodei S-R curves decreased linearly as sites became less stable indicating that this species' ability to recover from low stock sizes decreases with decreasing hydroperiod (Figure 5B).

Our population growth models revealed contrasting evidence of how hydrological variability influences the strength of DD. Linear models best described how site hydrology influenced the strength of DD for P. latipinna and $J$. floridae. This was strongly positively correlated with the $\mathrm{CV}$ of hydroperiod for $J$. floridae (Figure 6A), but weakly correlated for P. latipinna $\left(\mathrm{R}^{2}<0.02\right)$. A quadratic model best described changes 
in the strength of density-dependence in response to hydrological variability for the remaining four species (Figure 6B). We detected significant slopes for both the $\mathrm{CV}^{2}$ (except L. goodei) and CV terms for these four species. The correlation between $\mathrm{CV}_{\mathrm{Hydro}}$ and the strength of DD varied between $F$. chrysotus $\left(\mathrm{R}^{2}=0.25\right), G$. holbrooki $\left(\mathrm{R}^{2}=0.24\right)$, H. formosa $\left(\mathrm{R}^{2}=0.34\right)$, and L. goodei $\left(\mathrm{R}^{2}=0.31\right)$. This revealed a decrease in negative density-dependence from long to intermediate hydroperiods, followed by an increase in density-dependent feedback as the environment became less stable. We also found significant decreases in the strength of DD based on disturbance intensity for J. floridae $\left(F_{2,18}=11.80, \mathrm{p}<0.05\right)$. ANOVA's also indicated that the strength of DD was largest at intermediate disturbances and lowest at both short and long hydroperiods for H. formosa $\left(F_{2,18}=5.60, \mathrm{p}<0.05\right)$.

The relationships between hydrology and the strength of DD were greatly altered when considering the density-dependent models from our Type III analyses. A hydrological analysis revealed no relationship between hydrology and the strength of DD; however, population dynamics models revealed contrasting effects of hydrology on the strength of DD. We saw an improvement in model fit for $F$. chrysotus $\left(\mathrm{R}^{2}=0.34\right), H$. formosa $\left(\mathrm{R}^{2}=0.39\right)$ and $P$. latipinna $\left(\mathrm{R}^{2}=0.12\right)$; however, model fit decreased for $G$. holbrooki $\left(\mathrm{R}^{2}=0.22\right)$, J. floridae $\left(\mathrm{R}^{2}=0.02\right)$, and L. goodei $\left(\mathrm{R}^{2}=0.07\right)$. The shapes of these relationships also changed, and we detected a significant positive relationship for $F$. chrysotus (Figure 7A). Our analyses did not reveal any significant slopes for the positive linear relationship (L. goodei, P. latipinna), negative linear relationship (J.floridae) or parabolic relationship (G. holbrooki, H. formosa). Overall, we detected a decrease in 
negative density-dependence as the environment became less stable when seasonal terms were included in the model (Figure 7B).

\section{Discussion}

Hydrological variability is the major source of reduced recruitment in floodplain ecosystems (Agostinho et al. 2004). Using two modeling strategies, our study supported that conclusion for the Everglades by documenting correlations of negative densitydependent processes impacting recruitment as a function of hydrological variability. We also noted species-specific differences in these effects, probably tied to reproductive or movement strategies. Our application of several S-R and population growth models revealed compelling evidence for variation in the strength of density-dependent recruitment along a hydrological gradient. Both the S-R curves and population growth models revealed strong evidence for DD recruitment. The lack of detectable DI influence directly on recruitment may be attributed to reproductive strategies that exploit seasonal inundation of the floodplain (Chase 1999; Winemiller 2004). These adaptations seem to buffer species from increased mortality caused by environmental variability. We also found similar results to other studies in floodplains evaluating how hydrology influences recruit abundance (Godfrey et al. 2017).

Our study investigated how hydrology influenced these complex processes by evaluating both DI and DD feedback along a wide hydrological gradient. We found that hydrology not only alters recruit abundance, but these changes result in stronger or weaker density-dependent feedback dependent on the species. This indicated interspecific variation in the impact of hydrological variation on recruitment, with 
evidence that negative density-dependence was strongest at the most stable and longest hydroperiod sites. Drying may increase the concentration of recruits resulting in increased DD at shorter hydroperiods for all species except $J$. floridae and P. latippina. The observed increase of negative DD at longer hydroperiods may result from increased abundance resulting in higher DD mortality. Furthermore, intermediate disturbance appears to reduce the strong density-dependent effects on recruits, revealed by weaker, but significant, DD feedback at intermediate hydroperiods.

We believe our analyses to be robust; however, our stock-recruitment models may have violated some of the basic assumptions that accompany this modeling approach (Ricker 1975). The first assumption, stock and recruitment are measured without error, could arise from researcher impact and sample bias associated with a $1-\mathrm{m}^{2}$ throw trap. Studies suggest that a combination of size-selective bias and reduced recovery probabilities influence the sampling efficiency of both recruits and spawning stock (Gatto and Trexler 2019; Jordan et al. 1997). These studies have indicated that the sampling of H. formosa is impacted most by under-sampling of small specimens, but this did not hinder our ability to detect density-dependent recruitment for this species. We did not apply the cohort analysis suggested in Gatto and Trexler (2019) prior to analysis because they used age-structured models similar to those fit here, creating a circular modeling process. Further analysis is needed to understand the impacts of size-based sampling bias on our ability to detect density-dependent recruitment, but this type of bias is typical in fisheries data (Williams 2002).

Stock-recruitment analyses also assume that the relationship of $\mathrm{R}$ to $\mathrm{S}$ begins at the origin (i.e., $S=0$ and $R=0$ ). We know that our data violate this assumption because 
seasonal pulses in hydrology are linked to age-specific emigration and immigration to our study sites. Inundation of the floodplain would result in an increase in spawning stock abundance followed by a pulse in reproduction $(S>0, R=0)$. Furthermore, emigration to refuge habitats by spawning stock during a dry-down could leave recruits stranded during times of hydrological stress $(R>0, S=0)$. Violation of the assumption of closed populations varies among species we evaluated, with relatively little immigration/emigraion for $L$. goodei and relatively frequent in $J$. floridae and $F$. chrysotus. These were best described by higher model variance associated with poorer model fit for these highly dispersing species (F. chrysotus, J. floridae) and low model variance, strong model fit for poor dispersing species (L. goodei, H. formosa). However, support for DD remained high for all species $(>70 \%)$ regardless of movement strategy. Hydrology may induce movement causing age-specific differences in floodplain use, but density-dependent feedback on recruits occurs predominately when both recruits and spawning stock co-occur.

This study provided conflicting evidence for the influence of hydrology on the strength of density-dependent recruitment. We were unable to detect changes in the strength of DD with S-R curves, which may have been caused by violation of assumptions for the models selected. The Beverton-Holt model assumes a maximum abundance imposed by resource limitation on early life stages resulting in linear negative density-dependent mortality and by predation that yields density-independent mortality. However, the Ricker model assumes that mortality rates are proportional to adult abundance through fecundity, either through cannibalism by adults or density-dependent reductions in individual growth rates coupled with size-selective predation (Wootton 
2012). The differences between the Beverton-Holt and Ricker assumptions could be impacted differently by hydrological variation. For example, seasonal fluctuations in water level would result in temporally varying carrying capacities (Beverton-Holt) or cause spatial-temporal changes in predation pressure and predator encounter rates (Ricker). Unlike our S-R models, MMI revealed that the Gompertz population model was selected as the primary model to describe changes in recruitment level. This model assumes a constant linear decrease in a populaton's instantaneous growth rate (recruitment rate) as a function of the natural logarithm of abundance, implying that the strength of negative density-dependence decreases as a function of increasing population size (Dennis and Ponciano 2014).

The application of S-R curves and population growth models provided contrasting interpretations on the source of density-dependence within floodplain ecosystems. S-R analysis revealed that pulses in spawning stock abundance can lead to density-dependent feedback; however, population dynamics models revealed that this feedback was more commonly caused by seasonal pulses in recruit abundance. We detected strong support for DD using S-R curves, which revealed evidence of stock-dependence for our six species within the Everglades system. In contrast, the population growth models indicated density-dependent feedback from recruits rather than spawning stock in all species. The population dynamic models capture density-dependent feedback that could result from increased competition among recruits, but not cannibalism or competition from spawning stock. Our Type III regressions also indicated that support for DD using S-R curves decreased after adding seasonal components. These outcomes indicated recruitment that increases indefinitely with increasing spawning stock abundance via 
production $(\alpha)$. The limit to recruitment within the Everglades system is most likely set by environmental perturbation that drives spawning stock abundance. This is best supported by the Cushing S-R model being the predominant model selected and our Type III analyses. The Cushing S-R curve has been criticized for its effectiveness at predicting recruitment when spawning stock is high (theoretical maximum recruitment $=\infty$ ); however, annual disturbances appear to reset the environment preventing stock sizes from becoming too large. These environmental perturbations may best explain why the Cushing S-R curve best described fish populations across a wide hydrological gradient.

Population growth models revealed changes in negative density-dependence along a hydrological gradient. We obtained variable responses that represented either a parabolic change in DD or a linear correlation that was either positively or negatively correlated with hydrology. We believe that an increase in negative density-dependence as sites become more frequently disturbed is generated by two mechanisms: 1) spawning diapausing (resting) eggs and 2) increasing encounter rates between recruits and spawning stock as water levels recede. The ability to lay diapausing eggs is an evolved reproductive strategy for species in hydrologically stressful environments and evidence suggests that some members of the Order Cyprinodontiformes lay eggs capable of diapause (Furness 2016). These eggs become rehydrated following inundation, hatch, and release recruits within a resource-limited environment. The presence of diapausing eggs would decrease as the environment becomes more stable, causing a decrease in the possibility of density-dependent feedback associated with this life-history trait along the same hydrological gradient. Furthermore, pulses in emigration/immigration in response to changing hydrology are well documented, with encounter rates among recruits and 
spawning stock increasing during times of hydrological stress (Hoch et al. 2015). The increase in encounter rates would result in an increase in density and density-dependent processes, especially as the environment begins to shrink and resources become scarce. Hydrology has been described as the major abiotic factor influencing fish communities in floodplain ecosystems (Balcombe et al. 2006; King et al. 2003). These populations often recover from hydrological stress by immigrating into newly inundated habitats. The ability for each species to recover from drying events has been well documented for species within our study and are differentiated by dispersal potential (Goss et al. 2014; Obaza et al. 2011). In stock assessment, a fish stock's ability to recover from low stock levels is often described by the steepness of the S-R curve. Fast recovering species are associated with higher steepness, being able to produce high recruitment at low stock levels. Our analyses revealed that steepness may not be a reliable metric to describe population-level responses within hydrologically variable environments. The slopes of our S-R curves at low stock levels remained constant and apparently did not vary along a hydrological gradient. Of the species analyzed, we did not find any increase in steepness at frequently disturbed sites for rapidly recovering species (G. holbrooki, J. floridae). For L. goodei, our analyses revealed a decrease in its ability to recover from low stocks as hydrological variability increased. This species is often associated with slow recovery following drying events (DeAngelis et al. 2005; Trexler et al. 2005), but we were unable to detect changes in steepness for the remaining species associated with slow recovery $(H$. formosa, P. latipinna). This does not support depensatory density-dependence since there was little support for a depensatory 
Beverton-Holt S-R model. For $L$. goodei, this represented steeper compensatory densitydependence via the Cushing S-R curve along a hydrological gradient.

Density-dependent S-R models often include recruitment maxima to describe compensatory density-dependence sizes (e.g., Ricker model, $R_{\max }=\frac{\alpha}{\beta e}$ ). These models may approach an asymptote or have higher flexibility in the shapes of the curves. Recruitment for the latter tends to decrease at higher stock sizes after this maximum is reached, resulting in overcompensation at high stock sizes. The inclusion of a seasonal term revealed recruitment that increases indefinitely as a function of spawning stock. In the Cushing S-R model, which exhibits compensatory density dependence (decrease in recruits-per-spawner as spawning stock increases) there is no imposed limit on recruitment. Our models may appear unbounded because they do not include a temporally variable carrying capacity or recruitment maximum. This could produce a curve that approaches Beverton-Holt or similar model with seasonal oscillations around the maximum. Some research has suggested dividing the time series into segments or conducting a change-point analysis to generate models where model parameters suddenly change due to some environmental perturbation (Perälä et al. 2016; Richards et al. 2012). The inclusion of seasonal density-dependent terms would allow more flexibility in the stock recruitment relationship, similar to the additional term $(\gamma)$ in the Saila-Lorda or Shepherd models. Further work is needed to investigate temporally variable recruitment rates and how the strength of density-dependence varies between seasons.

MMI permitted us to determine the presence or absence of density-dependent recruitment of fish stocks in a hydrologically variable environment. Other studies have described the importance of using MMI to evaluate S-R models for stock assessment and 
management practices (Hilborn and Walters 1992; Wang and Liu 2006). Furthermore, these tools allowed us to apply commonly applied management models for marine species to floodplain ecosystems. Evidence suggests interspecific variation in how hydrological processes influence recruitment dynamics through seasonal pulses of both spawning stock and recruits. Notably, we did have conflicting evidence for DI and DD between the S-R and population dynamics models. Our results indicated a difference between stock-dependence and density-dependence, revealing larger support for recruits causing density-dependent feedback. The strength of this feedback decreased from short to intermediate hydroperiods and began to increase as hydroperiod increased. Both S-R models and population models revealed strong support for DD; however, only intraspecific effects were investigated in the present study. Spatial-temporal variation in predation pressure from large, piscivorous fish species can increase density-dependent mortality rates. Fluctuating water levels can buffer recruits from predation risk when water levels are too low or increase this risk when water levels are high by altering the abundance of these predatory species (Chick et al. 2004). Further studies are needed to understand how interspecific interactions of both spawning stock and recruits may influence density-dependent feedback for a collection of coexisting species.

\section{Acknowledgments}

This work was supported by the American Killifish Association George Maier Fund and by a Cooperative Agreement between Everglades National Park and FIU (Critical Ecosystem Science Initiative Task Agreement P06AC00043). We thank Jeff Kline, Everglades National Park, for making available data from sites 6, 23, and 50. This 
material was developed in collaboration with the Florida Coastal Everglades Long-Term

Ecological Research program under National Science Foundation Grant No. DEB-

1237517. This is contribution No. XXX from the Southeastern Environmental Research

Center of FIU.

References

Agostinho AA, Gomes LC, Veríssimo S, Okada EK (2004) Flood regime, dam regulation and fish in the Upper Paraná River: effects on assemblage attributes, reproduction and recruitment Reviews in Fish Biology and Fisheries 14:11-19

Anderson JT (1988) A review of size dependent survival during pre-recruit stages of fishes in relation to recruitment Journal of Northwest Atlantic Fishery Science $8: 55-66$

Arthington AH, Balcombe SR (2011) Extreme flow variability and the 'boom and bust'ecology of fish in arid-zone floodplain rivers: a case history with implications for environmental flows, conservation and management Ecohydrology 4:708-720

Balcombe SR, Arthington AH, Foster ND, Thoms MC, Wilson GG, Bunn SE (2006) Fish assemblages of an Australian dryland river: abundance, assemblage structure and recruitment patterns in the Warrego River, Murray-Darling Basin Marine and Freshwater Research 57:619-633

Beverton R (1995) Spatial limitation of population size; the concentration hypothesis Netherlands Journal of Sea Research 34:1-6

Beverton RJ, Holt SJ (1957) On the dynamics of exploited fish populations, Fishery Investigations Series II, Vol. XIX, Ministry of Agriculture Fisheries and Food $1: 957$

Blackhart K, Stanton DG, Shimada A (2006) NOAA Fisheries Glossary. United States Department of Commerce, National Oceanic and Atmospheric Administration,

Bozelli RL, Thomaz SM, Padial AA, Lopes PM, Bini LM (2015) Floods decrease zooplankton beta diversity and environmental heterogeneity in an Amazonian floodplain system Hydrobiologia 753:233-241 
Brook BW, Bradshaw CJ (2006) Strength of evidence for density dependence in abundance time series of 1198 species Ecology 87:1445-1451

Burnham KP, Anderson DR (2004) Multimodel inference: understanding AIC and BIC in model selection Sociological methods \& research 33:261-304

Chao Y-CE, Zhao Y, Kupper LL, Nylander-French LA (2008) Quantifying the relative importance of predictors in multiple linear regression analyses for public health studies Journal of occupational and environmental hygiene 5:519-529

Chase JM (1999) To grow or to reproduce? The role of life-history plasticity in food web dynamics The American Naturalist 154:571-586

Chick JH, Ruetz CR, Trexler JC (2004) Spatial scale and abundance patterns of large fish communities in freshwater marshes of the Florida Everglades Wetlands 24:652664

Clark F, Brook BW, Delean S, Akçakaya HR, Bradshaw CJ (2010) The theta-logistic is unreliable for modelling most census data Methods in Ecology and Evolution 1:253-262

Cushing D (1973) Dependence of recruitment on parent stock Journal of the Fisheries Board of Canada 30:1965-1976

DeAngelis DL, Trexler JC, Loftus WF (2005) Life history trade-offs and community dynamics of small fishes in a seasonally pulsed wetland Canadian Journal of Fisheries and Aquatic Sciences 62:781-790

Dennis B, Ponciano JM (2014) Density-dependent state-space model for populationabundance data with unequal time intervals Ecology 95:2069-2076

Dennis B, Taper ML (1994) Density dependence in time series observations of natural populations: estimation and testing Ecological monographs 64:205-224

DingsØr GE, Ciannelli L, Chan K-S, Ottersen G, Stenseth NC (2007) Density dependence and density independence during the early life stages of four marine fish stocks Ecology 88:625-634

Dorn NJ, Cook MI (2015) Hydrological disturbance diminishes predator control in wetlands Ecology 96:2984-2993

Dutterer A, Mesing C, Cailteux R, Allen M, Pine W, Strickland P (2013) Fish recruitment is influenced by river flows and floodplain inundation at Apalachicola River, Florida River Research and Applications 29:1110-1118 
Fennema RJ, Neidrauer CJ, Johnson RA, MacVicar TK, Perkins WA (1994) A computer model to simulate natural Everglades hydrology Everglades: the ecosystem and its restoration:249-289

Fogarty MJ (1993) Recruitment in randomly varying environments ICES Journal of Marine Science 50:247-260

Fogarty MJ, Sissenwine MP, Cohen EB (1991) Recruitment variability and the dynamics of exploited marine populations Trends in Ecology \& Evolution 6:241-246

Furness AI (2016) The evolution of an annual life cycle in killifish: adaptation to ephemeral aquatic environments through embryonic diapause Biological Reviews 91:796-812

Gatto JV, Trexler JC (2019) Seasonality of fish recruitment in a pulsed floodplain ecosystem: Estimation and hydrological controls Environmental Biology of Fishes 102:595-613 doi:10.1007/s10641-019-00856-9

Geddes M, Puckridge J Survival and growth of larval and juvenile native fish: the importance of the floodplain. In: Proceedings of a workshop on native fish management, Canberra. Murray-Darling Basin Commission, Canberra, 1989. pp $101-116$

Godfrey PC, Arthington AH, Pearson RG, Karim F, Wallace J (2017) Fish larvae and recruitment patterns in floodplain lagoons of the Australian Wet Tropics Marine and Freshwater Research 68:964-979

Goss CW, Loftus WF, Trexler JC (2014) Seasonal fish dispersal in ephemeral wetlands of the Florida Everglades Wetlands 34:147-157

Heath M, Gallego A (2000) Modelling the spatial and temporal structure of survivorship to settlement in North Sea and west of Scotland haddock ICES CM:17

Hilborn R, Walters CJ (1992) Quantitative fisheries stock assessment: choice, dynamics and uncertainty Reviews in Fish Biology and Fisheries 2:177-178

Hoch JM, Sokol ER, Parker AD, Trexler JC (2015) Migration Strategies Vary in Space, Time, and Among Species in the Small-fish Metacommunity of the Everglades Copeia 2015:157-169

Iles TC (1994) A review of stock-recruitment relationships with reference to flatfish populations Netherlands Journal of Sea Research 32:399-420 doi:https://doi.org/10.1016/0077-7579(94)90017-5

Insititute S (2012) SAS 9.4 for Windows SAS Institue Inc, Cary, NC, USA 
Jordan F, Coyne S, Trexler JC (1997) Sampling fishes in vegetated habitats: effects of habitat structure on sampling characteristics of the 1-m2 throw trap Transactions of the American Fisheries Society 126:1012-1020

Junk WJ, Bayley PB, Sparks RE (1989) The flood pulse concept in river-floodplain systems Canadian special publication of fisheries and aquatic sciences 106:110127

King A, Humphries P, Lake P (2003) Fish recruitment on floodplains: the roles of patterns of flooding and life history characteristics Canadian Journal of Fisheries and Aquatic Sciences 60:773-786

Lasker R (1981) The role of a stable ocean in larval fish survival and subsequent recruitment Marine fish larvae: morphology, ecology and relation to fisheries:8187

Liu Z, Volin JC, Dianne Owen V, Pearlstine LG, Allen JR, Mazzotti FJ, Higer AL (2009) Validation and ecosystem applications of the EDEN water-surface model for the Florida Everglades Ecohydrology 2:182-194

Mangel M, MacCall AD, Brodziak J, Dick E, Forrest RE, Pourzand R, Ralston S (2013) A perspective on steepness, reference points, and stock assessment Canadian Journal of Fisheries and Aquatic Sciences 70:930-940

Martin TG et al. (2005) Zero tolerance ecology: improving ecological inference by modelling the source of zero observations Ecology letters 8:1235-1246

Menge BA, Sutherland JP (1987) Community regulation: variation in disturbance, competition, and predation in relation to environmental stress and recruitment The American Naturalist 130:730-757

Myers RA (1998) When do environment-recruitment correlations work? Reviews in Fish Biology and Fisheries 8:285-305

Nickum J et al. (2004) Guidelines for the use of fishes in research FISHERIESBETHESDA- 29:26-26

Obaza A, DeAngelis D, Trexler JC (2011) Using data from an encounter sampler to model fish dispersal J Fish Biol 78:495-513

Ogden JC, Davis SM, Jacobs KJ, Barnes T, Fling HE (2005) The use of conceptual ecological models to guide ecosystem restoration in South Florida Wetlands 25:795-809 doi:10.1672/0277-5212(2005)025[0795:tuocem]2.0.co;2 
Parkos III JJ, Ruetz III CR, Trexler JC (2011) Disturbance regime and limits on benefits of refuge use for fishes in a fluctuating hydroscape Oikos 120:1519-1530

Perälä TA, Swain DP, Kuparinen A (2016) Examining nonstationarity in the recruitment dynamics of fishes using Bayesian change point analysis Canadian journal of fisheries and aquatic sciences 74:751-765

Richards RA, Fogarty MJ, Mountain DG, Taylor MH (2012) Climate change and northern shrimp recruitment variability in the Gulf of Maine Marine Ecology Progress Series 464:167-178

Ricker WE (1954) Stock and recruitment Journal of the Fisheries Board of Canada $11: 559-623$

Ricker WE (1975) Computation and interpretation of biological statistics of fish populations Bull Fish Res Bd Can 191:1-382

Scharbert A, Borcherding J (2013) Relationships of hydrology and life-history strategies on the spatio-temporal habitat utilisation of fish in European temperate river floodplains Ecological indicators 29:348-360

Schiller C, Harris J (2001) Native and alien fish Rivers as ecological systems: the Murray-Darling Basin:229-258

Stenseth NC, VIljugrein H, Jędrzejewski W, Mysterud A, Pucek Z (2002) Population dynamics ofClethrionomys glareolus andApodemus flavicollis: seasonal components of density dependence and density independence Acta Theriologica 47:39-67

Telis PA (2006) The Everglades Depth Estimation Network (EDEN) for support of ecological and biological assessments. Geological Survey (US),

Trexler JC, Loftus WF, Chick JH (2003) Setting and monitoring restoration goals in the absence of historical data: the case of fishes in the Florida Everglades Monitoring ecosystems: interdisciplinary approaches for evaluating ecoregional initiatives Island Press, Washington, DC:351-376

Trexler JC, Loftus WF, Perry S (2005) Disturbance frequency and community structure in a twenty-five year intervention study Oecologia 145:140-152

Turchin P (2003) Complex population dynamics: a theoretical/empirical synthesis vol 35. Princeton University Press, 
Wang Y, Liu Q (2006) Comparison of Akaike information criterion (AIC) and Bayesian information criterion (BIC) in selection of stock-recruitment relationships Fisheries Research 77:220-225

Williams EH (2002) The effects of unaccounted discards and misspecified natural mortality on harvest policies based on estimates of spawners per recruit North American Journal of Fisheries Management 22:311-325

Winemiller KO Floodplain river food webs: generalizations and implications for fisheries management. In: Proceedings of the second international symposium on the management of large rivers for fisheries, 2004. Food and Agriculture Organization \& Mekong River Commission, FAO Regional ..., pp 285-309

Wootton RJ (2012) Ecology of teleost fishes vol 1. Springer Science \& Business Media, 
Table 1. Stock-recruitment models considered for our analysis. The seasonal and DSD models were added for comparison to standard S-R models (Iles 1994).

\begin{tabular}{ccc}
\hline & Stock-Recruitment Models & \\
\hline Model Name & Log-Transformed Model & Independent Variables \\
\hline Random Walk & $\ln R_{t}=\ln R_{t-1}$ & N/A \\
Stock Production & $\ln R_{t}=\ln \mathrm{a}+\ln S$ & $\mathrm{~N} / \mathrm{A}$ \\
Cushing & $\ln R_{t}=\ln \mathrm{a}+\mathrm{y} \ln S$ & $\mathrm{~S}_{\mathrm{t}}, \mathrm{S}_{\mathrm{t}-1}$ \\
Saila-Lorda & $\ln R_{t}=\ln \mathrm{a}-\beta S+y \ln S$ & $\mathrm{~S}_{\mathrm{t}}, \mathrm{S}_{\mathrm{t}-1}$ \\
Ricker & $\ln R_{t}=\ln \mathrm{a}-\beta S+\ln S$ & $\mathrm{~S}_{\mathrm{t}}, \mathrm{S}_{\mathrm{t}-1}$ \\
Beverton-Holt & $\ln R_{t}=\ln \alpha+\ln S-\ln (1+\beta S)$ & $\mathrm{S}_{\mathrm{t}}, \mathrm{S}_{\mathrm{t}-1}$ \\
Shepherd & $\ln R_{t}=\ln \alpha+\ln S-\ln \left(1+\beta S^{c}\right)$ & $\mathrm{S}_{\mathrm{t}}, \mathrm{S}_{\mathrm{t}-1}$ \\
Seasonal (Quadratic) & $\ln R_{t}=$ Season $^{2}+$ Season $+b$ & Season ${ }^{2}, \mathrm{Season}$ \\
Seasonal (Linear) & $\ln R_{t}=$ Season $+b$ & Season \\
DSD & $\ln R_{t}=$ DSD $+b$ & $\mathrm{DSDD}_{\mathrm{t}}$ \\
\hline
\end{tabular}


Table 2. Population dynamics models that were considered for our analyses (Dennis and Taper 1994). The response variable was changed from changes in population abundance $\left(\mathrm{N}_{t+1} / \mathrm{N}_{t}\right)$ to changes in recruit abundance $\left(\mathrm{R}_{\mathrm{t}+1} / \mathrm{R}_{\mathrm{t}}\right)$. This represents changes in the recruitment rate.

\begin{tabular}{ccc}
\hline & Population Dynamics Models & \\
\hline Model Name & Recruitment Model & Independent Variables \\
\hline Random Walk & $\ln \frac{R_{t+1}}{R_{t}}=\ln \frac{R_{t}}{R_{t-1}}$ & N/A $/ \mathrm{A}$ \\
Exponential Growth & $\ln \frac{R_{t+1}}{R_{t}}=r_{\text {max }}$ & $\mathrm{R}_{\mathrm{t}}, \mathrm{R}_{\mathrm{t}-1}, \mathrm{~S}_{\mathrm{t}}, \mathrm{S}_{\mathrm{t}-1}$ \\
Ricker & $\ln \frac{R_{t+1}}{R_{t}}=r_{\text {max }}+\beta x$ & $\mathrm{R}_{\mathrm{t}}, \mathrm{R}_{\mathrm{t}-1, \mathrm{~S}_{\mathrm{t}}, \mathrm{S}_{\mathrm{t}-1}}$ \\
Gompertz & $\ln \frac{R_{t+1}}{R_{t}}=r_{\text {max }}+\beta \ln x$ & $\mathrm{DSD}_{\mathrm{t}}$ \\
$\ln \frac{R_{t+1}}{R_{t}}=D S D_{t}+b$ &
\end{tabular}


Table 3. Estimates for the density-independent $(\alpha)$ and -dependent $(\beta)$ terms for our S-R models. Estimates of $\beta$ were set to zero if a density-independent model was selected. N/A was assigned to the recruit-per-spawner term if a seasonal or hydrology model was selected (Season, Season ${ }^{2}$, DSD).

\begin{tabular}{|c|c|c|c|c|c|c|c|c|c|c|c|c|}
\hline \multirow[b]{2}{*}{ Site } & \multicolumn{2}{|c|}{ F. chrysotus } & \multicolumn{2}{|c|}{ G. holbrooki } & \multicolumn{2}{|c|}{ H. formosa } & \multicolumn{2}{|c|}{ J. floridae } & \multicolumn{2}{|c|}{ L. goodei } & \multicolumn{2}{|c|}{ P. latipinna } \\
\hline & $\alpha$ & $\beta$ & $\alpha$ & $\beta$ & $\alpha$ & $\beta$ & $\alpha$ & $\beta$ & $\alpha$ & $\beta$ & $\alpha$ & $\beta$ \\
\hline SRS 06 & 15.69 & 19.47 & 1.96 & 0.65 & 0.14 & 0.81 & 0.39 & 0.40 & 3.42 & 0.37 & 0.49 & 0.62 \\
\hline SRS 07 & 0.78 & 0.49 & 2.01 & 0.84 & 0.17 & 0.0 & 13.81 & 34.09 & 1.70 & 0.18 & 0.63 & 0.80 \\
\hline SRS 08 & 9.96 & 29.38 & 4.39 & 0.78 & 0.11 & 0.84 & $\mathrm{~N} / \mathrm{A}$ & 0.0 & 0.90 & 0.79 & 0.23 & 0.55 \\
\hline SRS 23 & 22.40 & 50.49 & 1.60 & 0.77 & 0.08 & 0.65 & 0.42 & 0.46 & 3.00 & 2.23 & 0.28 & 0.60 \\
\hline SRS 37 & 5.46 & 25.54 & 4.11 & 0.44 & 0.30 & 0.82 & 2.37 & 2.46 & 1.18 & 0.88 & 0.15 & 0.71 \\
\hline SRS 50 & $\mathrm{~N} / \mathrm{A}$ & 0.0 & 0.86 & 0.80 & 0.01 & 0.26 & $\mathrm{~N} / \mathrm{A}$ & 0.0 & 0.30 & 0.79 & 0.17 & 0.61 \\
\hline TSL CP & 0.52 & 0.61 & 0.50 & 0.73 & 0.05 & 0.49 & 0.78 & 0.42 & 1.27 & 0.0 & 1.68 & 98.17 \\
\hline $\begin{array}{l}\text { TSL } \\
\text { MD }\end{array}$ & 0.57 & 0.57 & 4.13 & 1.57 & 0.12 & 0.76 & 0.55 & 0.58 & 1.97 & 0.13 & N/A & 0.0 \\
\hline $\begin{array}{c}\text { TSL } \\
\text { MDsh }\end{array}$ & 0.32 & 0.57 & 0.61 & 0.67 & 0.06 & 0.51 & N/A & 0.0 & 0.95 & 0.92 & 1.33 & 31.46 \\
\hline TSL TS & 15.73 & 58.95 & 0.67 & 0.58 & 0.07 & 0.61 & 0.84 & 0.56 & 1.41 & 0.86 & 1.41 & 40.26 \\
\hline $\begin{array}{l}\text { TSL } \\
\text { TSsh }\end{array}$ & 0.57 & 0.61 & 0.58 & 0.75 & 0.02 & 0.31 & 6.81 & 14.52 & 1.31 & 0.0 & 2.32 & 269.46 \\
\hline $\begin{array}{c}\text { WCA } \\
01\end{array}$ & 0.48 & 0.34 & 1.23 & 0.73 & 0.11 & 0.74 & 0.51 & 0.75 & 4.22 & 0.89 & 0.13 & 0.59 \\
\hline $\begin{array}{c}\text { WCA } \\
02\end{array}$ & 1.02 & 0.51 & 1.80 & 0.0 & 0.16 & 0.72 & 0.83 & 0.66 & 3.16 & 0.32 & 0.21 & 0.60 \\
\hline $\begin{array}{c}\text { WCA } \\
03\end{array}$ & N/A & 0.0 & 2.88 & 0.62 & 0.11 & 0.71 & N/A & 0.0 & 0.98 & 0.0 & N/A & 0.0 \\
\hline $\begin{array}{c}\text { WCA } \\
04\end{array}$ & 6.39 & 18.48 & 1.17 & 0.85 & 0.09 & 0.63 & 0.40 & 0.70 & 4.21 & 0.53 & 0.09 & 0.54 \\
\hline $\begin{array}{c}\text { WCA } \\
05\end{array}$ & 6.67 & 7.94 & 2.39 & 0.14 & 0.19 & 0.75 & 0.92 & 0.80 & 3.40 & 0.40 & 0.19 & 0.58 \\
\hline $\begin{array}{c}\text { WCA } \\
06\end{array}$ & 2.11 & 3.97 & 2.45 & 0.27 & 0.12 & 0.66 & 2.34 & 1.41 & 2.53 & 0.34 & 0.15 & 0.58 \\
\hline $\begin{array}{c}\text { WCA } \\
07\end{array}$ & 3.16 & 2.11 & 3.80 & 0.30 & 0.14 & 0.74 & 0.49 & 0.58 & 1.32 & 0.29 & 0.84 & 0.86 \\
\hline $\begin{array}{c}\text { WCA } \\
08\end{array}$ & 4.78 & 10.12 & 3.26 & 0.44 & 0.08 & 0.59 & 3.37 & 6.74 & 1.57 & 0.56 & 0.54 & 0.70 \\
\hline $\begin{array}{c}\text { WCA } \\
09\end{array}$ & 1.33 & 3.47 & 2.11 & 0.21 & 0.18 & 0.74 & 2.47 & 7.60 & 1.10 & 0.32 & 0.20 & 0.63 \\
\hline $\begin{array}{c}\text { WCA } \\
10\end{array}$ & 2.15 & 3.70 & 2.76 & 0.43 & 0.10 & 0.67 & 5.71 & 12.60 & 0.79 & 0.83 & 0.21 & 0.65 \\
\hline
\end{tabular}


Table 4. Partial correlations for each parameter included in our Type III S-R regressions. Correlations were averaged based on disturbance intensity (Mean $\left.{ }^{+} /-\mathrm{SE}\right)$. Correlations for $\beta$ are missing if a density-independent model was selected.

\begin{tabular}{|c|c|c|c|c|}
\hline Species & Parameter & Short & Intermediate & Long \\
\hline & Season $^{2}$ & $0.01(0.01)$ & $0.01(0.01)$ & $0.02(0.01)$ \\
\hline & Season & $0.03(0.01)$ & 0.01 & 0.01 \\
\hline \multirow[t]{5}{*}{ F. chrysotus } & Adult Stock & 0.05 & 0.37 & N/A \\
\hline & $\beta$ & $0.03(0.01)$ & $0.07(0.02)$ & $0.08(0.02)$ \\
\hline & Interaction & $0.04(0.02)$ & $0.10(0.04)$ & $0.06(0.03)$ \\
\hline & Season $^{2}$ & $0.03(0.01)$ & 0.01 & $0.05(0.02)$ \\
\hline & Season & $0.05(0.02)$ & $0.03(0.01)$ & $0.02(0.01)$ \\
\hline \multirow[t]{5}{*}{ G. holbrooki } & Adult Stock & N/A & N/A & 0.73 \\
\hline & $\beta$ & $0.08(0.05)$ & $0.17(0.05)$ & $0.41(0.14)$ \\
\hline & Interaction & $0.05(0.02)$ & $0.03(0.01)$ & $0.03(0.01)$ \\
\hline & Season $^{2}$ & $0.03(0.01)$ & $0.04(0.02)$ & $0.12(0.01)$ \\
\hline & Season & $0.03(0.02)$ & $0.03(0.01)$ & $0.05(0.01)$ \\
\hline \multirow[t]{5}{*}{ H. formosa } & Adult Stock & N/A & N/A & N/A \\
\hline & $\beta$ & $0.17(0.04)$ & $0.38(0.03)$ & N/A \\
\hline & Interaction & $0.16(0.09)$ & $0.21(0.04)$ & $0.35(0.05)$ \\
\hline & Season $^{2}$ & $0.03(0.01)$ & 0.02 & $0.03(0.01)$ \\
\hline & Season & $0.07(0.03)$ & 0.01 & $0.02(0.01)$ \\
\hline \multirow[t]{5}{*}{ J. floridae } & Adult Stock & N/A & 0.10 & N/A \\
\hline & $\beta$ & $0.08(0.03)$ & $0.07(0.01)$ & $0.05(0.02)$ \\
\hline & Interaction & $0.04(0.03)$ & $0.06(0.03)$ & $0.03(0.01)$ \\
\hline & Season $^{2}$ & $0.02(0.01)$ & $0.03(0.01)$ & $0.03(0.01)$ \\
\hline & Season & $0.02(0.01)$ & $0.03(0.01)$ & $0.03(0.01)$ \\
\hline \multirow[t]{5}{*}{ L. goodei } & Adult Stock & N/A & $0.59(0.14)$ & $0.73(0.02)$ \\
\hline & $\beta$ & $0.21(0.01)$ & $0.06(0.05)$ & $0.05(0.02)$ \\
\hline & Interaction & $0.03(0.01)$ & $0.04(0.02)$ & $0.01(0.01)$ \\
\hline & Season $^{2}$ & $0.04(0.03)$ & $0.01(0.01)$ & $0.01(0.01)$ \\
\hline & Season & $0.10(0.05)$ & $0.06(0.01)$ & $0.02(0.01)$ \\
\hline \multirow[t]{3}{*}{ P. latipinna } & Adult Stock & N/A & N/A & N/A \\
\hline & $\beta$ & $0.03(0.02)$ & $0.19(0.07)$ & 0.18 \\
\hline & Interaction & $0.16(0.08)$ & $0.18(0.05)$ & $0.20(0.05)$ \\
\hline
\end{tabular}


Table 5. Partial correlations for each parameter included in our Type III population models. Correlations were averaged based on disturbance intensity (Mean $\left.{ }^{+} /-\mathrm{SE}\right)$.

\begin{tabular}{|c|c|c|c|c|}
\hline Species & Parameter & Short & Intermediate & Long \\
\hline \multirow{4}{*}{ F. chrysotus } & Season $^{2}$ & $0.01(0.01)$ & $0.03(0.02)$ & 0.01 \\
\hline & Season & 0.01 & 0.01 & 0.01 \\
\hline & $\beta$ & $0.12(0.03)$ & $0.10(0.02)$ & $0.16(0.02)$ \\
\hline & Interaction & $<0.01$ & $0.03(0.01)$ & $0.02(0.01)$ \\
\hline \multirow{4}{*}{ G. holbrooki } & Season $^{2}$ & $0.04(0.04)$ & $0.05(0.02)$ & $0.01(0.01)$ \\
\hline & Season & $0.03(0.03)$ & $0.03(0.02)$ & 0.01 \\
\hline & $\beta$ & $0.17(0.03)$ & $0.15(0.03)$ & $0.19(0.04)$ \\
\hline & Interaction & $0.02(0.01)$ & $0.02(0.01)$ & $0.03(0.01)$ \\
\hline \multirow{4}{*}{ H. formosa } & Season $^{2}$ & $0.02(0.01)$ & $0.03(0.01)$ & $0.03(0.01)$ \\
\hline & Season & $0.02(0.01)$ & $0.01(0.01)$ & $0.01(0.01)$ \\
\hline & $\beta$ & $0.06(0.04)$ & $0.04(0.01)$ & $0.12(0.03)$ \\
\hline & Interaction & $0.03(0.01)$ & $0.02(0.01)$ & $0.02(0.01)$ \\
\hline \multirow{4}{*}{ J. floridae } & Season $^{2}$ & $0.03(0.01)$ & $0.02(0.01)$ & $0.01(0.01)$ \\
\hline & Season & $0.03(0.01)$ & 0.01 & 0.01 \\
\hline & $\beta$ & $0.20(0.04)$ & $0.20(0.03)$ & $0.13(0.03)$ \\
\hline & Interaction & $0.03(0.01)$ & $0.05(0.01)$ & $0.04(0.01)$ \\
\hline \multirow{4}{*}{ L. goodei } & Season $^{2}$ & $0.08(0.03)$ & $0.09(0.01)$ & $0.01(0.01)$ \\
\hline & Season & $0.04(0.02)$ & $0.07(0.01)$ & 0.01 \\
\hline & $\beta$ & $0.05(0.02)$ & $0.11(0.04)$ & $0.04(0.01)$ \\
\hline & Interaction & $<0.01$ & $0.04(0.02)$ & $0.01(0.01)$ \\
\hline \multirow{4}{*}{ P. latipinna } & Season $^{2}$ & $0.03(0.03)$ & 0.02 & 0.01 \\
\hline & Season & $0.05(0.03)$ & $0.02(0.01)$ & $0.01(0.01)$ \\
\hline & $\beta$ & $0.07(0.03)$ & $0.04(0.01)$ & $0.09(0.02)$ \\
\hline & Interaction & $<0.01$ & $0.01(0.01)$ & $<0.01$ \\
\hline
\end{tabular}


Figure 1. Boxplots describing the strength of evidence for each species across all 21 study sites. The strength of evidence was calculated by summing the Aikake weights $\left(\mathrm{AIC}_{\mathrm{w}}\right)$ for all density-independent and -dependent models respectively.

Figure 2. The $\log _{10}$-transformed evidence ratios (LER) for the stock-recruitment models. This includes the Random Walk (RW), density-independent (EX St), lagged densityindependent (EX S $\mathrm{S}_{\mathrm{t}-1}$ ), Seasonal models (SE), DSD model (HY), density-dependent S-R models (DD $\mathrm{S}_{\mathrm{t}}$ ), and lagged density-dependent models (DD S $\left.\mathrm{S}_{\mathrm{t}-1}\right)$. B) LER's for the population dynamics models. This includes the density-independent models (DI), days since last dry down (DSD), and density dependent models (DD). DD models are separated based on the independent variable used $\left(\mathrm{R}_{t}, \mathrm{R}_{\mathrm{t}-1}, \mathrm{~S}_{\mathrm{t}} \mathrm{S}_{\mathrm{t}-1}\right)$.

Figure 3. Bar graph describing the significant parameters for our Type III stockrecruitment analysis. A) Density-independent models and B) Density-dependent models.

Figure 4. Bar graph describing the significant parameters for our Type III population dynamics model.

Figure 5. A) Scatterplot showing the relationship between the CV of hydroperiod and the density-independent stock-recruitment parameter ( $\alpha$ ) for L. goodei. B) Scatterplot showing the relationship between the $\mathrm{CV}$ of hydroperiod and the steepness of the S-R relationship (h) for L. goodei. Estimates were calculated based on the best model at each site $(\triangle \mathrm{AIC}=0)$.

Figure 6. A) Scatterplot showing the relationship between the CV of Hydroperiod and the strength of density-dependence for $J$. floridae. B) Model predicted values for the 
relationship between the $\mathrm{CV}$ of Hydroperiod and the strength of density-dependence. Estimates for $\beta$ were taken from the best model at each site $(\triangle \mathrm{AIC}=0)$.

Figure 7. A) Scatterplot from our Type III regressions showing the relationship between the $\mathrm{CV}$ of Hydroperiod and the strength of density-dependence for F. chrysotus. B) Model predicted values for the relationship between the $\mathrm{CV}$ of Hydroperiod and the strength of density-dependence. Estimates for $\beta$ were taken from the best model at each site using Type III Sum of Squares $(\triangle \mathrm{AIC}=0)$. 
Figure 1

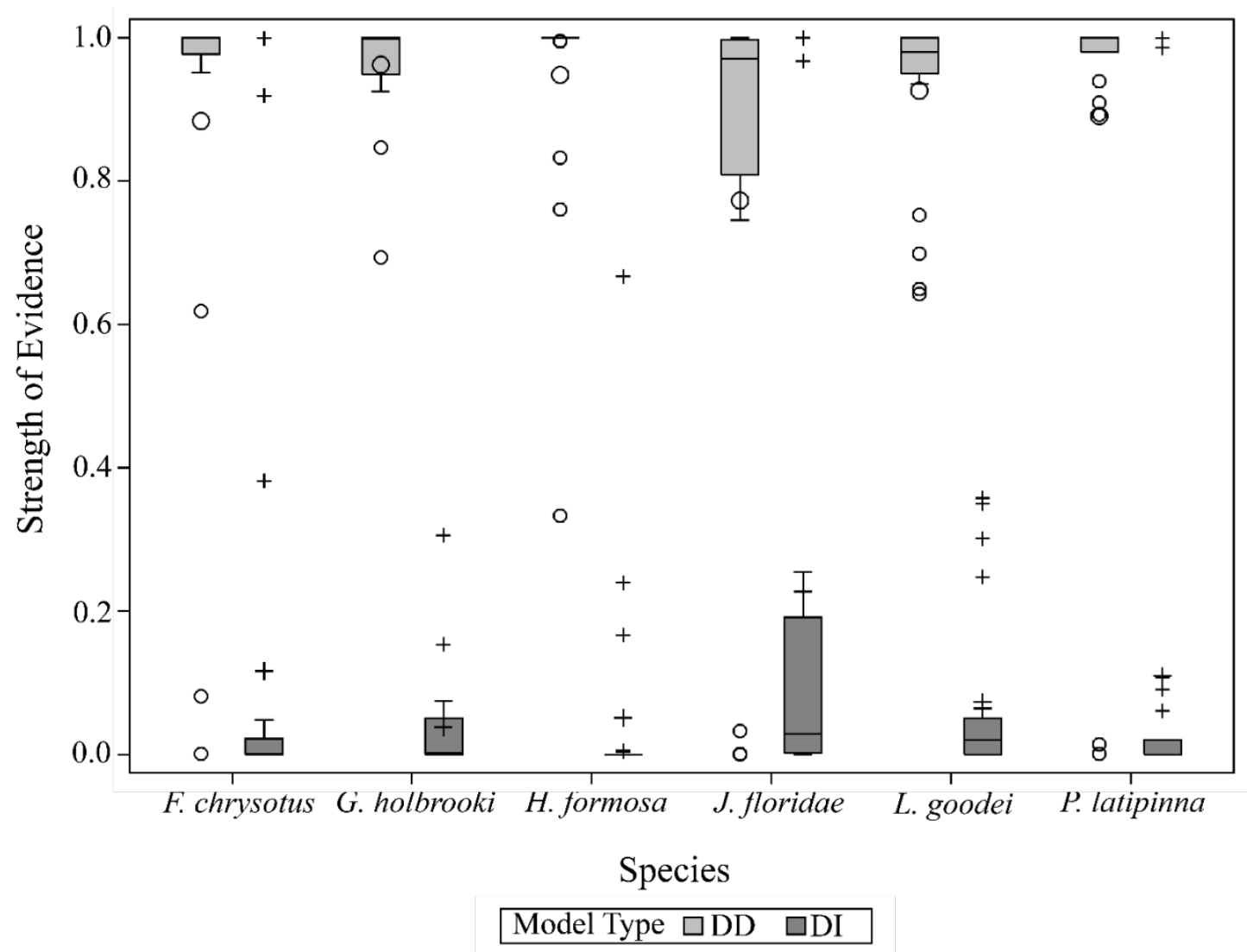


Figure 2

A)

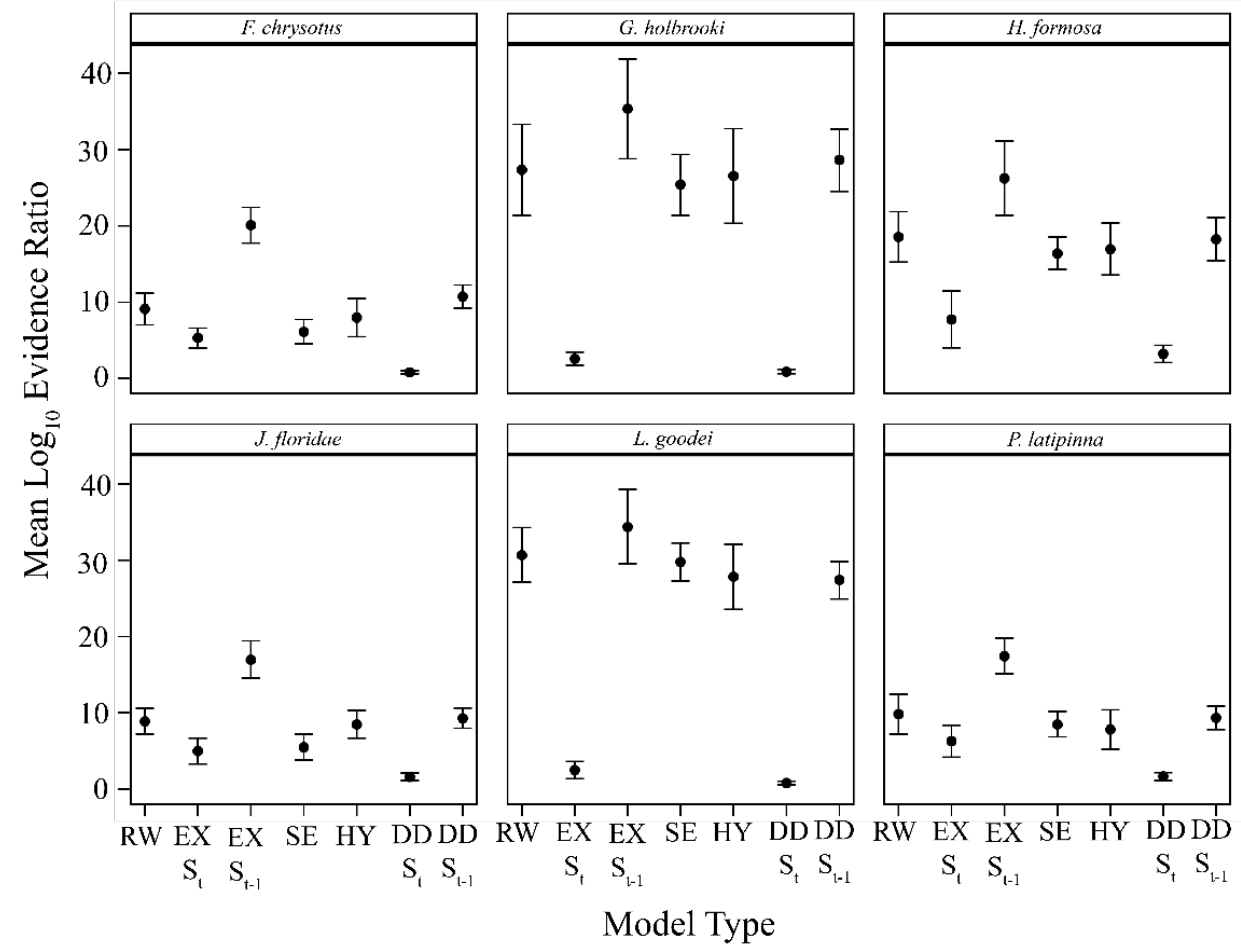

B)

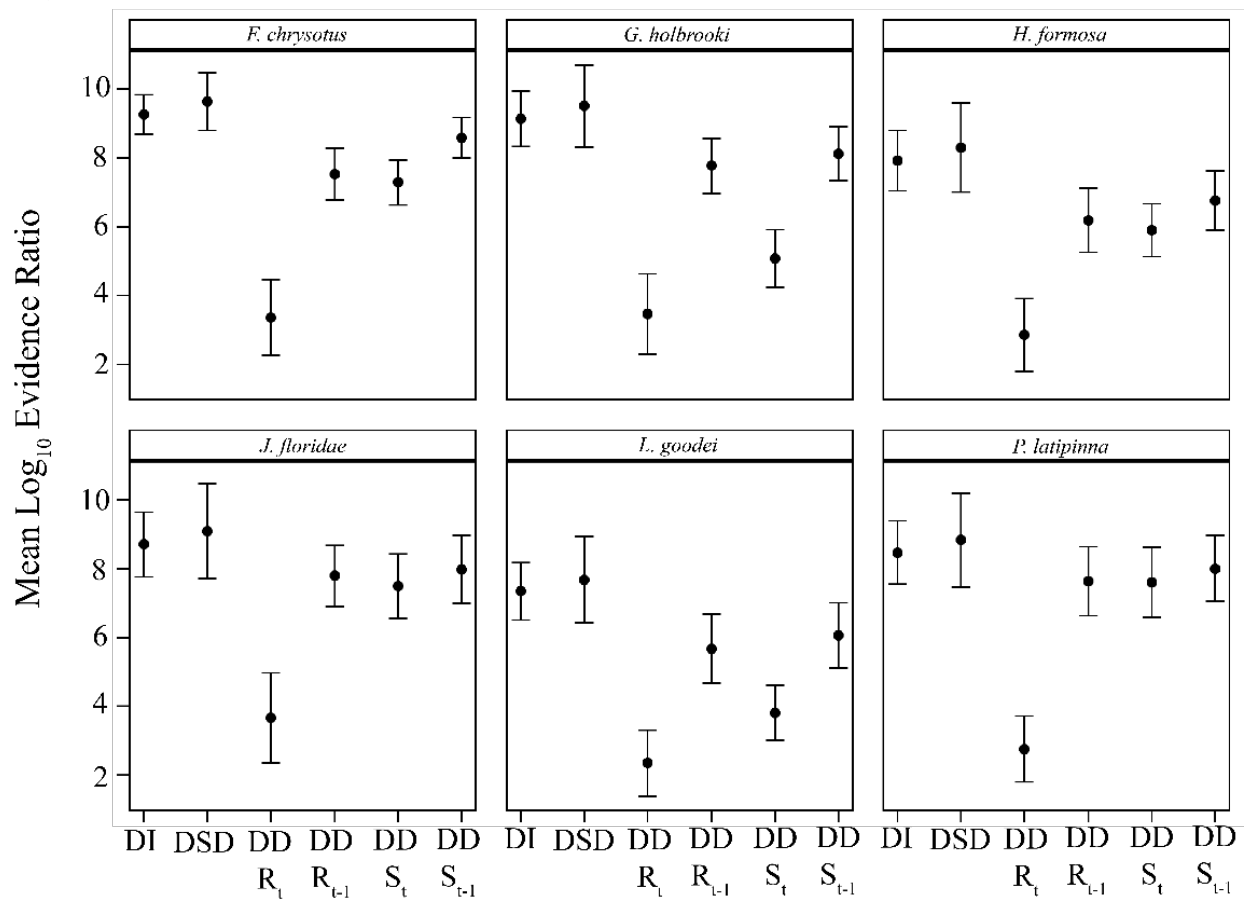

Model Type 
Figure 3

A)

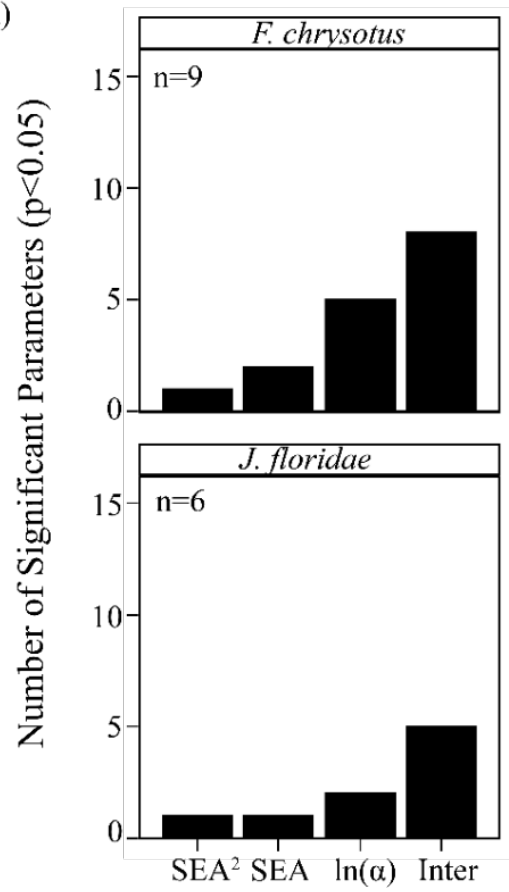

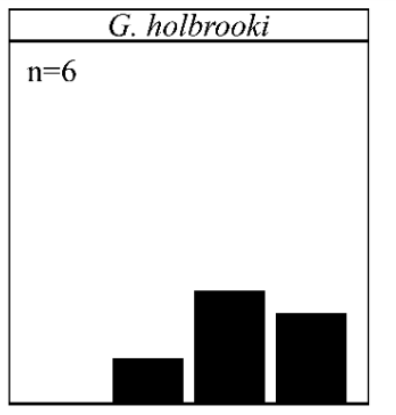
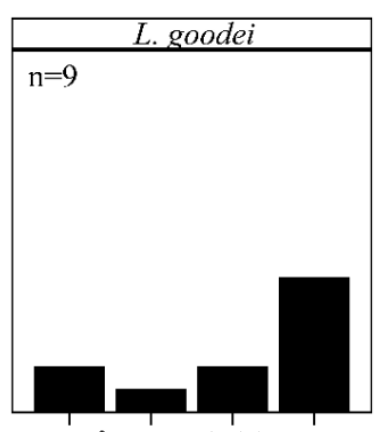

SEA $^{2}$ SEA $\ln (\alpha)$ Inter

Parameter
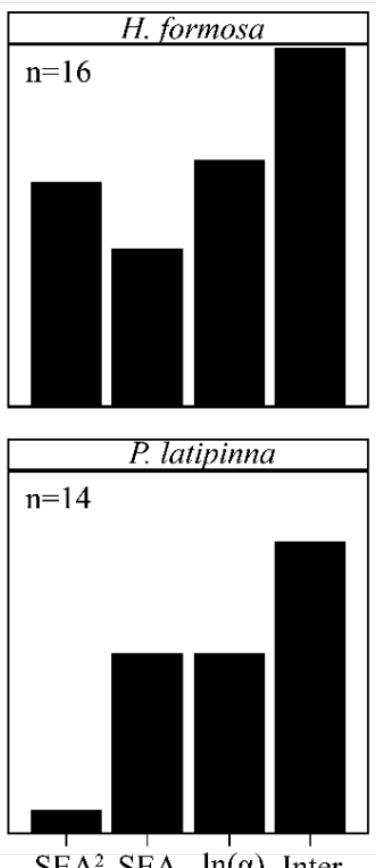

SEA $^{2}$ SEA $\ln (\alpha)$ Inter

B)
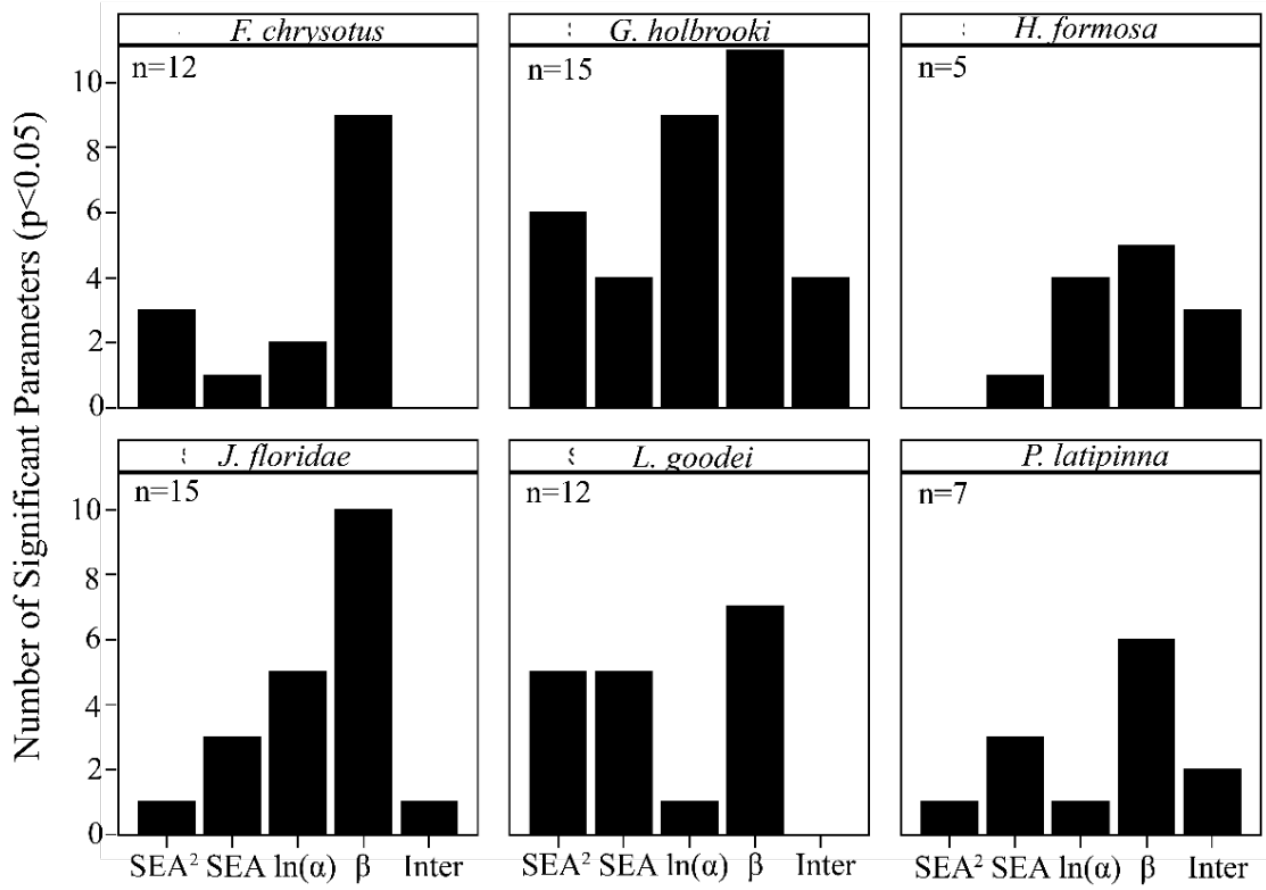

$\mathrm{SEA}^{2} \mathrm{SEA} \ln (\alpha) \quad \beta \quad$ Inter

Parameter 
Figure 4

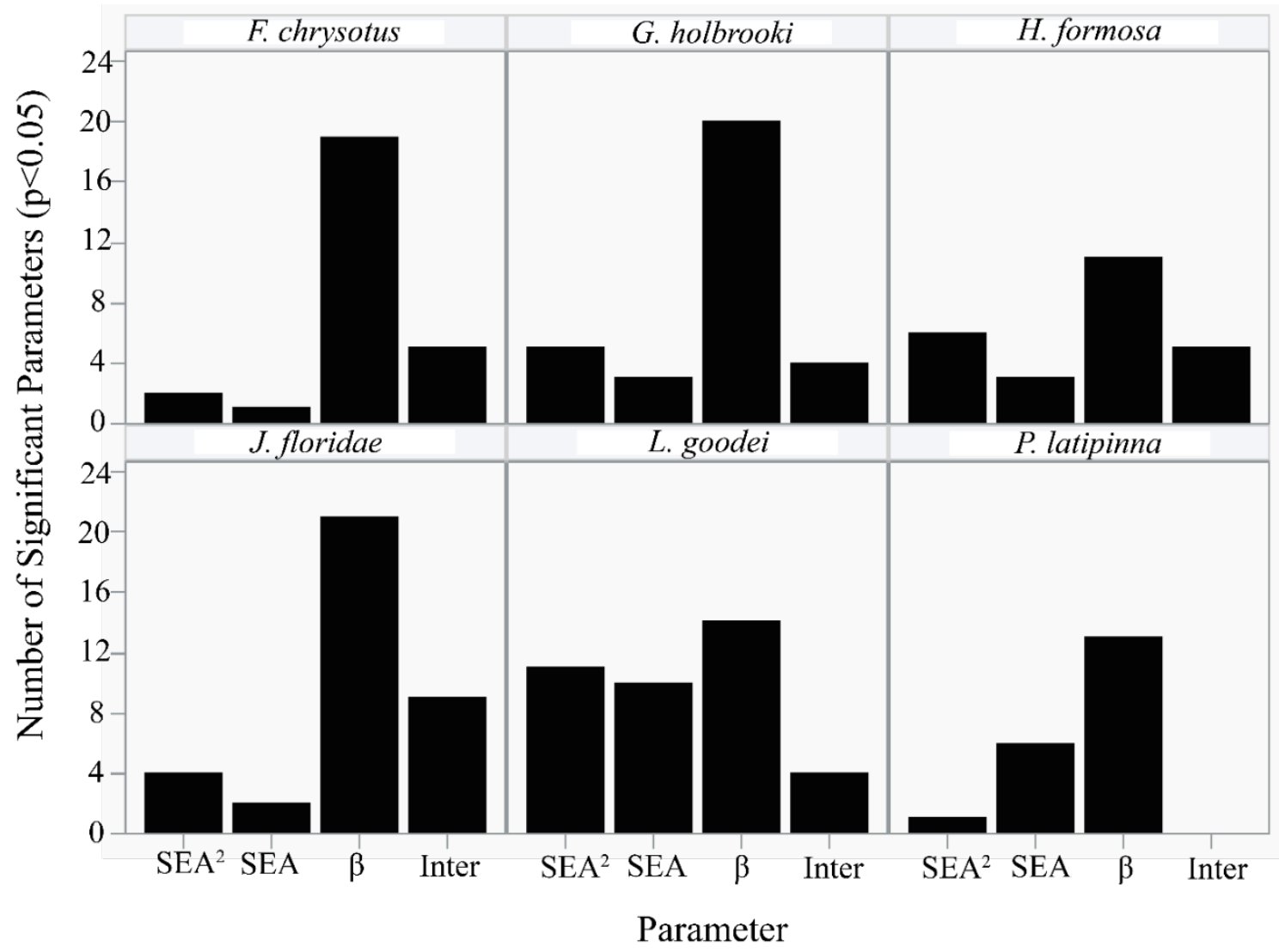


Figure 5
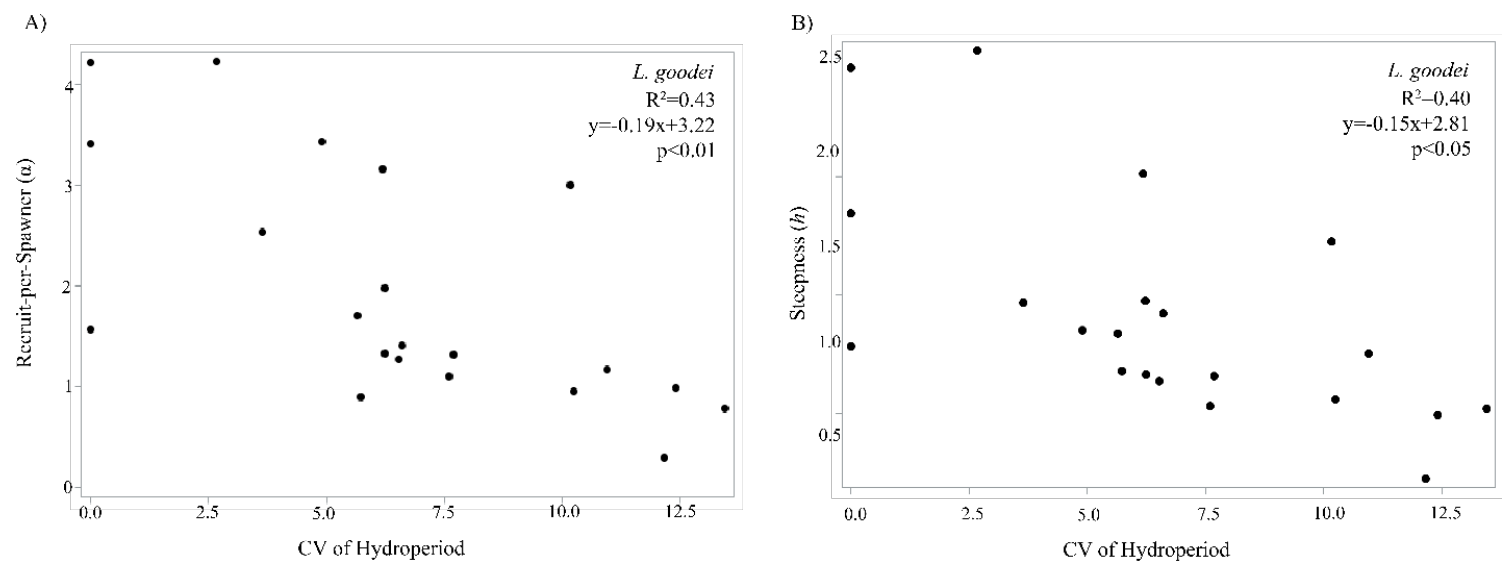
Figure 6
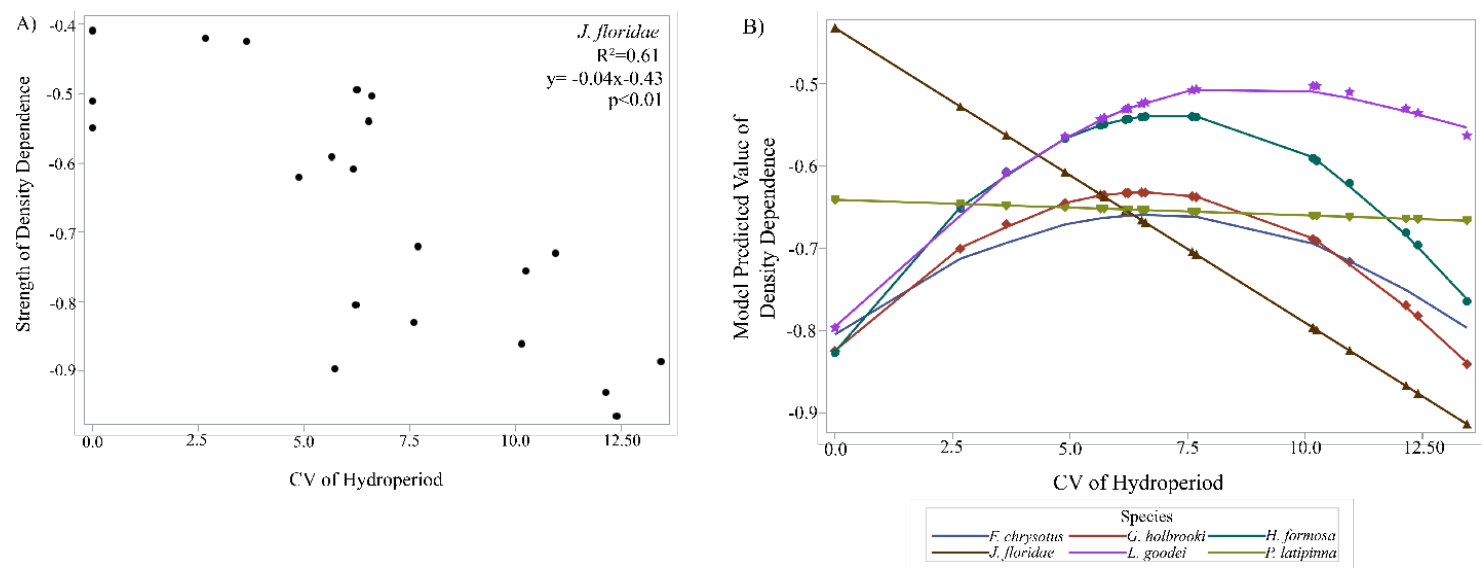
Figure 7
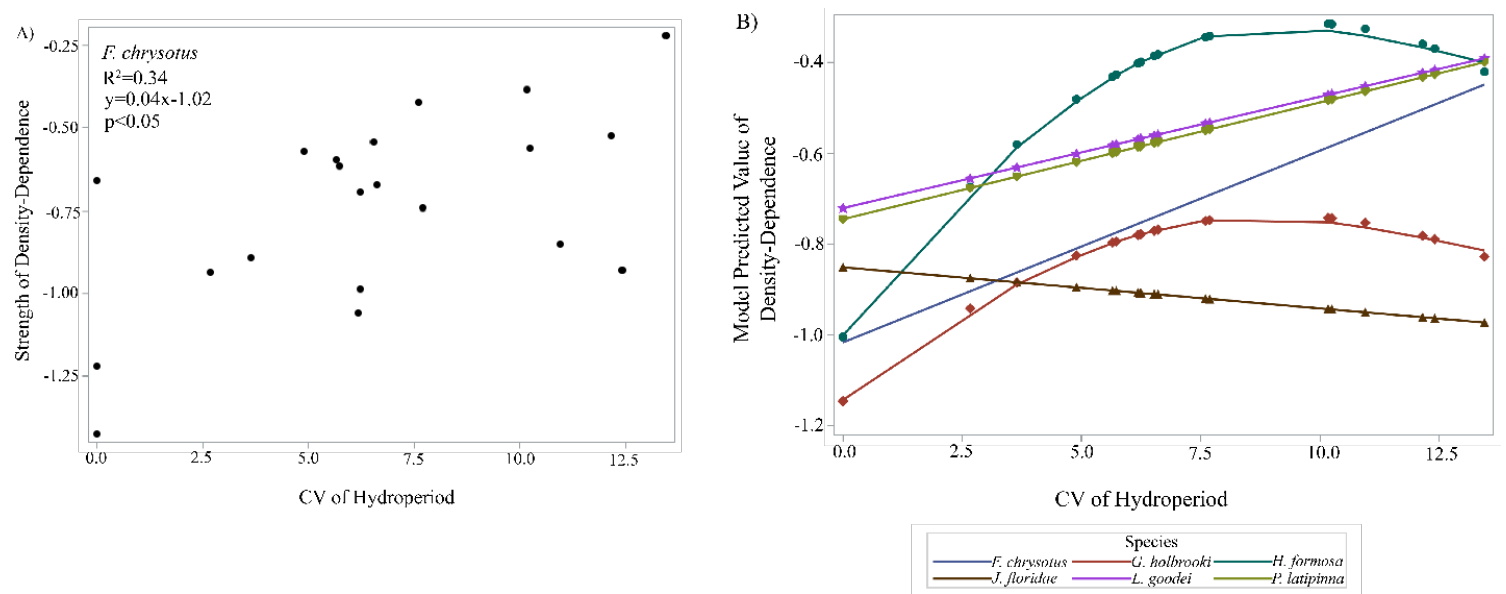
CHAPTER IV

SPEED AND DIRECTEDNESS PREDICT COLONIZATION SEQUENCE POSTDISTURBANCE 


\section{Abstract}

1. Trait-based analyses of communities has advanced our ability to predict patterns of community assembly, but critical traits related to movement have yet to be identified beyond a theoretical context. It is not clear if two historically modeled traits, speed and directional bias (directedness), can describe animal dispersal in a nature.

2. We hypothesized that these two behavioral traits can predict the order of colonization by fishes in a complex landscape. Colonization patterns following hydrological disturbance were documented in a 20 -year multi-site time series of marsh fish in the Florida Everglades (U. S. A.), and we evaluated the ability of a model parameterized only with speed and directedness to predict these patterns.

3. We characterized directedness and field swimming speed previously using encounter samplers. The critical swimming speeds (U $\mathrm{U}_{\mathrm{CRIT}}$ ) for six fish common in the Everglades were estimated using endurance tests. We incorporated both speed and direction into several Agent Based Models (ABM's) to simulate dispersal following disturbance. Six virtual "species", with varying levels of directedness, "swam" in an artificial environment to reach a refuge habitat. The time of first arrival for each species was saved at the end of each run and used to calculate the probability of arrival order. We used our U URIT and field-estimated swimming performance to match simulated results to colonization order observed in the field.

4. Our simulated results generated predictions on order of arrival consistent with observed colonization patterns in our long-term dataset. Over 500 drying events 
were analyzed and revealed a consistent pattern (first to last: Jordanella floridae, Gambusia holbrooki, Fundulus chrysotus, Lucania goodei, Heterandria formosa, and Poecilia latipinna). Swim tunnel results revealed that fast (high $\mathrm{U}_{\mathrm{CRIT}}$ ) estimates were characteristic of early colonizing species; whereas, slow (low $\mathrm{U}_{\mathrm{CRIT}}$ ) estimates were characteristic of late colonizing species. In simulations, directional bias better predicted order of arrival than speed, though both parameters contributed to prediction.

5. This study demonstrated that two behavioral traits were adequate to predict the order of species colonization post-disturbance in a large and complex wetland ecosystem. These results support the use of relatively simple models to generate realistic community assembly dynamics.

Keywords: Agent Based Modeling; critical swimming speed; diffusion model; dispersal; functional traits; primary succession; sequential colonization; wetland

\section{Introduction}

The order of species arrival post-disturbance (sequential colonization) is hypothesized to be a critical factor in successional dynamics following intense disturbance (Spiller, Schoener \& Piovia-Scott 2018). Sequential colonization can lead to priority effects that provide a competitive advantage to early colonizing species over later ones (Symons \& Arnott 2014). Early arrivals may block or inhibit colonization of later arriving species by monopolizing newly available resources (Fraser, Banks \& Waters 2015; Fukami 2015). Although strong dispersal potential is believed to cause these priority effects (Waters, Fraser \& Hewitt 2013), trait-based studies investigating the key 
traits leading to sequential colonization and early arrival following disturbance are lacking.

Ecological studies classify movement into three modes: passive; diffusive; and directed (Possingham \& Roughgarden 1990; Tilman \& Kareiva 1997). Passive movement, the spread of organisms by means of outside forces, characterizes displacement by stochastic or deterministic processes such as currents or winds (Okubo 1994). Diffusive spread and random walks describe non-directional organismal movement through a landscape (Skellam 1951; Reynolds \& Rhodes 2009). Movement is characterized as a series of 'steps' when the animal displaces itself in a unitary direction and speed before beginning a new step at a randomly selected angle from the previous one. Some random dispersal models, such as Levy flights, vary step lengths by varying time traveled in the step at a constant rate or by varying movement rate at a constant time in the step. Finally, organisms display directed movement, or taxis, by responding to environmental cues and moving directionally in response to stimuli (Armsworth \& Roughgarden 2005). Although evidence for directed movement is increasing (Nams 2006; Goss, Loftus \& Trexler 2013; Hoch et al. 2015), much of our understanding of the implications of movement on ecological dynamics is based on random movement of various forms (Méndez, Campos \& Bartumeus 2016).

Functional trait-based mechanistic models have gained interest as tools to improve predictions of community composition and diversity (Cadotte et al. 2015). Foundational ecological models identified two traits to describe movement, directional bias (directedness or turning angle) and speed (Fisher 1937; Skellam 1951), but no study has investigated if these two historically modeled traits are adequate to describe animal 
dispersal and colonization order in nature as it relates to community assembly. Most studies rely on the comparison of step length distributions to those predicted by models such as Levy flights (Viswanathan 2010) creating a need for trait-based mechanistic analyses of movement patterns in field conditions (Hays et al. 2016). Species persistence in fluctuating environments may be dependent on their mode of dispersal (Johst, Brandl \& Eber 2002), yet studies seldom quantify dispersal-specific traits for assemblages of coexisting organisms.

Functional variation in dispersal traits plays a central role in some theoretical depictions of metacommunity dynamics and spatial partitioning of biodiversity (e.g., dispersal-competition trade-offs in patch dynamics models: Leibold and Chase 2018). The relative mix of species with random and directed movement may maintain biodiversity since random movement supports both y and a diversity, while directed movement tends to support $\beta$ diversity via local coexistence and niche partitioning, respectively (Armsworth \& Roughgarden 2005). It is still unclear how interspecific variation in movement strategies influences the rates at which species colonize newly available habitats and their role in early successional dynamics beyond a theoretical context (Cote et al. 2017; Jeltsch et al. 2017). We are aware of no animal study (but for plants, see Campbell et al. 2003) that has directly described or linked the range of movement traits in a regional pool of species to colonization rates for a collection of coexisting species post-disturbance.

In this paper, we explore the predictive power of information on species' dispersal traits in a field setting with extensive time-series data on community reformation following disturbance. We developed a framework to determine how interspecific 
variation in movement traits relate to colonization success by screening a group of coexisting species for their speed (maximum critical swimming speed) and directedness. This study coupled functional analyses of swimming performance with a simple model to predict the order of species re-colonization of sites following disturbance. We then evaluated those predictions with a 20 -year dataset on recolonization patterns in a complex floodplain ecosystem, the Everglades of Florida, U.S.A.

\section{Methods}

\section{Study Site and Species}

The freshwater marshes of the Florida Everglades experience seasonal rainfall patterns with an annual dry (November-May) and wet (June-October) period (Ogden et al. 2005), with seasonal inundation a direct result of rainfall and recession caused by drainage and evaporation of surface water (Fennema et al. 1994). The persistence of fish communities in these landscapes is facilitated by the hydrologic connectivity between permanent and ephemeral habitats. This results in temporal shifts of fish densities, causing these organisms to immigrate in with flooding or emigrate out when drying or face desiccation (Trexler, DeAngelis \& Jiang 2011). Furthermore, flow velocity is consistently low $(<3 \mathrm{~cm} / \mathrm{s})($ Larsen et al. 2011) and colonization following inundation is driven primarily by changes in movement behaviors (Larsen et al. 2011; Hoch et al. 2015).

From 1996 and 2016, we collected fish using a 1-m², 2-mm mesh, throw trap following a standard protocol (Jordan et al. 1997) at 21 monitoring sites in the Everglades, Florida, U. S. A (Fig.1). Six sites were in Shark River Slough (SRS), five in Taylor Slough (TSL), and 10 in Water Conservation Areas (WCA) 3A and 3B. Samples 
were collected at each site in five months of each year (July, October, December, February, and April) to characterize a 'water year' from the wet season (begins in May) to dry season (begins December). Each site consisted of three plots, except for shorthydroperiod sites in TSL (MDsh and TSsh), which had two plots each. Five (WCA 3A and 3B) or seven (SRS, TSL) throw trap samples were collected within each. Plots located in WCA 3A and 3B yielded 25 samples per year (5 throws $x 5$ sample events), while plots in SRS and TSL yielded 35 samples per water-year (7 throws per plot x 5 sample events). Throw locations within each plot were determined using a random number table. After securing the trap, floating vegetation (non-rooted vascular plants and periphyton mat) was quantified and cleared before fish were removed following a standardized protocol of sweeps with a bar seine and dip nets. Vertebrate organisms were euthanized using a solution of MS-222 and ambient marsh water (Nickum et al. 2004). There is no evidence of visitor impact on these long-term study sites, possibly because marsh plants re-grow quickly and periodic marsh drying overwhelms sampler impacts on vegetation and soil (Wolski et al. 2004). Additional information on the study sites and sampling design are described in detail in other publications (Busch \& Trexler 2003; Trexler, Loftus \& Perry 2005; Porter 2010).

This study focused on the six most abundant marsh fish species at all study sites. These include three members of the Poeciliidae: Gambusia holbrooki (Eastern Mosquitofish), Heterandria formosa (Least Killifish), and Poecilia latipinna (Sailfin Molly), two members of the Fundulidae: Lucania goodei (Bluefin Killifish) and Fundulus chrysotus (Golden Topminnow), and one member of the Cyprinodontidae: Jordanella floridae (Flagfish). These species can be further classified based on three distinctive life 
history strategies related to recovery following drought: rapid recovery and sustained high density (G. halbrooki), rapid recovery followed by a decline in density (J. floridae), and slow recovery over time (L. goodei, H. formosa, P. latipinna). These have been described in detail in other publications (DeAngelis, Trexler \& Loftus 2005; Trexler, Loftus \& Perry 2005). Furthermore, the relative importance of local reproduction in recovery patterns of these populations in response to drought is poorly understood, but cannot explain some of the previously discussed life history patterns (Goss, Loftus \& Trexler 2014). Differences in colonization potential between these six species is driven primarily by immigration and not local reproduction.

\section{Colonization Patterns}

We analyzed a 20-year time-series dataset to determine the colonization patterns following re-inundation at 21 long-term monitoring sites. To determine when a habitat became re-inundated, hydrology data were extracted from the Everglades Depth Estimation Network (EDEN). EDEN uses water-surface models to interpolate measured water depths at monitored gauges to estimate daily water depth at our study sites (Telis 2006; Liu et al. 2009). We used these data to create a count variable, days since the site was last dry (DSD), which records the cumulative number of days since gauges recorded a water depth $<5 \mathrm{~cm}$ for each sampling event. At $5 \mathrm{~cm}$, only a slurry of organic matter remains, and fish generally suffocate in the low oxygen conditions and organic matter blocking their gills. We used plot-level data as replicates. All data collected prior to the first detectable drying event were not considered because colonization time could not be estimated. Plots lacking a disturbance event were also excluded from our analyses. We then determined all samples that were collected between disturbance events and recorded 
the presence or absence of each species in these samples. Using temporal tabulations of species presence (count $>0$ ) or absence (count $=0$ ), we recorded the cumulative number of sample periods that each species was absent prior to first detection following marsh reflooding.

We hypothesized that regional fish density was correlated with the time to recolonize a site following drought. To test this hypothesis, we calculated three metrics of density: density at first arrival post-drought, average density while inundated, and maximum density while inundated. Densities were calculated using the abundance of fish in each of the 5-7 1- $\mathrm{m}^{2}$ throw trap samples while sites were inundated. We first determined the initial density of fish (density at first arrival) by calculating the density when fish were initially present following inundation. Mean density while inundated was calculated by averaging the densities for all samples collected between successive drying events. Furthermore, we determined the peak density during inundation to determine if early colonization was related to increased population size (maximum density while inundated). Spearman's rho, a nonparametric correlation, was used to document the relationship of recolonization patterns and density metrics. For statistical analyses, a species was assigned a colonization time equal to the maximum number of samples collected following a disturbance when no specimens of the species were collected. This ensured that these species received the highest rank possible, even when accounting for ties. Spearman's rho was calculated separately for each drying event using the rank order of arrival time and each metric of density (density at first arrival post-inundation, average density, maximum density). These, and all other analyses, were conducted using SAS 9.4 (Insititute 2012). 
We also calculated arrival order at each site by species. To determine arrival order, we ranked each species' arrival time (earliest $=1$, latest $=6$ ) and addressed ties by assigning the lowest rank for all species with the same arrival time. Ties occurred when species first arrived at the same sample event. To avoid fractional orders of arrival, a rank of 1 was associated with all species that arrived first to ensure a range of whole numbers from 1 to 6 . We then used these ranks to calculate arrival probabilities, or the proportion of drying events where a species arrived at each arrival order, for each species by using the following formula:

$$
\mathrm{p}_{i}=\frac{X_{i}}{n}
$$

where $p_{i}$ is the probability of arrival, $X_{i}$ is the number of drying events where a species arrived in the $i$ th order, and $\mathrm{n}$ is the number of drying events in the time series.

Quantifying Swimming Speed

We estimated critical swimming speed (U $\left.\mathrm{U}_{\mathrm{CRIT}}\right)$, or the maximum sustained aerobic speed, as a metric of fish swimming ability (Plaut 2001). We hypothesized that the maximum aerobic speed would be physiologically limiting and one species-specific aspect of colonization potential. To investigate interspecific variation in $\mathrm{U}_{\text {CRIT, adult and }}$ juvenile fish for each species were collected from the Everglades using a dip net and transported to an indoor wet lab at Florida International University, Miami, FL. All fish were housed in 75.7-1 aquaria under a 12/12 photoperiod. Individuals were fed Tetramin ${ }^{\circledR}$ once daily prior to each trial. Species were allowed 3-4 days to recover from stress caused by transport and transplantation into laboratory aquaria. Individual fish were then placed in a Blazka-style swim chamber (Blazka, Volf \& Cepela 1960) and 
allowed to acclimate at low-flow speeds $\left(2-6 \mathrm{cms}^{-1}\right.$ or $\left.1-3 \mathrm{BLs}^{-1}\right)$ for 30 minutes to induce rheotaxis. Following the acclimation period, flow velocity was increased by $2 \mathrm{~cm} / \mathrm{s}$ every 5 minutes until the individual could no longer swim against the current and was swept backward onto the meshed end of the chamber. Fatigue was assessed when an individual could no longer maintain its position against the flow and did not respond to stimulation for three consecutive attempts. Aeration was placed at the downstream end of the flume to ensure that the water was properly oxygenated and not a limiting factor during each trial. Both the final velocity and the time until exhaustion at the final velocity were recorded. The critical swimming speed was then calculated using the formula:

$$
\mathrm{U}_{\mathrm{CRIT}}=\mathrm{U}+\left[\mathrm{U}_{\mathrm{i}} *\left(\mathrm{t} / \mathrm{t}_{\mathrm{i}}\right)\right]
$$

where $U_{i}$ is the velocity increment $(2 \mathrm{~cm} / \mathrm{s}), t_{i}$ is the time increment ( 5 minutes), $U$ is the final velocity a fish swum for the full 5 minutes, and $t$ is the time swum at the final velocity (Plaut 2001).

The critical swimming speed was evaluated for 20 juveniles and 20 adults of varying lengths (approximately one individual per $\mathrm{mm}$ in length) of each species $(\mathrm{n}=40$ per species). The size range selected for each species was based on the observed size range of specimens within the 20 -year time series. Time in captivity and time since last feeding were also assessed to determine any influence that these variables may have on estimated critical swimming speed. Furthermore, no fish that were housed for more than 12 days were used to prevent domestication of housing and feeding conditions. We used an ANOVA to evaluate differences in species' swimming ability. A post-hoc Tukey’s pairwise comparison was used to group each species into high, moderate, or low dispersal capacity based on their respective $U_{\text {CRIT. }}$ Furthermore, we used absolute speed $(\mathrm{cm} / \mathrm{s})$, 
not relative speed (body lengths per second, $\mathrm{BLs}^{-1}$ ), for our analyses since the objective was to determine which species would arrive first based on speed.

\section{Using Agent Based Models to Simulate Dispersal}

Previous studies have indicated that these species vary in their level of directedness in response to changing hydrology (Obaza, DeAngelis \& Trexler 2011; Hoch et al. 2015). To investigate the effects of both swimming speed and direction on dispersal potential, we created a series of ABM's that incorporated both our laboratory estimates of speed and previously described estimates of directedness (Grimm et al. 2006). We created an artificial environment in a computer-generated world using Netlogo 5.3.1 (Wilensky 1999). This virtual environment was scaled to the speeds estimated from swimming performance study to simulate long-distance dispersal of these fish (Baber et al. 2002; Hohausová, Lavoy \& Allen 2010). This limited the environment to a $3.52 \mathrm{~km}^{2}(2000 \mathrm{~m} \mathrm{X} 1760 \mathrm{~m})$ fully connected virtual world consisting of a homogenous landscape designed to avoid the complexity that would be posed by a variety of habitat types and preferences. Further, we assigned coordinates in our world to correspond to the cardinal plane $\left(\right.$ North $=0^{\circ}$, East $=90^{\circ}$, South $=180^{\circ}$, and West $\left.=270^{\circ}\right)$. A refuge habitat simulating a canal or alligator pond was created and located 1,000 $\mathrm{m}$ due north of the initial habitat (Fig. 1).

We created virtual individuals (agents) to swim in our artificial marsh habitat to simulate the movement of individual fish in a marsh that is drying. Six virtual "species", each with varying levels of directedness, were created at a density of 1 -individual per $\mathrm{m}^{2}$ (100 individuals for each species). This standardized the results of our simulations to reflect only changes in speed and directedness since field results indicated colonization 
time was independent of density (see Results). Each individual was assigned a random heading and placed within an artificial habitat $\left(100 \mathrm{~m}^{2}, 10 \mathrm{~m} \mathrm{X} 10 \mathrm{~m}\right)$ located 1,000-m due south of the refuge habitat. Directedness was manipulated by restricting the heading of each species to regions of the cardinal plane. This reduced the range of motion for each of the six species to $180^{\circ}$ (most directed), $225^{\circ}, 270^{\circ}, 315^{\circ}, 330^{\circ}$, and $360^{\circ}$ (least directed) respectively (Table 1). Individuals were programmed to re-orient themselves within $20^{\circ}$ opposite of the restricted region when approaching their respective restricted movement area. This corresponds with the maximum turning angle that fish can maintain within a 1-second period (Domenici \& Blake 1997).

We generated a series of movement commands following each tick (Netlogo unit of time) for every individual to follow until they reached the refuge habitat. To simulate real time, we equated 1 tick to 1 second of real time. Initially, each individual was programmed to make a turn randomly selected from a normal distribution $(\mu=0, \sigma=10)$ prior to moving forward. We assigned right turns to positive values and left turns to negative values of this distribution. Therefore, a turning angle of -10 corresponds to the fish turning left ten degrees. Following each turn, individuals moved forward a distance randomly selected from an exponential distribution of mean $\mu$. We specifically tested speeds in $3 \mathrm{~cm} / \mathrm{s}$ increments $(\mu=9,12,15,18,21$, and $24 \mathrm{~cm} / \mathrm{s})$ based on interspecific variation in $\mathrm{U}_{\mathrm{CRIT}}$ derived from this study. The exponential distribution was selected because of its resemblance to prolonged swimming speed curves (Fisher \& Bellwood 2002). The objective for each species was to swim for 12 hours $(43,200$ ticks) and reach the refuge habitat located $1,000 \mathrm{~m}$ north. Therefore, individual simulations ran for 43,200 ticks in simulated time to correspond with a 12/12 photoperiod. 
Netlogo's program BehaviorSpace was used to model every speed/directionality combination (six speeds, six levels of directedness, $6^{6}$ or 46,656 simulations). To account for the stochastic nature of the random-number generators in our speed and turning angle variables, we replicated each scenario 10 times, for a total of 466,560 runs. Summary statistics (mean, minimum, maximum, standard deviation) for the time at first arrival, abundance at each microhabitat, and average distance traveled were saved at the end of each run. We then averaged the time at first arrival for the 10 replicates and calculated the probability of arrival order, or the proportion of each simulated run that a species arrived in a particular order, using the following formula:

$$
\mathrm{p}_{i}=\frac{X_{i}}{n}
$$

where $p_{i}$ is the probability of arrival, $X_{i}$ is the number of simulated runs that a species arrived in the $i$ th order, and $\mathrm{n}$ is the total number of simulated speed/directedness combinations $(\mathrm{n}=46,656)$. We then calculated Kendall's Tau $(\tau)$, a nonparametric correlation test, to compare the arrival probabilities between our observed and simulated data. We considered significance at both $\alpha=0.10$ to account for the small sample size in these comparisons $(\mathrm{n}=6)$.

\section{Results}

\section{Colonization Patterns}

Our analysis revealed 536 drying events at 51 plots throughout the 20 years of this study (0-19 disturbance events per plot). Seven plots experienced no drying events and were removed from further analyses. Of the 536 drying events, $>70 \%$ of observed recolonizations were independent of density regardless of the density metric used. These 
results also revealed that early colonization did not lead to higher density for any species. The rank of inter-specific arrivals at re-inundated plots was highly repeatable (Table 2). Three species (L. goodei, H. formosa, P. latipinna) consistently recovered slowly following disturbance and often required multiple sampling events post re-flooding before they re-appeared. In contrast, this was rare for early colonizing species ( $G$. holbrooki, J. floridae, F. chrysotus), which regularly returned in a few weeks postdisturbance.

\section{Quantifying Swimming Speed}

Our analyses revealed that subtle differences in prolonged swimming speed were enough to differentiate species based on their speed/endurance. Our ANOVA model revealed these differences in swimming speed ( $4-6 \mathrm{~cm} / \mathrm{s}$ between groups) to be significantly different $\left(\mathrm{F}_{5,234}=20.09, \mathrm{p}<0.001\right)$. A post hoc Tukey test using pairwise comparisons revealed three distinctive swimming speed groups in the six species (Fig. 3). Three species (G. holbrooki, J. floridae, F. chrysotus) had faster/higher endurance $\left(\mathrm{U}_{\text {CRIT }}>=19 \mathrm{~cm} / \mathrm{s}\right.$ ) than the other three species; whereas, two species (L. goodei, $H$. formosa) had the lowest speed/endurance ( $\left.\mathrm{U}_{\mathrm{CRIT}}<=13 \mathrm{~cm} / \mathrm{s}\right)$. One species, $P$. latipinna, had speed/endurance estimates that were similar to both F. chrysotus and H. formosa, indicating an intermediate species with moderate speed/endurance $\left(19 \mathrm{~cm} / \mathrm{s}>\mathrm{U}_{\mathrm{CRIT}}>13\right.$ $\mathrm{cm} / \mathrm{s}$ ). Furthermore, our estimates of $\mathrm{U}_{\text {CRIT }}$ were consistent (Mean Difference: $10.13^{+} /$3.26) with indirect estimates in the field using encounter samplers. This revealed that individuals with high $\mathrm{U}_{\mathrm{CRIT}}$ estimates also had high indirect measures of speed estimated in the field, though $\mathrm{U}_{\mathrm{CRIT}}$ estimates were generally higher (Table 3). Analyses also 
revealed that interspecific differences in swimming speed were not influenced by our housing or feeding conditions.

\section{Using Agent Based Models to Simulate Dispersal}

Our ABM's simulated over 466,560 different artificial disturbance events and produced arrival probabilities based on different speed/directedness combinations. The outcomes revealed that faster, more directed individuals were more likely to reach a habitat first compared to slower, non-directed ones. The fastest/most directed individuals were the first to arrive; whereas, the slowest/least-directed individuals were among the last. Although our simulations revealed that the most directed individuals were most likely to arrive earlier, traveling at slower speeds hindered their overall colonization time. Interspecific trends (rows) in simulated arrival probabilities (Table 4) were highly correlated $\left(\tau=0.55-0.89\right.$, Mean $\left.\tau=0.73^{+} /-0.05\right)$ with observed species arrival probabilities from field data; however, intraspecific trends (columns) in arrival probabilities were weakly correlated (Table 2). Overall, the arrival probabilities calculated from both our field data and ABM's were significantly correlated $(\tau=0.31, \mathrm{p}<0.05)$.

Our ABM's revealed that reduced speed and/or directedness hindered a species' overall colonization time. Model results revealed changes in arrival order between the fastest/most directed individuals (first), slower/less directed individuals (second through fourth), and the slowest/least directed individuals (fifth through sixth) post-disturbance

(Fig. 3A-C). We detected a linear increase in the probability of arriving first with increasing speed; however, we observed a nonlinear increase in first arrival with increasing directedness (Fig. 4A). This also revealed a sigmoidal relationship between increasing direction in the proportion of individuals who successfully colonized (Fig. 
4B). This relationship was linear when considering increasing speed, indicating that arrival is more sensitive to changes in directedness than to changes in speed. Overall, our simulations revealed that increasing directedness had the greatest impact on improving species' arrival order. This determined that increasing speed decreased the probability of arriving last from 0.03 to 0.02 ; whereas, increasing directedness decreased the probability of arriving last from 0.12 to zero. Similar trends were revealed for the probability of arriving fourth, decreasing from 0.39 to 0.20 (speed alone) and from 0.37 to 0.01 (directedness alone).

\section{Discussion}

Early attempts at modeling animal movement evaluated two traits in diffusion models: speed (distance and time moving in a direction) and turning angle. These theoretical models have been applied extensively when developing ecological theory (DeAngelis et al. 2010), and we provide empirical evidence that post-disturbance colonization of fishes in a complex wetland can be predicted by these two movement parameters, speed and directedness. We found that speed and directedness, estimated independently for six fish species from field and laboratory studies, predicted the same order of recolonization following drought that was observed in a complex wetland over a 20-year period. Our results demonstrate that simple behavioral parameters from a theoretical model could apply to field settings and parameterize a simple yet predictive model. The model permitted us to investigate the relative contribution of each movement parameter to both arrival order and recolonization success and suggested that directedness has a non-linear relationship with colonization success; increasing directedness had a greater impact on the probability of early arrival than increasing speed. 
Interspecific variation in movement types contributes to maintenance of biodiversity and community persistence in disturbed ecosystems (Johst, Brandl \& Eber 2002; Armsworth \& Roughgarden 2005). Chesson (2000) described trade-offs among life-history traits, including those related to dispersal, that promote coexistence of competing species in nonequilibrium communities. Our study provides a detailed evaluation of traits linked to dispersal by describing interspecific variation in physiology (speed/endurance) and behavior (directedness). The ABM's demonstrate that increased directedness had a greater impact on colonization success than speed. For example, $L$. goodei had the lowest $\mathrm{U}_{\mathrm{CRIT}}$ estimate of all species but colonizes a newly inundated habitat earlier than both H. formosa and P. latipinna. Previous studies have revealed that L. goodei, unlike $P$. latipinna and $H$. formosa, respond to environmental fluctuations in a directional fashion (Goss, Loftus \& Trexler 2013; Hoch et al. 2015). This species' lack of speed was compensated by its ability to respond directionally to a changing environment and seems to grant it an advantage over faster species. Both P. latipinna and $H$. formosa, two non-directed species, often required multiple drying events before successful re-colonization, apparently because they lack or have limited directed movement.

As expected, endurance tests revealed critical swimming speeds to be greater than ambient speeds estimated in nature using drift fences. However, the rank order of critical swimming speeds were consistent with ambient speeds estimated in the field. For example, laboratory estimates revealed that J. floridae, G. holbrooki, and F. chrysotus were among the fast/high endurance species. Indirect estimates of speed derived from field data revealed that these three species were highly active and among the fastest of the 
six species (Obaza, DeAngelis \& Trexler 2011; Hoch et al. 2015; Bush 2017). Both field and laboratory data suggest that $J$. floridae and $G$. holbrooki are high endurance species that respond directionally to changing hydrology. Several studies have also described the rapid colonization potential of these two species (DeAngelis, Trexler \& Loftus 2005), and our models have demonstrated that their ability to rapidly colonize is directly related to physical endurance and directedness in movement. Additionally, our ABM's described species with low first-order arrival probabilities that were associated with slow, nondirected species. This was consistent with field data that described species with a life history associated with slow recovery following inundation (H. formosa, $P$. latipinna).Spatial dynamics and dispersal have become a central theme in ecological studies and models (Bowler \& Benton 2005). Understanding persistence of aquatic animals in wetlands, dryland rivers, and floodplains requires a dynamic spatial perspective (Gibbs 1993; Junk \& Wantzen 2004). Refuges from disturbance increase population resilience and act as a source of recolonization (Poff \& Ward 1990). Several studies have linked dispersal modes from source populations to recolonization success (Whitlatch et al. 1998; Negrello Filho, Underwood \& Chapman 2006). Our work has demonstrated individual behavioral and/or physiological characteristics are critical for increased resilience to disturbance on large spatial-temporal scales (Lancaster \& Belyea 1997; Matthews 2012). Modeling such complex characteristics on both small and large spatial scales has proven difficult for ecologists and is hindered by a major gap in our empirical understanding of the mechanisms of colonization (Patterson et al. 2008).

Although random dispersal has been the predominant movement described in ecology, there has been increasing integration of directed, or non-random, dispersal into 
ecological theory (Yurk 2016; Row et al. 2017). Advances in movement ecology have been driven by improved analyses that rely on error-correction, calculation of movement, and statistical analyses designed for pattern recognition to classify individuals based on movement types. These statistical approaches require movement data derived from a variety of sources, such as satellite telemetry, to make inferences on movement patterns (Fauchald \& Tveraa 2003; Austin, Bowen \& McMillan 2004; Patterson et al. 2008). Our models investigated movement from a unique prospective by applying both field and laboratory estimates of speed and directedness to simulate movement, analyzing possible outcomes of recolonization, and relating model output to observed recolonization patterns. Results here describe how behavioral (directedness) and physiological (speed) characteristics drive movement patterns in a natural setting. These results are emphasized with the use of both empirical and theoretical approaches to describe recolonization patterns in a complex landscape. The simplistic nature of our model also demonstrates that ecological processes can be described by two parameters without the need for sophisticated statistical analyses.

ABM's have improved ecologist's ability to model movement in complex systems and explore the consequences of interactions among individuals and their environment (Grimm 1999; DeAngelis \& Mooij 2005; Marceau 2008). We believe that the results from our ABM's are robust since we were able to compare results from our endurance tests and simulations to field estimates of speed and arrival order. Our ABM's provided an excellent medium to simulate colonization from refuge habitats and produced a simple model that proved effective in predicting dynamics of recolonization post-disturbance in a large ecosystem. Input data for our ABM's were gathered independently from 
laboratory and field observations of speed and directedness were enough to generate simulated colonization patterns. These results were then comparable to our field estimates of colonization and revealed that both speed and directedness are capable to describing complex recolonization patterns.

This study has demonstrated that colonization patterns can be predicted when a species' dispersal potential is quantified by estimating both speed and directedness. Also, we provide evidence that rapid colonization may not be correlated to population size. Our multi-method approach has improved our ability to understand post-successional dynamics and the mechanisms that drive biodiversity in spatially-dynamic communities. However, these models focused solely on the behavioral and physiological aspects of colonization. Differences in other traits such as fecundity, somatic growth, and competitive ability may play a vital role in allowing for species coexistence postcolonization (DeAngelis, Trexler \& Loftus 2005). Further studies on post-colonization dynamics are needed to fully understand the drivers of species coexistence and biodiversity.

\section{Acknowledgements}

This work was supported by the American Killifish Association George Maier Fund and by a Cooperative Agreement between Everglades National Park and FIU (Critical Ecosystem Science Initiative Task Agreement P06AC00043). We are grateful to Alan Katzenmeyer and Jan Hoover from the United States Army Corps of Engineers (USACE) for lending us their Blazka-style swim chamber. We thank Jeff Kline, Everglades National Park, for making available data from sites 6, 23, and 50. We would also like to thank Dr. Yannis Papastamatiou for introducing us to Netlogo and Mike 
Bush, Joseph Travis, and Don DeAngelis for feedback on earlier versions of the manuscript. This work was conducted under FIU Institutional Animal Use and Care permits IACUC-16-034 and IACUC-17-035. This material was developed in collaboration with the Florida Coastal Everglades Long-Term Ecological Research program under National Science Foundation Grant No. DEB-1237517. This is contribution No. XXX from the Southeastern Environmental Research Center of FIU.

\section{Authors' Contributions}

John Gatto helped design this study, conducted swim tunnel experiments, programed and carried out all data analyses and simulations, and wrote the manuscript.

Joel Trexler helped design this study, solicited funding for and supervised collection of long-term field data, collaborated on data analyses and manuscript writing.

\section{Data Availability Statement}

Data available from the Florida Coastal Everglades Long-Term Ecological Research webpage at $h$ ttp://fcelter.fiu.edu/data/.

\section{Works Cited}

Armsworth, P.R. \& Roughgarden, J.E. (2005) The impact of directed versus random movement on population dynamics and biodiversity patterns. The American Naturalist, 165, 449-465. 
Austin, D., Bowen, W. \& McMillan, J. (2004) Intraspecific variation in movement patterns: modeling individual behaviour in a large marine predator. Oikos, 105, $15-30$.

Baber, M.J., Childers, D.L., Babbitt, K.J. \& Anderson, D.H. (2002) Controls on fish distribution and abundance in temporary wetlands. Canadian Journal of Fisheries and Aquatic Sciences, 59, 1441-1450.

Blazka, P., Volf, M. \& Cepela, M. (1960) A new type of respirometer for the determination of the metabolism of fish in an active state. Physiol. Bohemoslov, 9, 553-558.

Bowler, D.E. \& Benton, T.G. (2005) Causes and consequences of animal dispersal strategies: relating individual behaviour to spatial dynamics. Biological Reviews, 80, 205-225.

Busch, D.E. \& Trexler, J.C. (2003) Monitoring ecosystems: interdisciplinary approaches for evaluating ecoregional initiatives. Island Press.

Bush, M.R. (2017) Experimental Analysis of the Effects of Hydroscape Structure on Fishes in a Dynamic Wetland.

Cadotte, M.W., Arnillas, C.A., Livingstone, S.W. \& Yasui, S.-L.E. (2015) Predicting communities from functional traits. Trends in Ecology \& Evolution, 30, 510-511.

Cote, J., Bestion, E., Jacob, S., Travis, J., Legrand, D. \& Baguette, M. (2017) Evolution of dispersal strategies and dispersal syndromes in fragmented landscapes. Ecography, 40, 56-73.

DeAngelis, D.L. \& Mooij, W.M. (2005) Individual-based modeling of ecological and evolutionary processes. Annu. Rev. Ecol. Evol. Syst., 36, 147-168.

DeAngelis, D.L., Trexler, J.C., Cosner, C., Obaza, A. \& Jopp, F. (2010) Fish population dynamics in a seasonally varying wetland. Ecological modelling, 221, 1131-1137.

DeAngelis, D.L., Trexler, J.C. \& Loftus, W.F. (2005) Life history trade-offs and community dynamics of small fishes in a seasonally pulsed wetland. Canadian Journal of Fisheries and Aquatic Sciences, 62, 781-790.

Domenici, P. \& Blake, R. (1997) The kinematics and performance of fish fast-start swimming. Journal of Experimental Biology, 200, 1165-1178.

Fauchald, P. \& Tveraa, T. (2003) Using first-passage time in the analysis of arearestricted search and habitat selection. Ecology, 84, 282-288. 
Fennema, R.J., Neidrauer, C.J., Johnson, R.A., MacVicar, T.K. \& Perkins, W.A. (1994) A computer model to simulate natural Everglades hydrology. Everglades: the ecosystem and its restoration, 249-289.

Fisher, R. \& Bellwood, D. (2002) The influence of swimming speed on sustained swimming performance of late-stage reef fish larvae. Marine Biology, 140, 801807.

Fisher, R.A. (1937) The wave of advance of advantageous genes. Annals of eugenics, 7, 355-369.

Fraser, C.I., Banks, S.C. \& Waters, J.M. (2015) Priority effects can lead to underestimation of dispersal and invasion potential. Biological Invasions, 17, 1-8.

Fukami, T. (2015) Historical contingency in community assembly: integrating niches, species pools, and priority effects. Annual Review of Ecology, Evolution, and Systematics, 46, 1-23.

Gibbs, J.P. (1993) Importance of small wetlands for the persistence of local populations of wetland-associated animals. Wetlands, 13, 25-31.

Goss, C., Loftus, W. \& Trexler, J. (2013) Seasonal Fish Dispersal in Ephemeral Wetlands of the Florida Everglades. Wetlands, 1-11.

Goss, C.W., Loftus, W.F. \& Trexler, J.C. (2014) Seasonal fish dispersal in ephemeral wetlands of the Florida Everglades. Wetlands, 1-11.

Grimm, V. (1999) Ten years of individual-based modelling in ecology: what have we learned and what could we learn in the future? Ecological modelling, 115, 129148.

Grimm, V., Berger, U., Bastiansen, F., Eliassen, S., Ginot, V., Giske, J., Goss-Custard, J., Grand, T., Heinz, S.K. \& Huse, G. (2006) A standard protocol for describing individual-based and agent-based models. Ecological modelling, 198, 115-126.

Hays, G.C., Ferreira, L.C., Sequeira, A.M., Meekan, M.G., Duarte, C.M., Bailey, H., Bailleul, F., Bowen, W.D., Caley, M.J. \& Costa, D.P. (2016) Key questions in marine megafauna movement ecology. Trends in Ecology \& Evolution, 31, 463475.

Hoch, J.M., Sokol, E.R., Parker, A.D. \& Trexler, J.C. (2015) Migration Strategies Vary in Space, Time, and Among Species in the Small-fish Metacommunity of the Everglades. Copeia, 2015, 157-169. 
Hohausová, E., Lavoy, R.J. \& Allen, M.S. (2010) Fish dispersal in a seasonal wetland: influence of anthropogenic structures. Marine and Freshwater Research, 61, 682694.

Huston, M. (1979) A general hypothesis of species diversity. American Naturalist, 81101.

Insititute, S. (2012) SAS 9.4 for Windows. SAS Institue Inc., Cary, NC, USA.

Jeltsch, F., Bonte, D., Pe'er, G., Reineking, B., Leimgruber, P., Balkenhol, N., SchröderEsselbach, B., Buchmann, C.M., Müller, T., Blaum, N., Zurell, D., BöhningGaese, K., Wiegand, T., Eccard, J.A., Hofer, H., Reeg, J., Eggers, U. \& Bauer, S. (2017) Integrating movement ecology with biodiversity research.

Johst, K., Brandl, R. \& Eber, S. (2002) Metapopulation persistence in dynamic landscapes: the role of dispersal distance. Oikos, 98, 263-270.

Junk, W.J. \& Wantzen, K.M. (2004) The flood pulse concept: new aspects, approaches and applications-an update. Second International Symposium on the Management of Large Rivers for Fisheries, pp. 117-149. Food and Agriculture Organization and Mekong River Commission, FAO Regional Office for Asia and the Pacific.

Lancaster, J. \& Belyea, L.R. (1997) Nested hierarchies and scale-dependence of mechanisms of flow refugium use. Journal of the North American Benthological Society, 16, 221-238.

Larsen, L., Aumen, N., Bernhardt, C., Engel, V., Givnish, T., Hagerthey, S., Harvey, J., Leonard, L., McCormick, P. \& McVoy, C. (2011) Recent and historic drivers of landscape change in the Everglades ridge, slough, and tree island mosaic. Critical reviews in environmental science and technology, 41, 344-381.

Leibold, M. A., and J. M. Chase. 2018. Metacommunity Ecology. Princeton University Press, Princeton, NJ.

Liu, Z., Volin, J.C., Dianne Owen, V., Pearlstine, L.G., Allen, J.R., Mazzotti, F.J. \& Higer, A.L. (2009) Validation and ecosystem applications of the EDEN watersurface model for the Florida Everglades. Ecohydrology, 2, 182-194.

Marceau, D. (2008) What can be learned from multi-agent systems. pp. 411-424. University of Arizona Press.

Matthews, W.J. (2012) Patterns in freshwater fish ecology. Springer Science \& Business Media. 
Méndez, V., Campos, D. \& Bartumeus, F. (2016) Stochastic foundations in movement ecology. Springer.

Nams, V.O. (2006) Detecting oriented movement of animals. Animal Behaviour, 72, 1197-1203.

Negrello Filho, O., Underwood, A. \& Chapman, M. (2006) Recolonization of infauna on a tidal flat: an experimental analysis of modes of dispersal. Journal of Experimental Marine Biology and Ecology, 328, 240-250.

Nickum, J., Bart Jr, H., Bowser, P., Greer, I., Hubbs, C., Jenkins, J., MacMillan, J., Rachlin, J., Rose, J. \& Sorensen, P. (2004) Guidelines for the use of fishes in research. FISHERIES-BETHESDA-, 29, 26-26.

Obaza, A., DeAngelis, D. \& Trexler, J.C. (2011) Using data from an encounter sampler to model fish dispersal. J Fish Biol, 78, 495-513.

Ogden, J., Davis, S., Jacobs, K., Barnes, T. \& Fling, H. (2005) The use of conceptual ecological models to guide ecosystem restoration in South Florida. Wetlands, 25, 795-809.

Okubo, A. (1994) The role of diffusion and related physical processes in dispersal and recruitment of marine populations. The Bio-physics of marine larval dispersal, 532.

Patterson, T.A., Thomas, L., Wilcox, C., Ovaskainen, O. \& Matthiopoulos, J. (2008) State-space models of individual animal movement. Trends in Ecology \& Evolution, 23, 87-94.

Plaut, I. (2001) Critical swimming speed: its ecological relevance. Comparative Biochemistry and Physiology Part A: Molecular \& Integrative Physiology, 131, 41-50.

Poff, N.L. \& Ward, J. (1990) Physical habitat template of lotic systems: recovery in the context of historical pattern of spatiotemporal heterogeneity. Environmental management, 14, 629 .

Porter, K.G. (2010) The Everglades, Florida Bay, and coral reefs of the Florida Keys: an ecosystem sourcebook. CRC Press.

Possingham, H.P. \& Roughgarden, J. (1990) Spatial population dynamics of a marine organism with a complex life cycle. Ecology, 71, 973-985.

Reynolds, A.M. \& Rhodes, C.J. (2009) The Lévy flight paradigm: random search patterns and mechanisms. Ecology, 90, 877-887. 
Row, J.R., Knick, S.T., Oyler-McCance, S.J., Lougheed, S.C. \& Fedy, B.C. (2017) Developing approaches for linear mixed modeling in landscape genetics through landscape-directed dispersal simulations. Ecology and evolution, 7, 3751-3761.

Shea, K., Roxburgh, S.H. \& Rauschert, E.S. (2004) Moving from pattern to process: coexistence mechanisms under intermediate disturbance regimes. Ecology Letters, 7, 491-508.

Skellam, J.G. (1951) Random dispersal in theoretical populations. Biometrika, 38, 196218.

Spiller, D.A., Schoener, T.W. \& Piovia-Scott, J. (2018) Recovery of food webs following natural physical disturbances. Annals of the New York Academy of Sciences, 1429, 100-117.

Symons, C.C. \& Arnott, S.E. (2014) Timing is everything: priority effects alter community invasibility after disturbance. Ecology and evolution, 4, 397-407.

Telis, P.A. (2006) The Everglades Depth Estimation Network (EDEN) for support of ecological and biological assessments. Geological Survey (US).

Tilman, D. \& Kareiva, P.M. (1997) Spatial ecology: the role of space in population dynamics and interspecific interactions. Princeton University Press.

Trexler, J.C., DeAngelis, D.L. \& Jiang, J. (2011) Ecology and evolution of poeciliid fishes Community assembly and mode of reproduction: predicting the distribution of livebearing fishes (eds J.P. Evans, A. Pilastro \& I. Schlupp), pp. 95-108. The University of Chicago Press, Chicago, IL [etc.].

Trexler, J.C., Loftus, W.F. \& Perry, S. (2005) Disturbance frequency and community structure in a twenty-five year intervention study. Oecologia, 145, 140-152.

Viswanathan, G.M. (2010) Ecology: Fish in Lévy-flight foraging. Nature, 465, 1018.

Waters, J.M., Fraser, C.I. \& Hewitt, G.M. (2013) Founder takes all: density-dependent processes structure biodiversity. Trends in Ecology \& Evolution, 28, 78-85.

Whitlatch, R.B., Lohrer, A.M., Thrush, S.F., Pridmore, R., Hewitt, J., Cummings, V.J. \& Zajac, R. (1998) Scale-dependent benthic recolonization dynamics: life stagebased dispersal and demographic consequences. Hydrobiologia, 375, 217-226.

Wilensky, U. (1999) Netlogo. Center for Connected Learning and Computer-Based Modeling, Northwestern University, Evanston, IL. 
Wolski, L.F., Trexler, J.C., Nelson, E.B., Philippi, T. \& Perry, S.A. (2004) Assessing researcher impacts from a long-term sampling program of wetland communities in the Everglades National Park, Florida, USA. Freshwater Biology, 49, 13811390.

Yurk, B.P. (2016) Homogenization of a directed dispersal model for animal movement in a heterogeneous environment. Bulletin of mathematical biology, 78, 2034-2056. 
Table 1 Restrictions and characteristics of the six virtual species (agents) used in the ABM's. Restrictions on orientation were used to produce varying levels of directedness.

\begin{tabular}{cccl}
\hline Species & $\begin{array}{c}\text { Restricted } \\
\text { Orientations }\end{array}$ & $\begin{array}{c}\text { Range of } \\
\text { Motion }\end{array}$ & \multicolumn{1}{c}{ Movement Type } \\
\hline Species 1 & No restriction & $360^{\circ}$ & Passive Diffusion \\
Species 2 & $180^{\circ+} /-15^{\circ}$ & $330^{\circ}$ & Cannot move due South \\
Species 3 & $180^{\circ} /-22.5^{\circ}$ & $315^{\circ}$ & Slightly directional \\
Species 4 & $180^{\circ+} /-45^{\circ}$ & $270^{\circ}$ & Increased directedness; cannot move between \\
& & & SW and SE \\
Species 5 & $180^{\circ+} /-67.5^{\circ}$ & $225^{\circ}$ & Highly directional \\
Species 6 & $180^{\circ+} /-90^{\circ}$ & $180^{\circ}$ & Highly directional; no southern heading \\
\hline
\end{tabular}


Table 2 The arrival probabilities for each species $(n=536)$ estimated from field data collected post-disturbance $\left({ }^{+} /-95 \% \mathrm{CI}\right)$. Some species arrived at the same sample event and were assigned the same ranks; probabilities were calculated by species, so columns but not rows sum to one.

\begin{tabular}{ccccccc}
\hline & \multicolumn{5}{c}{ Species } \\
\cline { 2 - 7 } $\begin{array}{c}\text { Arrival } \\
\text { Order }\end{array}$ & $\boldsymbol{J}$. floridae & $\boldsymbol{G . ~ h o l b r o o k i}$ & $\boldsymbol{F .}$ chrysotus & $\boldsymbol{L}$. goodei & H. formosa & $\begin{array}{c}\boldsymbol{P} \text {. } \\
\text { latipinna }\end{array}$ \\
\hline $1^{\text {st }}$ & $0.88(0.03)$ & $0.87(0.03)$ & $0.59(0.04)$ & $0.52(0.04)$ & $0.50(0.04)$ & $0.28(0.04)$ \\
$2^{\text {nd }}$ & $0.04(0.01)$ & $0.04(0.02)$ & $0.06(0.02)$ & $0.05(0.02)$ & $0.03(0.01)$ & $0.01(0.01)$ \\
$3^{\text {rd }}$ & $0.02(0.01)$ & $0.06(0.02)$ & $0.13(0.03)$ & $0.11(0.03)$ & $0.07(0.02)$ & $0.06(0.02)$ \\
$4^{\text {th }}$ & $0.02(0.01)$ & $0.03(0.01)$ & $0.11(0.03)$ & $0.12(0.03)$ & $0.14(0.03)$ & $0.09(0.02)$ \\
$5^{\text {th }}$ & $0.04(0.02)$ & $<0.01$ & $0.08(0.02)$ & $0.12(0.03)$ & $0.20(0.03)$ & $0.17(0.03)$ \\
$6^{\text {th }}$ & $<0.01$ & $<0.01$ & $0.03(0.01)$ & $0.08(0.02)$ & $0.06(0.02)$ & $0.39(0.04)$ \\
\hline
\end{tabular}


Table 3 Comparison of species dispersal characteristics from both laboratory and field studies. Direct estimates of speed were calculated following endurance tests (Mean ${ }^{+} /-$ $\mathrm{SE}$ ). Field measures of speed (Mean ${ }^{+} /-\mathrm{SE}$ ) were estimated using encounter samplers (Bush 2017). Observed directedness was taken from Hoch et al (2015).

\begin{tabular}{|c|c|c|c|c|}
\hline Species & $\begin{array}{c}\text { Arrival } \\
\text { Order }\end{array}$ & $\begin{array}{l}\text { Direct Estimate of } \\
\text { Speed }(\mathrm{cm} / \mathrm{s})\end{array}$ & $\begin{array}{l}\text { Field Estimate of } \\
\text { Speed }(\mathrm{cm} / \mathrm{s})\end{array}$ & $\begin{array}{c}\text { Observed } \\
\text { Directedness }\end{array}$ \\
\hline $\begin{array}{c}G . \\
\text { holbrooki }\end{array}$ & $1 \mathrm{st} / 2^{\text {nd }}$ & $22.86^{+} /-1.05$ & $9.75^{+} /-1.21$ & Directed \\
\hline J. floridae & $1^{\mathrm{st}} / 2^{\mathrm{nd}}$ & $19.23^{+} /-0.97$ & $13.25^{+} /-2.13$ & Directed \\
\hline $\begin{array}{c}F . \\
\text { chrysotus }\end{array}$ & $3^{\text {rd }}$ & $20.85^{+/}-1.45$ & $6.13^{+} /-0.74$ & Directed \\
\hline L. goodei & $4^{\text {th }}$ & $11.94^{+} /-0.45$ & $3.82+/-0.61$ & Directed \\
\hline H. formosa & $5^{\text {th }}$ & $12.39^{+} /-0.59$ & $\mathrm{~N} / \mathrm{A}$ & Undirected \\
\hline P. latipinna & $6^{\text {th }}$ & $16.40 \% /-1.15$ & $7.66^{+} /-1.55$ & Undirected \\
\hline
\end{tabular}


Table 4 Arrival probabilities for each species of simulated dispersal using ABM's and Kendall's Rank Correlation Coefficient $(\tau)$. Species are arranged left to right by decreasing levels of directedness. Some species arrived at the same sample event and were assigned the same ranks; therefore, only column values will sum to one. Kendall's Tau is calculated based on comparing values in the same row and columns (Arrival Order) from Table 2. Two asterisks (**) indicate significance at $\alpha=0.05$ and single asterisk $(*)$ indicates significance at $\alpha=0.10$.

\begin{tabular}{|c|c|c|c|c|c|c|c|}
\hline \multirow[b]{2}{*}{$\begin{array}{l}\text { Arrival } \\
\text { Order }\end{array}$} & \multicolumn{6}{|c|}{ Species } & \multirow[b]{2}{*}{$\begin{array}{c}\text { Kenda } \\
\text { Il's } \\
\text { Tau } \\
(\tau)\end{array}$} \\
\hline & Species 6 & Species 5 & Species 4 & Species 3 & Species 2 & Species 1 & \\
\hline $1^{\text {st }}$ & 0.65 & 0.28 & 0.07 & $<0.01$ & 0.00 & 0.00 & $0.89 * *$ \\
\hline $2^{\text {nd }}$ & 0.24 & 0.43 & 0.27 & 0.05 & 0.01 & $<0.01$ & 0.55 \\
\hline $3^{\text {rd }}$ & 0.10 & 0.19 & 0.42 & 0.26 & 0.17 & 0.09 & $0.69^{*}$ \\
\hline $4^{\text {th }}$ & 0.01 & 0.07 & 0.18 & 0.50 & 0.49 & 0.38 & $0.73^{*}$ \\
\hline $5^{\text {th }}$ & 0.00 & 0.03 & 0.06 & 0.18 & 0.31 & 0.41 & $0.73^{*}$ \\
\hline $6^{\text {th }}$ & 0.00 & $<0.01$ & $<0.01$ & 0.01 & 0.02 & 0.12 & $0.77^{*}$ \\
\hline $\begin{array}{c}\text { Column } \\
\tau\end{array}$ & 0.59 & $0.69 *$ & 0.33 & 0.00 & 0.20 & 0.28 & \\
\hline
\end{tabular}


Fig. 1 A visual representation of the virtual world for ABM's created in Netlogo. The original habitat (striped region) is located 1000m due south of refuge habitat (checkered region).

Fig. 2 Results of ANOVA with Tukey's Pairwise Comparisons on interspecific variation in $\mathrm{U}_{\text {CRIT. }}$ Three distinct groups were detected (Fast, Intermediate, Slow) and are indicated by the enclosure of the means in ellipses.

Fig. 3 Three-dimensional plot describing arrival probabilities based on speed/directedness combinations from the ABM's for A) Arriving First and B) Arriving Fourth. The horizontal axes for Figure $3 \mathrm{~B}$ were rotated $180^{\circ}$ to highlight differences between fast/directed and slow/non-directed. Arrival probabilities were calculated based on arrival time at the end of each simulated run. C) Observed field probabilities of arriving first based on a species estimated U CRIT and observed directedness in the field. $\mathrm{U}_{\text {CRIT }}$ was calculated from endurance tests. Directed species were assigned a value of 1 and non-directed species a value of 0 . Observed field probabilities were calculated based on species' arrival times following re-inundation of the habitat (Table 2).

Fig. 4 Probability plots of two metrics of recolonization potential: Speed and directedness. A) The probability of arriving first based on a species' level of directedness (independent of speed) and speed (independent of directedness). B) The proportion of each individual arriving at the refuge habitat after each run based on a species' level of directedness (independent of speed) and speed (independent of directedness). 
Fig. 1

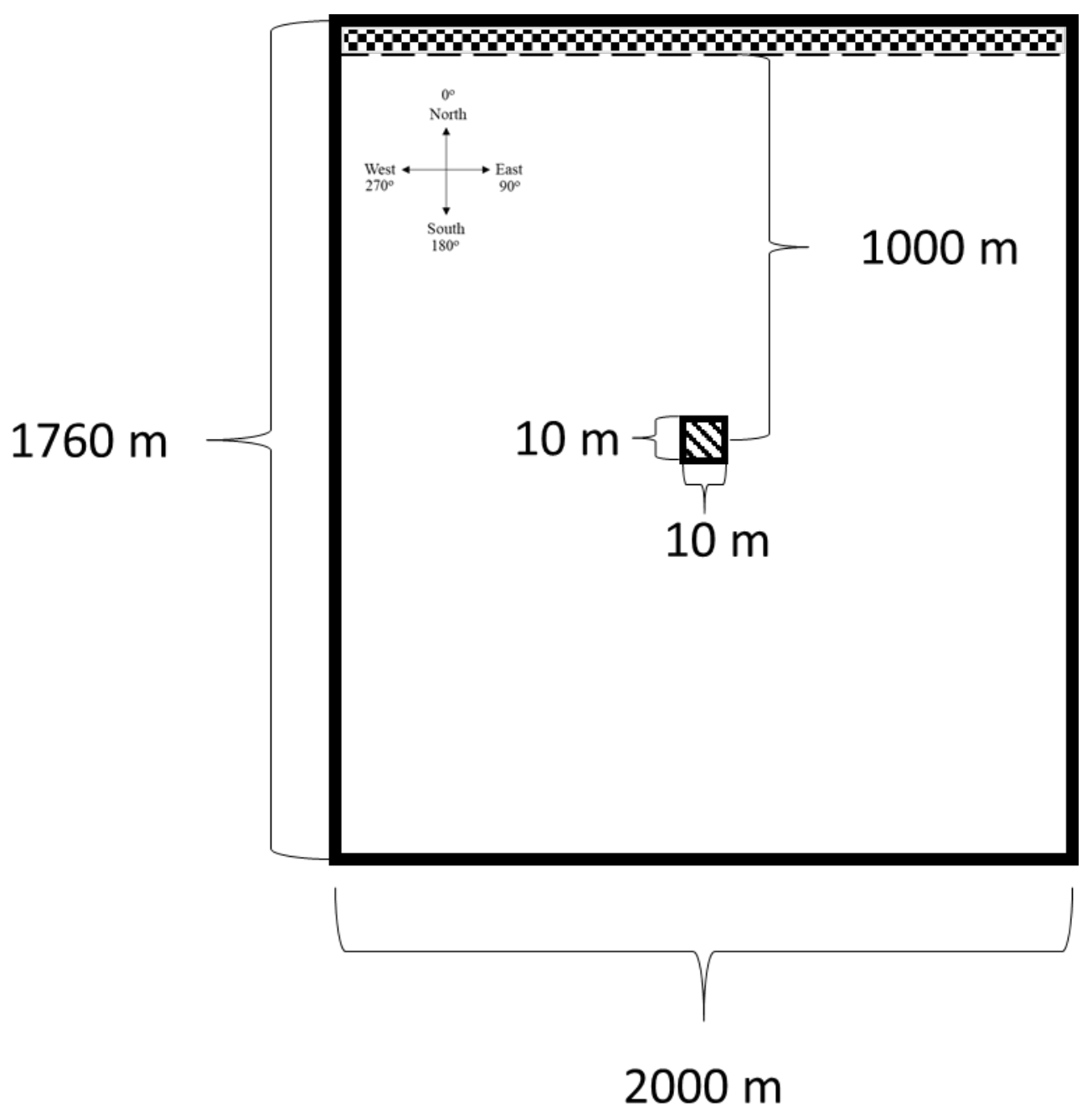


Fig. 2

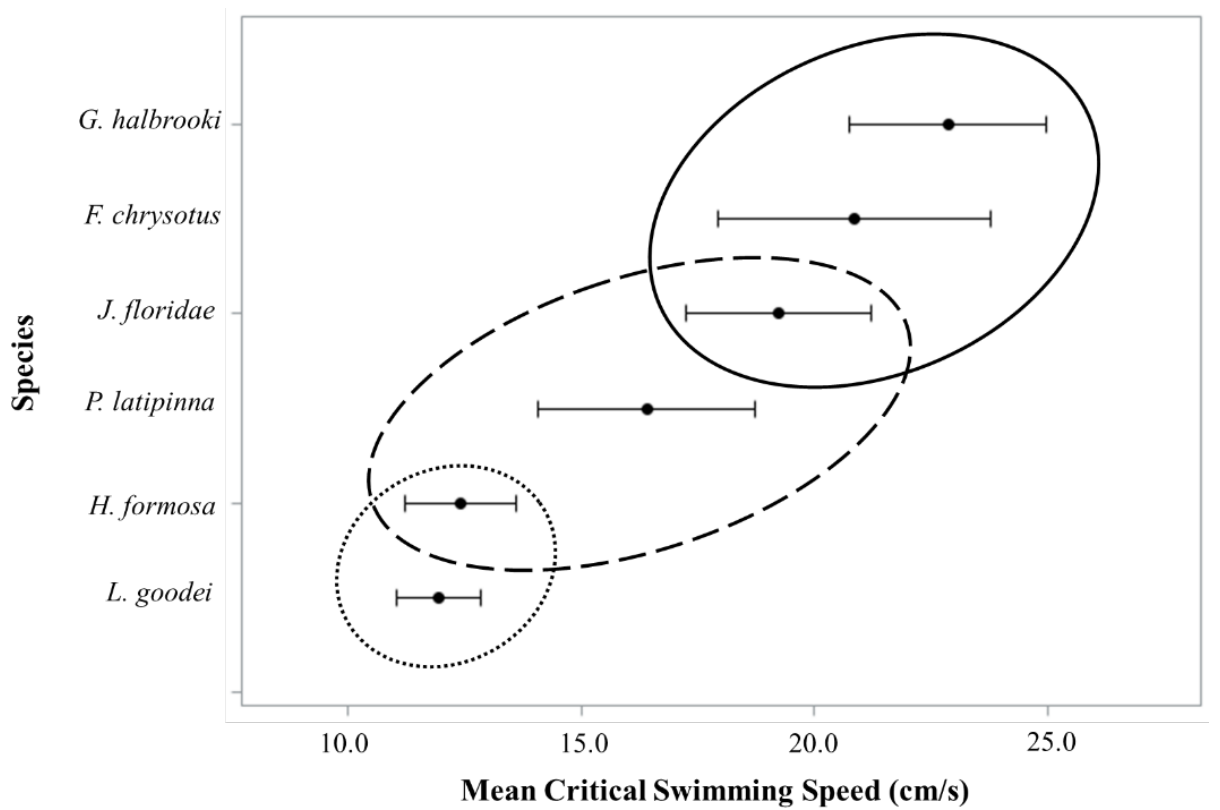


Fig. 3
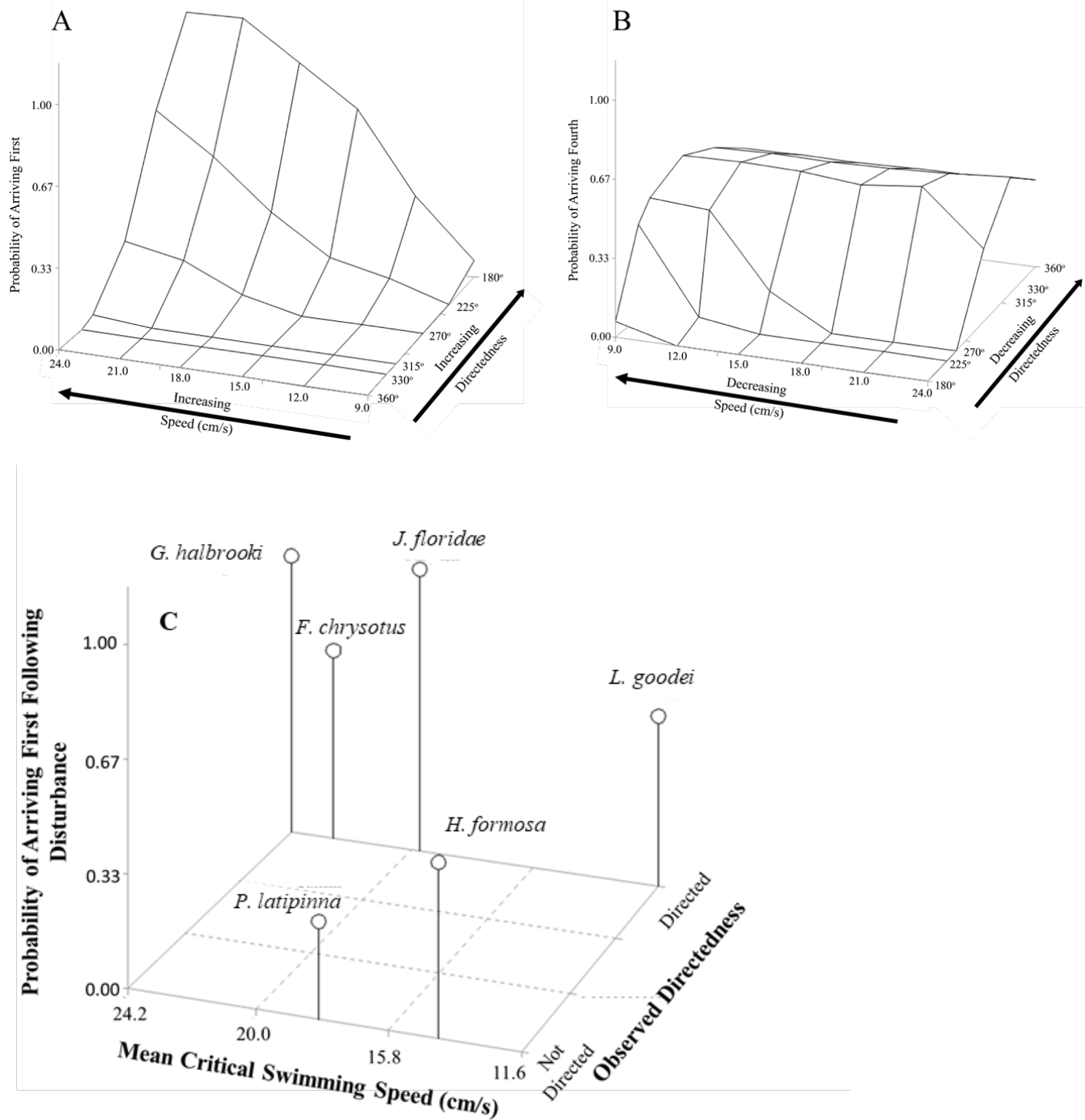
Fig. 4
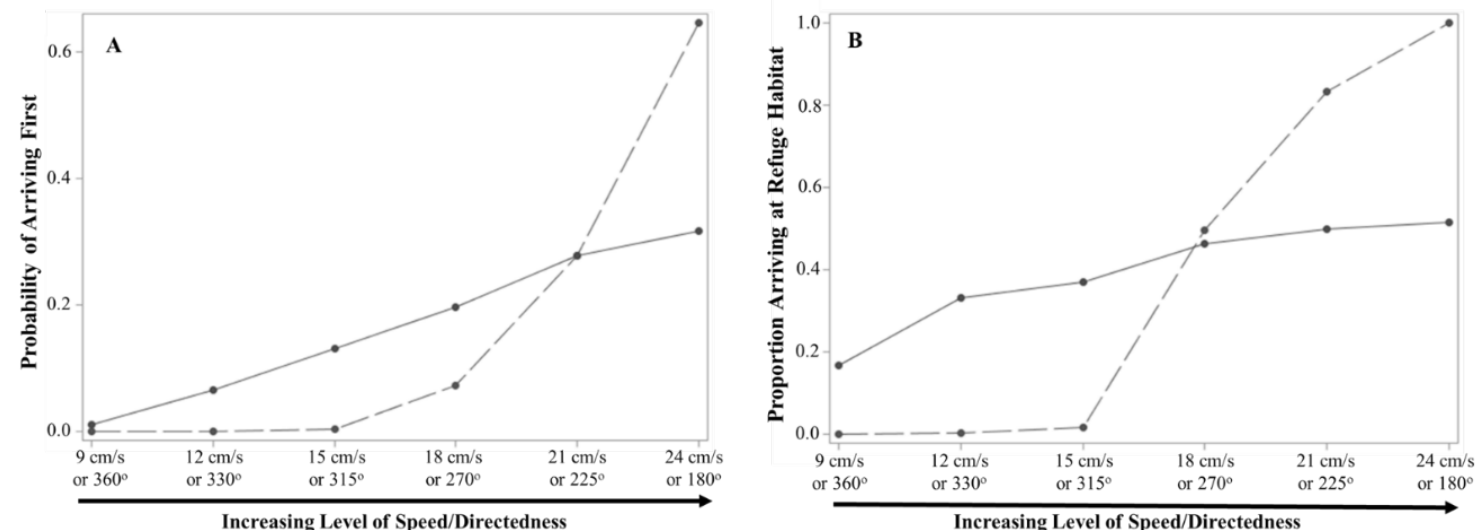

Directedness - - - - - Speed $\longrightarrow$ 


\section{CHAPTER V \\ LINKING AGE-SPECIFIC MORTLAITY AND GROWTH RATES TO ANNUAL CHANGES IN ABUNDANCE AND BIOMASS WITHIN A FLUCTUATING ENVIRONMENT}




\begin{abstract}
Identifying trends in species biomass is important for maintaining sustainable fish stocks and the management of anthropogenically modified ecosystems. Three key phases have been identified that are related to fluctuations in biomass production during early life. A "transitional stage", the size or age when age-specific mortality is equivalent to weightspecific growth $\left(\mathrm{M}^{\prime} / \mathrm{G}^{\prime}=1\right)$, has become an important indicator of recruitment success and cohort biomass production in sustainable fish stocks. In floodplain and wetland habitats, hydrology may contribute to biomass loss, but it is unclear how it influences the timing of this important transitional stage. We evaluated age-specific mortality and growth for six marsh fishes along a hydrological gradient. Fish were collected for three years at six hydrologically variable sites for analysis of age-specific growth rates. Individuals were aged using saggital otoliths and growth models were fit to length-at-age data. We estimated age-specific mortality by following 10-day cohorts in a 20 -year time series of population density collected at 21 sites in the Everglades. The transitional length/size was back-calculated using these relationships, log-transformed, and regressed against annual density and biomass. We compared the transitional length and size to hydrological variables generated from monitored water gauges at each site. Analysis of covariance revealed species-specific growth rates were not consistent among sites and years. On average, variability in mortality was 1.8 to 4.4 times greater than growth and variability increased as the environment became more stable. The ages and length at the transition stage also differed among Heterandria formosa $\left(8.82^{+} /-0.14\right.$ days), Gambusia holbrooki $\left(14.97^{+} /-0.13\right.$ days), Lucania goodei $\left(15.82^{+} /-0.18\right.$ days), Poecilia latipinna (24.66 ${ }^{+} /-0.77$ days), Jordanella floridae (28.17 ${ }^{+} /-0.62$ days), and Fundulus chrysotus
\end{abstract}


(30.08 $\%-0.46$ days). Annual changes in density were inversely correlated with the transitional age for most observations in the time series; however, there was a weak inverse relationship between the transition age and population biomass. The strong relationship with abundance and weak relationship with biomass indicated that there were periods of high adult recruitment (high abundance, high biomass) versus high juvenile recruitment (high abundance, low biomass) among sites. The mean transition age increased as disturbance intensity increased for G. holbrooki, L. goodei, H. formosa; however, evidence for this was weak for J. floridae, F. chrysotus, and P. latipinna. This may be caused by life history differences among these species associated with dispersal; two highly mobile species were less likely to have transitional ages that increase with disturbance intensity. The transition age is an important indicator of trends in species biomass and abundance; however, it is necessary to understand how movement strategies can alter this relationship when applying this information to management practices within hydrologically variable environments.

Keywords: recruitment; growth; mortality; disturbance; life history, Everglades fishes

\section{Introduction}

Investigating the biotic and abiotic controls of recruitment has become an integral part in understanding the population dynamics of fish species (Hjort 1914; Hjort 1926). Early life stage survival is the predominant focus of recruitment dynamics, with hypotheses proposing both density-independent (e. g., Stable Ocean Hypothesis) and some density-dependent (e. g., Match-Mismatch Hypothesis) processes that act on this 
vulnerable life stage (Cury and Roy 1989; Cushing 1990; Lasker 1981). Environmental variability tends to control survival rates of the pre-recruit stages and is more influential at earlier life stages than later ones (Fogarty et al. 1991). Other studies have focused more on individual growth, with faster growth being associated with better survival and higher recruitment levels (Beyer 1989; Ware 1975). Further evidence suggests a link between mortality, growth, and other physiological characteristics that describe a population's response to food availability (Beverton and Holt 1957, 1959).

Life cycles can be characterized by three phases during early life related to fluctuations in biomass production. These phases are related to the ratio of age-specific growth to mortality ( $\left.\mathrm{M}^{\prime} / \mathrm{G}^{\prime}\right)$, which best describes a species response to food availability (Cushing 1975). This ratio is most variable at the larval and juvenile stages, with subtle changes in growth and mortality having large implications on recruitment (Houde 1987). Cohort biomass tends to decrease when mortality is high relative to growth $\left(\mathrm{M}^{\prime} / \mathrm{G}^{\prime}>1\right)$ and increases when low relative to growth $\left(\mathrm{M}^{\prime} / \mathrm{G}^{\prime}<1\right)$. Therefore, the size or age when $\mathrm{M}^{\prime} / \mathrm{G}^{\prime}=1$ indicates a transitional phase that serves as an important indicator of potential recruitment success (Houde 1997). The timing of this transitional age/length can occur at any life stage, although they are most important in early life when recruitment levels are set. Fluctuation in species' growth and mortality rates are crucial to monitoring trends in species biomass in its implications for maintaining sustainable stocks and management practices within anthropogenically impacted ecosystems (McClanahan et al. 2015).

Hydrological processes in marine and freshwater ecosystems may contribute to changes in biomass by dispersing larvae to and from nursery areas or by inducing movement during drying and flooding events (Boehlert and Mundy 1988; Goss et al. 
2013). Favorable environments can promote larval growth and survival via enrichment of the habitat, concentration of prey, and hydrological retention of larvae (Bakun 1996; Bakun 1998). In floodplain ecosystems, this enhances recruitment by generating newly created habitats with abundant food sources for fish (Geddes and Puckridge 1989; Schiller and Harris 2001). Recruitment success of some fish species in inundated habitats is dependent on both the flood dynamics and life history characteristics that are adapted to exploit pulses in primary production (Zeug and Winemiller 2008; King et al. 2003). These adaptive characteristics include synchronization of reproductive strategy and migratory patterns with hydrology and phenotypic plasticity (Bailly et al. 2008; Denver 1997). It is still unclear how hydrological processes influences the timing of the transitional size or age linked to recruitment success.

Life history strategies have large implications for population regulation and fisheries management (Winemiller 2005). Stressful habitats are an integral part of shaping life history according to theory by favoring strategies to overcome adverse effects on survivorship, growth, and fertility (Cohen 1966; Rose 1959). These life history components are linked through complex trade-offs, which ultimately determine agespecific mortality schedules (Bertschy and Fox 1999; Roff 1984). We investigated both stage-specific mortality and somatic growth rates for several fish species inhabiting a diverse hydrological gradient. These estimates were compared among sites of varying hydrological disturbance to determine how hydrology influences life histories. This permitted us to evaluate how subtle differences in age-specific mortality and growth influence the transition age/length $\left(\mathrm{M}^{\prime} / \mathrm{G}^{\prime}=1\right)$ and recruitment in a pulsed floodplain ecosystem. 


\section{Methods}

Time series data

We used a 20-year time series of population density estimates that was collected between 1996 and 2016 to explore the controls of recruitment in 6 common marsh fishes inhabiting the Everglades, Florida, U. S. A. (Trexler et al. 2003). Fish were collected using a 1-m², 2-mm mesh, throw trap using a standard protocol (Jordan et al. 1997) at 21 monitoring sites (Supplemental Appendix 1). These sites were distributed in Shark River Slough (SRS), Taylor Slough (TSL), and Water Conservation Areas (WCA) 3A and 3B. Samples were collected in five months of each year (July, October, December, February, and April), with water-year sampling starting in July (early in South Florida wet season) and ending in April of the following year (late in South Florida dry season). Three or five plots were selected at each site, and five (WCA 3A and 3B) or seven (SRS, TSL) throw-trap samples were collected within a plot. Sites located in WCA 3A and 3B yielded 75 samples per year ( 3 plots x 5 throws x 5 sample events), while sites in SRS and TSL yielded 105 samples per water-year (3 plots x 7 throws per plot x 5 sample events); in dry years requiring helicopter access, 5 throws were taken per plot. The location of each throw within each plot was determined using a random number table. Plot sizes varied from $10,000 \mathrm{~m}^{2}(100 \mathrm{~m} \times 100 \mathrm{~m})$ to $2,100 \mathrm{~m}^{2}(70 \mathrm{~m} \times 30 \mathrm{~m})$, depending on surrounding vegetation and availability of sampleable habitat (Trexler et al. 2003; Trexler et al. 2002). After securing the trap, floating mat volume (submerged aquatic vascular plants, periphyton, etc), water depth, and emergent plant stem counts (by species) were recorded before fish and macroinvertebrates were removed following a standardized protocol of sweeps with a bar seine and dip nets (Jordan et al. 1997). Long- 
term monitoring at these sites from July, 1996, to April, 2016, (20 water years) yielding over 20,000 community samples with over 400,000 fish and invertebrates. There is no evidence of visitor impact on these long-term study sites, possibly because randomization makes revisiting sampling points unlikely, marsh plants re-grow quickly, and periodic marsh drying overwhelms sampler impacts on vegetation and soil (Wolski et al. 2004). From these samples, we report estimates of annual density (individuals $/ \mathrm{m}^{2}$ ), size-specific mass of individuals of a species (g), and annual biomass (summed mass of all individuals of the same species in a year, $\mathrm{g} / \mathrm{m}^{2}$ ).

To assure adequate sample sizes for this study, only the six most common fish species were used. These species were Bluefin Killifish Lucania goodei, Least Killifish Heterandria formosa, Flagfish Jordanella floridae, Sailfin Molly Poecilia latipinna, Eastern Mosquitofish Gambusia holbrooki, and Golden Topminnow Fundulus chrysotus. Age estimates from otolith analyses suggest that the typical lifespan of these species is much less than one year in the Everglades (Haake and Dean 1983; Konnert 2002). The age at sexual maturity for these species is between 30 and 90 days, less than or similar to the time between sequential samples. Thus, the 100 sequential samples in this study (20 years x 5 samples per year) represent between 34 and 51 generations for each species.

\section{Species-Specific Growth Rates}

We investigated the effect of hydroperiod on species-specific growth rates by collecting fish at sites with varying levels of hydrological disturbance. Fish were collected from two long- hydroperiod ( $<4$ drying events in 20 years, WCA 04 and 05 ), two intermediate-hydroperiod (4-12 drying events in 20 years, SRS 07 and WCA 02), 
and two short-hydroperiod sites ( $>12$ drying events in 20 years, TSL MDsh and WCA 03) every October from 2014 to 2016 . Historical age-at-length data (collected between 1996 and 2016) for P. latippina, J. floridae, and L. goodei were also available for growth curve analysis at sites SRS 50, SRS 37, WCA 08, WCA 04, and WCA 05.

Fish standard length (mm), wet mass (g), and sex (male, female, juvenile) were recorded prior to otolith extraction. Each pair of sagittal otoliths were removed using a $20 \%$ bleach solution for 12 females and 12 juveniles. These otoliths were then rinsed with deionized (DI) water and stored. Otoliths were cleaned of any remaining organic matter with $90 \%$ ethanol, dried, and embedded in Spurr low-viscosity embedding resin (10g VCD, 26g NSA, 6g DER 736, and 0.4g DMAE (Spurr 1969)). A Spurr-resin block was created by heating the resin overnight at $70^{\circ} \mathrm{C}$. Embedded otoliths were then sanded down and polished to create a thin section. One side of the otolith was sanded to the sagittal plane and attached to a microscope slide using Crystalbond ${ }^{\mathrm{TM}}$ adhesive. The remaining side was then sanded and polished to create a thin cross-section which exposed otolith growth rings. Otoliths were then etched using a $10 \% \mathrm{HCl}$ solution prior to counting (Konnert 2002).

To evaluate species-specific growth rates, we considered three popular growth models to determine which model best fit our age-at-length data. The three candidate models were the Von Bertalanffy (VBGM), Gompertz (GGM), and Logistic (LGM) growth models (Kaufmann 1981). Multimodel Inference (MMI) using Akaike information criterion (AIC) then determined which of the three candidate models best explained our data (Burnham and Anderson 2004). We then used non-linear least squares (NLS) with the Newton optimization method to estimate two parameters (growth 
parameter $K$ and $t_{0}$ ). $L_{\infty}$ was not estimated using these models but assigned to each species based on the maximum length observed in the time series ( $F$. chrysotus $=80 \mathrm{~mm}, G$. holbrooki $=47 \mathrm{~mm}, H$. formosa $=43 \mathrm{~mm}, J$. floridae $=55.35 \mathrm{~mm}, L$. goodei $=44.4 \mathrm{~mm}, P$. latipinna $=68 \mathrm{~mm}$ ). These estimates were similar to those used in previous growth studies on the same species in the Everglades (Haake and Dean 1983). Length-specific growth rates were then calculated using the differential equation for the best model $(\triangle \mathrm{AIC}=0)$. Length-mass relationships were calculated using ordinary least squares (OLS) regression based on log-transformed mass and length data. An Analysis of Covariance (ANCOVA) was used to compare both the length-at-age and length-mass relationships across sites and water-years within sites for each species. We substituted model-predicted values of length as the response variable for the length-at-age data since three different growth curves were represented.

\section{Species-Specific Mortality}

We evaluated species-specific mortality rates by using abundance-at-length data (catch curves) from a 20 -year time series dataset. These data generated catch curves for each species across each site and water year to estimate the instantaneous mortality rate (M). Following the methods of Gatto and Trexler (2019), we applied a generalized linear model to the adult cohorts within the abundance-at-length data to linearize the discretetime model:

$$
N_{t}=N_{0}^{-M t}
$$

where $\mathrm{N}_{\mathrm{t}}$ is the population size at length $l, \mathrm{~N}_{0}$ is the initial population size, and $M$ is the instantaneous mortality rate (individuals per unit time). We fit a negative binomial error 
distribution because the response variable (cohort abundance) was estimated as integers (counts). To account for the annual lifespan of these species ( $<300$ days), every wateryear was treated separately by producing a single model for each site by water-year (JulyApril), creating a maximum of 420 (21 sites x 20 water-years) cohort models for each species (Gatto and Trexler 2019).

Following our length-based approach, we investigated the age-specific mortality by classifying individuals into several distinct age classes. We accounted for the rapid life history of these species by generating both 10-day and 30-day cohorts. Preliminary analysis comparing these revealed that the 10-day cohort analysis was more robust. This divided the species into 31 different classes instead of 11 unique classes. Age was backcalculated using the age-at-length data by rearranging each growth curve in terms of length. We then determined the abundance-at-age and calculated the instantaneous mortality rate $(M)$ for each species at each site and wateryear. Generalized linear models using a negative binomial error distribution were then applied to cohorts $>30$ days. To test the main effects of length/age, site, and water years within sites on cohort abundance, we applied a generalized linear mix model (GLMM) using a negative binomial error distribution to our catch curves. We also included the interactions of length/age on both site and wateryear within site. We used GLMM with a negative binomial error distribution to model count data (Stroup 2015).

\section{$M / G$ Ratio and the Transitional Size and Age}

The length-mass relationships and our estimates of $M$ were used to investigate changes in the $\mathrm{M}^{\prime} / \mathrm{G}^{\prime}$ across life history. We evaluated both age and length specific 
changes in the $\mathrm{M}^{\prime} / \mathrm{G}^{\prime}$ by log-transforming the relationship between stage-specific survival and mass:

$$
\frac{N_{S}}{N_{s-1}}=\exp \left(-M_{S}\right)=\left[\frac{w_{s}}{w_{s-1}}\right]^{-M / G}
$$

where $\mathrm{N}_{\mathrm{s}}$ and $\mathrm{N}_{\mathrm{s}-1}$ are cohort abundances at two stages and $\mathrm{W}_{\mathrm{s}}$ and $\mathrm{W}_{\mathrm{s}-1}$ are fish masses at two stages. Our length-based approach defined subsequent stages $(s, s-1)$ as growing from one millimeter $(s-1)$ to the next (s). Subsequent age-based stages were defined as surviving from one 10-day cohort (s-1) to the next (s). Our estimates of $M$ were substituted for $M_{\mathrm{s}}$, and both $\mathrm{W}_{\mathrm{s}}$ and $\mathrm{W}_{\mathrm{s}-1}$ were calculated from length-mass relationships for each species, site, and water year. Age-based methods used the mass calculated from the estimated length at the end of each 10-day cohort. The stage-specific mortality rates were then estimated by multiplying the stage-specific $\mathrm{M}^{\prime} / \mathrm{G}^{\prime}$ by the stage-specific growth rate for both age and length-based methods. Since the M'G' ratio was observed to decline as a power function of larval mass, we fit a nonlinear model to the $\mathrm{M} / \mathrm{G}$ as a function of both age class and length (Houde 1997). We validated these models by regressing the model-predicted values against the observed values. Finally, the size and age of the transition stage $\left(\mathrm{M}^{\prime} / \mathrm{G}^{\prime}=1\right)$ was calculated by setting $\mathrm{M}^{\prime} / \mathrm{G}^{\prime}=1$ and solving the nonlinear model in terms of length or age.

\section{Time Series Analysis}

We investigated how the timing of the transition period related to changes in species abundance and biomass using a 20 -year time series data set. The previously 
described methods were used to calculate the age and length-specific $\mathrm{M}^{\prime} / \mathrm{G}^{\prime}$ ratios for all sites and wateryears within the time series dataset. For sites and wateryears that were outside the scope of our growth study, we used length-mass relationships from the literature to calculate the stage-specific mass (Kushlan et al. 1986). Ages for our agespecific approach were calculated using our age-at-length data when available. We pooled our length-at-age data for each species and approximated a VBGM to substitute a growth curve for the remaining sites and wateryears. We found the use of a pooled growth curve for aging fish could accurately age individual fish based on their length since the use of 10-day cohorts was very robust.

We used linear regression to determine the relationship between the transition period and annual changes in abundance for each species. We considered annual biomass and abundance (response variables) and both the transition age (age $\mathrm{M} / \mathrm{G}=1$ ) and size (length $\mathrm{M} / \mathrm{G}=1$ ) for each wateryear (independent variable). To account for unequal sample sizes, we calculated biomass density $\left(\mathrm{g} \mathrm{m}^{-2}\right)$ and species density (individuals $\mathrm{m}^{-2}$ ) based on the number of throw trap samples collected that year. These variables were logtransformed and regressed using OLS for each species at each site. We then compared sites within regions using a nested ANCOVA and tested the interaction among sites and the transition period for each species.

We investigated the effect of hydrology on the timing of this important life history characteristic. Hydrology data extracted from the Everglades Depth Estimation Network (EDEN) were used to determine the number of drying events at each site. EDEN uses water-surface models to interpolate measured water depths at monitored 
gauges to estimate daily water depth at our study sites (Liu et al. 2009; Telis 2006). We used these data to create two count variables, days since the site was last dry (DSD) and annual hydroperiod. DSD records the cumulative number of days since gauges recorded a water depth $<5 \mathrm{~cm}$ for each sampling event. At $5 \mathrm{~cm}$, only a slurry of organic matter remains, and fish generally suffocate in the low oxygen conditions and organic matter blocking their gills. Annual hydroperiod, a metric of disturbance intensity, records the cumulative days that water was $>5 \mathrm{~cm}$ within a wateryear. A drying event occurred when $\mathrm{DSD}_{\mathrm{t}+1}<\mathrm{DSD}_{\mathrm{t}}$ indicating a reset of this count variable. Another metric of hydrological disturbance, disturbance frequency, was calculated based on the number of drying events that occurred between 1996 and 2016.

To determine the effect of hydrology on the transition stage, we investigated both disturbance intensity (site hydroperiod) and disturbance frequency (number of drying events). We regressed the transitional stage against both annual hydroperiod and a squared term $\left(\mathrm{Hydro}^{2}\right)$ for each species to determine if annual variation in the timing of the transition stage was influenced by the number of days a site was inundated. The coefficient of variation for hydroperiod, a metric of variability in disturbance intensity, was calculated using the annual hydroperiod for each site across the 20 years of the time series. This was then regressed against the $\mathrm{CV}$ of transition period using OLS to determine if variability in the transition period was driven by variability in disturbance intensity. Finally, a general linear model was applied to our data to examine how either the length or age of the transition stager (response variable) for each species was influenced by disturbance frequency (independent variable). 


\section{Results}

\section{Species-Specific Growth}

Our analyses produced 79 different growth models for six species across eight different sites and six different years. MMI revealed that the VBGM best described our age-at-length data $(\triangle \mathrm{AIC}=0)$ for most sites and wateryears $(76.0 \%)$. Model-predicted values of length were highly correlated with observed values for F. chrysotus (Mean $\left.\mathrm{R}^{2}=0.97^{+} /-0.002\right)$, G. holbrooki $\left(\right.$ Mean $\left.\mathrm{R}^{2}=0.96^{+} /-0.004\right)$, H. formosa $\left(\right.$ Mean $\mathrm{R}^{2}=0.95$ $\left.{ }^{+} /-0.01\right)$, J. floridae (Mean $\left.\mathrm{R}^{2}=0.84^{+} /-0.04\right)$, L. goodei $\left(\right.$ Mean $\left.\mathrm{R}^{2}=0.95^{+} /-0.01\right)$, and $P$. latipinna $\left(\right.$ Mean $\left.\mathrm{R}^{2}=0.85^{+} /-0.05\right)$. Our ANCOVA revealed a significant positive relationship between otolith ring count (e.g. L. goodei, main effect: $F_{1,497}=30,36, \mathrm{p}<0.05$ ) and the model predicted length that differed among sites, and wateryears within a site, for all six species. The slopes of these relationships were also different among sites (age $\mathrm{X}$ site interaction: $\left.F_{8,497}=136.72, \mathrm{p}<0.05\right)$ and wateryears within sites (age $\mathrm{X}$ wateryears within sites interaction: $\left.F_{14,497}=82.13, \mathrm{p}<0.05\right)$. There was insufficient replication in growth curves for $J$. floridae (one wateryear per site) to test differences among wateryears within a site. Observed differences were driven by subtle differences in the growth parameter $K$ (Table 1). Although we found significant differences in speciesspecific growth rates among sites and wateryears, we did not find any differences in $K$ among hydroperiods.

We compared 60 different length-weight relationships for four of the six species in this study. Individual weights were highly correlated with length for all species included in this analysis $\left(\mathrm{R}^{2}>0.89\right)$. Our ANCOVA revealed a significant positive relationship between both individual weight and length for all species. However, the 
regression coefficients of these length-weight relationships were not different among sites (site interaction: $F_{5,264}=1.06, \mathrm{p}=0.38$ ) or wateryears for $H$. formosa (wateryears within sites interaction: $\left.F_{6,264}=0.29, \mathrm{p}=0.94\right)$. Furthermore, the main effects of site were not significant for $H$. formosa $\left(F_{5,264}=0.97, \mathrm{p}=0.44\right)$ and $G$. holbrooki $\left(F_{5,396}=2.05, \mathrm{p}=0.07\right)$.

We also did not find a significant relationship between the main effect of wateryear within site for $F$. chrysotus $\left(F_{6,264}=1.10, \mathrm{p}=0.36\right)$ and $H . F_{0 r m o s a}\left(F_{6,264}=0.43, \mathrm{p}=0.86\right)$. Species-Specific Mortality

Our length-based approach generated catch curves for all species and allowed us to estimate length-based instantaneous mortality rates $(M)$. Model-predicted values were highly correlated with observed values, and we detected no significant lack of fit. The relationship between abundance and length was significant for all species $(p<0.001)$. The slope $(M)$ was found to be different among sites and wateryear within sites for $G$. holbrooki, J. floridae, and L. goodei. Although we found differences among sites for $H$. formosa, we found no differences among wateryears within a site. No significant interaction was detected for either $F$. chrysotus or P. latipinna indicating no spatialtemporal differences in the slopes of the catch curves. Our estimates of $M$ were different among hydroperiods for G. holbrooki and H.formosa (Figure 1A); however, there was some support for differences among hydroperiods for $F$. chrysotus and L. goodei ( $\mathrm{p}=0.07$ for both species).

Our age-based approach produced different results for each species when compared to our length-based methods. Similar to length, a significant negative relationship between abundance and age class was detected for all species. We found significant temporal variation and spatial variation at both local and regional scales for 
both $G$. holbrooki and P. latipinna. Significant interactions $(\mathrm{p}<0.001)$ for these species revealed that the slopes of catch curves were different among sites and wateryears within a site. Although we found a similar pattern with J. floridae, the lack of replication prevented us from testing differences between wateryears. We detected no significant interaction between age class and site for both $L$. goodei $\left(F_{8,713}=1.51, \mathrm{p}=0.15\right)$ and $F$. chrystous $\left(F_{6,372}=1.19, \mathrm{p}=0.31\right)$ indicating no spatial differences in the slope of these catch curves. Furthermore, no significant interaction between age class and wateryear was found for $H$. formosa $\left(F_{6,372}=1.37, \mathrm{p}=0.23\right)$ and $F$. chrystous $\left(F_{6,372}=1.46, \mathrm{p}=0.19\right)$. Annual estimates of $M$ also varied for each species (Table 2); however, age-based estimates of $M$ only differed among hydroperiods for G. holbrooki and H. formosa (Figure 1B).

The Transitional Length/Age, Abundance, and Biomass

Our time series analysis revealed spatial-temporal trends in both mortality and growth for all species. The calculated M'/G' ratio for each size/age derived from Equation 2 was highly correlated with model-predicted values and declined exponentially as a function of both length (Mean $\mathrm{R}^{2}=0.99^{+} /-0.09$ for all species) and age class (Mean $\mathrm{R}^{2}=0.98^{+} /-0.07$ for all species). We also found evidence that the shape of these curves differed among hydroperiods for some species (Figure 2). These curves revealed that the transition period occurred earlier at long-hydroperiod sites compared to shorter ones. Spatial-temporal differences in stage-specific $\mathrm{M}^{\prime} / \mathrm{G}^{\prime}$ were driven by larger differences in M' among hydroperiods than G'. On average, interannual variability in mortality was 1.8 to 4.4 times greater than growth and this variability increased as the environment became 
more stable (Table 3). Analysis of stage-specific $\mathrm{M}^{\prime} / \mathrm{G}^{\prime}$ revealed that the transitional age/length occurred early in life history for all species when considering both length and age class. On average, the transitional age occurred within $8.82^{+} /-0.14$ days for $H$. formosa, $14.97^{+} /-0.13$ days for G. holbrooki, $15.82^{+} /-0.18$ days for $L$. goodei, $24.66^{+} /-$ 0.77 days for $P$. latipinna, $28.17^{+} /-0.62$ days for $J$. floridae, and $30.08^{+} /-0.46$ days for F. chrusotus. We detected spatial-temporal differences in the onset of the transitional age for all species; however, the transitional age was not different at regional spatial scales for $F$. chrysotus $\left(\mathrm{F}_{2,237}=0.78, \mathrm{p}=0.46\right)$ and local spatial scales for $J$. floridae $\left(\mathrm{F}_{18,314}=1.55\right.$, $\mathrm{p}=0.07)$. Length-based methods revealed that the transition size occurred slightly later in life than age-based methods. The transition size occurred at $28.88^{+} /-0.76 \mathrm{~mm}$ for $F$. chrusotus, $11.79^{+} /-0.34 \mathrm{~mm}$ for G. holbrooki, $7.64^{+} /-0.15 \mathrm{~mm}$ for $H$. formosa, $13.71^{+} /-$ $0.75 \mathrm{~mm}$ for $J$. floridae, $11.1^{+} /-0.23 \mathrm{~mm}$ for $L$. goodei, and $26.89^{+} /-2.53 \mathrm{~mm}$ for $P$. latipinna. Contrary to the transition age, spatial-temporal differences in the transition size were only found for G. holbrooki, H. formosa, and L. goodei.

Annual abundance decreased as the transitional age occurred later in life history for each species (Fig 3). This revealed a negative correlation between the transitional period and annual abundance for $92.1 \%$ (age-based) and $77.8 \%$ (length-based) of all species/site combinations (e.g. L. goodei, Figure 4). Of those models, 50.8\% (age-based) and $38.8 \%$ (length-based) revealed a significant correlation between abundance and the transition age/length. This relationship was weakest for $F$. chrysotus (Mean $\mathrm{R}^{2}=0.17^{+} /$0.04 ) and strongest for $L$. goodei (Mean $\mathrm{R}^{2}=0.46^{+} /-0.06$ ). We detected spatial-temporal differences in this relationship; however, these did not differ at local spatial scales for $F$. chrysotus, G. holbrooki, J. floridae, and P. latipinna. We also found a decline in model 
fit when using length-based methods. Annual abundance was also negatively correlated with the transitional length, with this relationship weakest for $J$. floridae (Mean $\mathrm{R}^{2}=0.12$ $+/-0.03$ ) and strongest for L. goodei $\left(\right.$ Mean $\left.\mathrm{R}^{2}=0.42^{+} /-0.05\right)$. Regional variability was only present for $H$. formosa and L. goodei, although we did detect local scale variability for P. latipinna and J. floridae.

Annual differences in the transition period poorly described changes in biomass for all species in the study. Although our analyses revealed a negative correlation between the transitional period and annual biomass for $69.1 \%$ (age-based) and $59.5 \%$ (length-based) of all species/site combinations, only 22.2\% (age-based) and 34.7\% (length-based) demonstrated a significant correlation between annual biomass and the transition period. Biomass was weakly correlated with the transition age, with the strength of this relationship highest for L. goodei (Mean $\left.\mathrm{R}^{2}=0.30^{+} /-0.06\right)$ and weakest for $J$. floridae $\left(\right.$ Mean $\left.\mathrm{R}^{2}=0.08^{+} /-0.03\right)$. Our ANCOVA revealed that the transition age was not correlated with biomass for either $J$. floridae or P. latipinna. We also only found spatial-temporal differences in this relationship for H. formosa and L. goodei when considering age-based methods. On average, length-based methods revealed no improvement in model fit for any species. This revealed that biomass was not significantly correlated with the transition size for P. latipinna, J. floridae, G. holbrooki, and $F$. chrysotus. We also found no spatial-temporal differences in this relationship for any species except $H$. formosa and $L$. goodei.

Hydrology and the Transitional Size/Age 
Time series analysis revealed changes in species abundance and biomass across the hydrological gradient. Species density was highest at long-hydroperiod sites compared to intermediate and short-hydroperiod sites for all species except $F$. chrysotus and $J$. floridae. Although the density of $J$. floridae was highest at short-hydroperiod sites, there was no difference in density across hydroperiod types (Figure 5A). Trends in biomass indicated a similar pattern to abundance for F. chrysotus, G. holbrooki, H. formosa, and J. floridae. Biomass increased for L. goodei when comparing short and intermediate-hydroperiod sites but peaked at intermediate hydroperiod. No differences in species biomass was found for J. floridae and P. latipinna (Figure 5B). These trends were driven by changes in the timing of the transition age (Figure 5C) and transition size (Figure 5D).

Hydrological disturbance influenced the length and age of the transition for 3 of the 6 study species. Our analyses indicated that disturbance intensity (Hydroperiod and Hydro $^{2}$ ) was not significantly correlated with the age or size at transition. These variables explained little variation in the models $\left(\mathrm{R}^{2}<0.03\right.$ for all species) and no significant slopes were detected (e.g., H. formosa, Fig. 6A). The CV of the transition age and length was also not correlated with hydrological variability within a site (CV Hydroperiod) for any species (Fig. 6B). Age-based methods revealed that the number of drying events a site experienced (disturbance frequency) increased the timing of the transitional age and length for all species except $J$. floridae (e.g. age-based methods, Fig. 7). These effects were greatest for $L$. goodei ( $\sim 13.65$ days at 0 disturbances and increased to $\sim 27.05$ days at 20 disturbances) and H. formosa ( $\sim 8.85$ days at 0 
disturbances and increased to $\sim 12.06$ days at 20 disturbances). Furthermore, lengthbased methods revealed that the transitional period was not influenced by disturbance intensity for $F$. chrysotus $\left(\mathrm{F}_{1,229}=0.93, \mathrm{p}=0.36\right), J$. floridae $\left(\mathrm{F}_{1,229}=1.01, \mathrm{p}=0.31\right), P$. latipinna $\left(\mathrm{F}_{1,186}=1.32, \mathrm{p}=0.19\right)$. Similar to our age-based approach, these effects were greatest for L. goodei $(\sim 8.58 \mathrm{~mm}$ at 0 disturbances and increased to $\sim 13.13 \mathrm{~mm}$ at 20 disturbances) and $H$. formosa ( $\sim 6.22 \mathrm{~mm}$ at 0 disturbances and increased to $\sim 10.43 \mathrm{~mm}$ at 20 disturbances).

\section{Discussion}

We found that the transitional age/length leading to cohort biomass production $\left(\mathrm{M}^{\prime} / \mathrm{G}^{\prime}>1\right)$ varied among our study species but consistently occurred at earlier ages/smaller size at long hydroperiod site than at shorter hydroperiod sites. Our results revealed spatial-temporal differences in both growth and mortality at local and regional spatial scales linked to changes in species' abundance revealed by variation in stagespecific M'/G'. For some of our study species, we noted higher recruitment, and higher biomass, when this transition stage occurred at smaller sizes/earlier ages. Biomass and abundance tended to be low when a species experienced higher mortality, shifting the transition period later in life. For some species, high mortality drastically associated with drying shifted this transition period to the adult phase, which resulted in low biomass/abundance for that year. Our analyses indicated that the timing of this transition is crucial to enhanced recruitment, with higher abundance associated with the transition period occurring at smaller sizes. Furthermore, results here also indicate that both recruitment and the timing of the transition period were influenced by hydrological 
variability among sites. Mortality, more than growth, was influenced by hydrological disturbance. We detected higher abundance at long-hydroperiod sites compared to shorter hydroperiod ones, and these differences were reflected by timing of the lifehistory transition period (earlier to later, respectively). The transition period occurred at earlier ages and smaller size at long-hydroperiod sites, with short-hydroperiod and presumably stressful environments delaying the onset of, and supporting less, biomass production.

The importance of stage-specific growth and mortality on recruitment has been extensively studied (Beyer 1989; Cushing 1975). These two life history parameters are highly correlated across species, and variability in both these characteristics alters recruitment potential (Houde 1989; Pepin 1991). Although our study found spatialtemporal differences in species-specific growth curves, we did not find any evidence that disturbance intensity influenced the growth parameters, or the rate at which $L$ approaches $L_{\infty}(K)$. Similar spatial-temporal trends in mortality were detected, but changes in hydrology caused larger changes in species-specific mortality rates. The CV for mortality was also higher than for growth, supporting other studies documenting that mortality is more variable than growth and that mortality may contribute more to variability in recruitment than growth (Houde 1997; Shoji and Tanaka 2007). Disturbance intensity may not have caused detectable differences in growth, but even subtle differences in either growth or mortality can contribute to large differences (as much as 10-fold) in recruitment (Houde 1987). Thus, the observed differences in growth, though 
small, could contribute to ecologically important recruitment variability in pulsed floodplain ecosystems.

Recruitment is inherently linked to the early life stages, but adults may "recruit" by immigrating into a newly inundated habitat. Age-specific surges in abundance following inundation have been documented in other pulsed ecosystems (Scharbert and Borcherding 2013). These species-specific patterns include recruitment and use of the floodplain by early life stages, age diversity in floodplain use, and high adult stock in temporarily connected waterbodies (King 2004). This may explain why the transition period was more closely linked to changes in annual abundance than biomass in this study. Age-specific differences in recruitment levels would result in drastic changes in biomass, but not abundance. For example, a year with high juvenile recruitment following re-inundation (high abundance, low biomass) will differ than a year with high adult recruitment (high abundance, high biomass). Furthermore, biomass loss due to emigration of adults during drying events could also result in lower than expected biomass based on the transition period.

The frequency, intensity, and spatial extent of disturbances plays a major role in altering species abundance and diversity (Huston and Huston 1994; Sousa 1984). These characteristics reduce abundance by removing individuals and relying on recolonization dynamics post-disturbance (McCabe and Gotelli 2000). We were able to describe how disturbance frequency influenced complex recruitment processes which lead to reduced species abundance. This study determined that disturbance frequency reduced recruitment, and we were able to link the extent of these changes in abundance to the 
timing of the transition period. However, we found no evidence that the transition period was influenced by disturbance intensity. This may be more tightly linked to the proximity of the drying event rather than duration of inundation since available habitat at our study sites can expand and contract at rapid time scales (Hoch et al. 2015). Testing how temporal proximity to the drying event on the transition period was outside the scope of the present study and additional information is needed to determine at which life stage the effects of disturbance are influencing. In contrast to annual hydroperiod, disturbance frequency (number of drying events) did result in the transition period occurring later in life history for G. holbrooki, L. goodei, and H. formosa. For some species, the M'/G' transition shifted from the juvenile life stage to after the onset of sexual maturation (e.g., H. formosa). Evidence for this was mixed between our age-based and length-based approaches for P. latipinna, J. floridae, and F. chrysotus, but we believe the shift indicates differences in dispersal strategies (immigration and emigration) in response to changing hydrology. These differences in movement strategies may have a greater impact on fluctuations of biomass and abundance than the factors acting on age-specific mortality and growth.

Dispersal strategies have been well documented for the species in this study, with species being classified as either early or late colonizers. Early colonizing species ( $G$. holbroooki, F. chrystous, J. floridae) tend to move fast and respond directionally in response to changing hydrology; whereas, late colonizing species (H. formosa, $P$. latipinna) tend to move slower and non-directionally (Goss et al. 2014; Hoch et al. 2015). These species have been further classified into three life-history strategies related to 
recovery following drought: rapid recovery after re-inundation then decline in density over time (J. floridae, F. chrysotus), rapid recovery followed by sustained high density (G. holbrooki), and slow to recovery over time (H. formosa and L. goodei) followed by sustained high density (DeAngelis et al. 2005; Trexler et al. 2005). Other studies have documented that emigration and immigration in response to changing hydrology play a crucial role in recruitment of migratory species (Agostinho et al. 2004), and this seems to disrupt the link between recruitment and the transition period in this study. Our results indicate that dispersal of $F$. chrustous and J. floridae plays a greater role in recruitment in the Everglades than changes in growth and mortality. For other abundant species $(G$. holbrooki, L. goodei, and H. formosa), trends in biomass and abundance at study sites were tightly linked with the transitional period and probably less influenced by dispersal. Thus, dispersal plays a small role in slow recovery following drought for poor dispersing species (H. formosa, L. goodei) and recruitment variability for these species is more tightly linked to local factors acting on growth and mortality. Furthermore, the life history strategy for G. holbrooki demonstrates that both dispersal and local factors influencing growth and mortality support high recruitment and sustained population size in floodplain ecosystems.

Hydrology is the major abiotic factor that influences fish recruitment in pulsed ecosystems via differences in movement strategies by recruits (Aarts et al. 2004; Arthington and Balcombe 2011; Godfrey et al. 2017). Three distinct movement periods have been described for newly inundated habitats: immigration following re-inundation of the floodplain, foraging associated with reduced movement, and increased movement 
and activity levels in response to drying (Goss et al. 2013). Recruitment in floodplain ecosystems often focus on the immigration/emigration periods, with few studies emphasizing recruitment dynamics during the intermediate movement period (foraging). We expanded previous research and focused on how hydrological variability influenced two key life history parameters, survivorship and individual growth. Our results emphasize that hydrology not only influences movement strategies but also plays an important role in causing spatial-temporal variability in growth and mortality. Movement strategies can disrupt this relationship, and we believe that the factors influencing growth and mortality in hydrologically variable environments can explain recruitment variability not otherwise explained by movement. The interaction between movement strategies, growth, and mortality all contribute to timing of the transition period, and ultimately recruitment, within pulsed floodplain ecosystems.

\section{Acknowledgements}

This work was supported by the American Killifish Association George Maier Fund and by Cooperative Agreements between FIU and the USGS (Greater Everglades Science Initiative Cooperative Agreement No. 02ERAG0040) and FIU and Everglades National Park (Critical Ecosystem Science Initiative Task Agreement P06AC00043). Otolith data were provided by Timothy Konnert, Steve Estes, and Shawna Baker; Aaron Zenone also assisted laboratory work. We would also like to thank Ed Houde for introducing us to the implications of growth and mortality on recruitment. This material was developed in collaboration with the Florida Coastal Everglades Long-Term Ecological Research program under National Science Foundation Grant No. DEB- 
1237517. This is contribution No. XXX from the Southeast Environmental Research

Center in the Institute of Water \& Environment at Florida International University.

\section{Works Cited}

Aarts, B.G., Van Den Brink, F.W., and Nienhuis, P.H. 2004. Habitat loss as the main cause of the slow recovery of fish faunas of regulated large rivers in Europe: the transversal floodplain gradient. River Research and Applications 20(1): 3-23.

Agostinho, A.A., Gomes, L.C., Veríssimo, S., and Okada, E.K. 2004. Flood regime, dam regulation and fish in the Upper Paraná River: effects on assemblage attributes, reproduction and recruitment. Reviews in Fish Biology and Fisheries 14(1): 1119.

Arthington, A.H., and Balcombe, S.R. 2011. Extreme flow variability and the 'boom and bust'ecology of fish in arid-zone floodplain rivers: a case history with implications for environmental flows, conservation and management. Ecohydrology 4(5): 708-720.

Bailly, D., Agostinho, A., and Suzuki, H. 2008. Influence of the flood regime on the reproduction of fish species with different reproductive strategies in the Cuiabá River, Upper Pantanal, Brazil. River Research and Applications 24(9): 12181229.

Bakun, A. 1996. Patterns in the ocean: ocean processes and marine population dynamics.

Bakun, A. 1998. Ocean triads and radical interdecadal stock variability: bane and boon for fishery management science. Reinventing Fisheries Management. Chapman and Hall, London: 331-358.

Bertschy, K.A., and Fox, M.G. 1999. The influence of age-specific survivorship on pumpkinseed sunfish life histories. Ecology 80(7): 2299-2313.

Beverton, R., and Holt, S. 1957. On the dynamics of exploited fish populations. Fisheries Investigation Series 2, Vol. 19, UK Ministry of Agriculture. Fisheries, and Food, London.

Beverton, R., and Holt, S. A review of the lifespans and mortality rates of fish in nature, and their relation to growth and other physiological characteristics. In Ciba Foundation Symposium-The Lifespan of Animals (Colloquia on Ageing), Volume 5. 1959. Wiley Online Library. pp. 142-180.

Beyer, J. 1989. Recruitment stability and survival simple size-specific theory with examples from the early life dynamics of marine fish. Dana 7(45): 147. 
Boehlert, G.W., and Mundy, B.C. Roles of behavioral and physical factors in larval and juvenile fish recruitment to estuarine nursery areas. In American Fisheries Society Symposium. 1988. pp. 1-67.

Burnham, K.P., and Anderson, D.R. 2004. Multimodel inference understanding AIC and BIC in model selection. Sociological methods \& research 33(2): 261-304.

Cohen, D. 1966. Optimizing reproduction in a randomly varying environment. Journal of theoretical biology 12(1): 119-129.

Cury, P., and Roy, C. 1989. Optimal environmental window and pelagic fish recruitment success in upwelling areas. Canadian Journal of Fisheries and Aquatic Sciences 46(4): 670-680.

Cushing, D. 1990. Plankton production and year-class strength in fish populations: an update of the match/mismatch hypothesis. In Advances in marine biology. Elsevier. pp. 249-293.

Cushing, D.H. 1975. Marine ecology and fisheries. CUP Archive.

DeAngelis, D.L., Trexler, J.C., and Loftus, W.F. 2005. Life history trade-offs and community dynamics of small fishes in a seasonally pulsed wetland. Canadian Journal of Fisheries and Aquatic Sciences 62(4): 781-790.

Denver, R.J. 1997. Environmental stress as a developmental cue: corticotropin-releasing hormone is a proximate mediator of adaptive phenotypic plasticity in amphibian metamorphosis. Hormones and behavior 31(2): 169-179.

Fogarty, M.J., Sissenwine, M.P., and Cohen, E.B. 1991. Recruitment variability and the dynamics of exploited marine populations. Trends in Ecology \& Evolution 6(8): 241-246.

Gatto, J.V., and Trexler, J.C. 2019. Seasonality of fish recruitment in a pulsed floodplain ecosystem: Estimation and hydrological controls. Environmental Biology of Fishes 102(4): 595-613.

Godfrey, P.C., Arthington, A.H., Pearson, R.G., Karim, F., and Wallace, J. 2017. Fish larvae and recruitment patterns in floodplain lagoons of the Australian Wet Tropics. Marine and Freshwater Research 68(5): 964-979.

Goss, C., Loftus, W., and Trexler, J. 2013. Seasonal Fish Dispersal in Ephemeral Wetlands of the Florida Everglades. Wetlands: 1-11. doi:10.1007/s13157-0130375-3. 
Goss, C.W., Loftus, W.F., and Trexler, J.C. 2014. Seasonal fish dispersal in ephemeral wetlands of the Florida Everglades. Wetlands 34(1): 147-157.

Haake, P.W., and Dean, J.M. 1983. Age and growth of four Everglades fishes using otolith techniques. National Park Service, South Florida Research Center, Everglades National Park.

Hjort, J. 1914. Fluctuations in the Great Fisheries of Northern Europe, Viewed in the Light of Biological Research. Andr. Fred. Høst \& Fils.

Hjort, J. 1926. Fluctuations in the year classes of important food fishes. Journal Du Conseil 1(1): 5-38.

Hoch, J.M., Sokol, E.R., Parker, A.D., and Trexler, J.C. 2015. Migration Strategies Vary in Space, Time, and Among Species in the Small-fish Metacommunity of the Everglades. Copeia 2015(1): 157-169.

Houde, E. Fish early life dynamics and recruitment variability. In Am. Fish. Soc. Symp. 1987. pp. 17-29.

Houde, E. 1997. Patterns and trends in larval-stage growth and mortality of teleost fish. Journal of Fish Biology 51: 52-83.

Houde, E.D. 1989. Comparative growth, mortality, and energetics of marine fish larvae: temperature and implied latitudinal effects. Fishery Bulletin 87(3): 471-495.

Huston, M.A., and Huston, M.A. 1994. Biological diversity: the coexistence of species. Cambridge University Press.

Kaufmann, K.W. 1981. Fitting and using growth curves. Oecologia 49(3): 293-299.

King, A. 2004. Ontogenetic patterns of habitat use by fishes within the main channel of an Australian floodplain river. Journal of Fish Biology 65(6): 1582-1603.

Konnert, T.J. 2002. The effects of hydroperiod on the life history parameters of poecilia latipinna and heterandria formosa (Poechiliidae) in the Florida Everglades.

Kushlan, J.A., Voorhees, S.A., Loftus, W.F., and Frohring, P.C. 1986. Length, mass, and calorific relationships of Everglades animals. Florida Scientist: 65-79.

Lasker, R. 1981. The role of a stable ocean in larval fish survival and subsequent recruitment. Marine fish larvae: morphology, ecology and relation to fisheries: 81-87. 
Liu, Z., Volin, J.C., Dianne Owen, V., Pearlstine, L.G., Allen, J.R., Mazzotti, F.J., and Higer, A.L. 2009. Validation and ecosystem applications of the EDEN watersurface model for the Florida Everglades. Ecohydrology 2(2): 182-194.

McCabe, D.J., and Gotelli, N.J. 2000. Effects of disturbance frequency, intensity, and area on assemblages of stream macroinvertebrates. Oecologia 124(2): 270-279.

McClanahan, T., Graham, N., MacNeil, M., and Cinner, J. 2015. Biomass-based targets and the management of multispecies coral reef fisheries. Conservation Biology 29(2): 409-417.

Pepin, P. 1991. Effect of temperature and size on development, mortality, and survival rates of the pelagic early life history stages of marine fish. Canadian Journal of Fisheries and Aquatic Sciences 48(3): 503-518.

Roff, D.A. 1984. The evolution of life history parameters in teleosts. Canadian Journal of Fisheries and Aquatic Sciences 41(6): 989-1000.

Rose, S.M. 1959. Population control in guppies. American Midland Naturalist: 474-481.

Scharbert, A., and Borcherding, J. 2013. Relationships of hydrology and life-history strategies on the spatio-temporal habitat utilisation of fish in European temperate river floodplains. Ecological indicators 29: 348-360.

Shoji, J., and Tanaka, M. 2007. Growth and mortality of larval and juvenile Japanese seaperch Lateolabrax japonicus in relation to seasonal changes in temperature and prey abundance in the Chikugo estuary. Estuarine, Coastal and Shelf Science 73(3-4): 423-430.

Sousa, W.P. 1984. Intertidal mosaics: patch size, propagule availability, and spatially variable patterns of succession. Ecology 65(6): 1918-1935.

Spurr, A.R. 1969. A low-viscosity epoxy resin embedding medium for electron microscopy. Journal of ultrastructure research 26(1): 31-43.

Stroup, W.W. 2015. Rethinking the analysis of non-normal data in plant and soil science. Agronomy Journal 107(2): 811-827.

Telis, P.A. 2006. The Everglades Depth Estimation Network (EDEN) for support of ecological and biological assessments. Geological Survey (US) 2327-6932.

Trexler, J.C., Loftus, W.F., and Chick, J.H. 2003. Setting and monitoring restoration goals in the absence of historical data: the case of fishes in the Florida Everglades. Monitoring ecosystems: interdisciplinary approaches for evaluating ecoregional initiatives. Island Press, Washington, DC: 351-376. 
Trexler, J.C., Loftus, W.F., and Perry, S. 2005. Disturbance frequency and community structure in a twenty-five year intervention study. Oecologia 145(1): 140-152.

Trexler, J.C., Loftus, W.F., Jordan, F., Chick, J.H., Kandl, K.L., McElroy, T.C., and Bass, O. 2002. Ecological scale and its implications for freshwater fishes in the Florida Everglades. The Everglades, Florida Bay, and Coral Reefs of the Florida Keys: An Ecosystem Sourcebook. CRC Press, Boca Raton, FL: 153-181.

Ware, D. 1975. Relation between egg size, growth, and natural mortality of larval fish. Journal of the Fisheries Board of Canada 32(12): 2503-2512.

Winemiller, K.O. 2005. Life history strategies, population regulation, and implications for fisheries management. Canadian Journal of Fisheries and Aquatic Sciences 62(4): 872-885. 
Table 1: Estimates of the VBGF growth parameter $K\left(\mathrm{~mm} \mathrm{day}^{-1}\right)$ and standard error for all species collected between 2014 and 2016. Data for F. chrysotus and H. formosa in 2016 were not available.

\begin{tabular}{ccccccc}
\hline \multirow{2}{*}{ Hydroperiod } & \multirow{2}{*}{ Site } & \multirow{2}{*}{ Wateryear } & \multicolumn{5}{c}{ Species } \\
\cline { 4 - 7 } & & & F. chrystous & G. holbrooki & H. formosa & L. goodei \\
\hline \multirow{6}{*}{ Short } & TSL & 2014 & $0.0038(0.0001)$ & $0.0074(0.0002)$ & $0.0034(0.0002)$ & $0.0074(0.0003)$ \\
& MDsh & 2015 & $0.0079(0.0003)$ & $0.0070(0.0002)$ & $0.0031(0.0001)$ & $0.0053(0.0002)$ \\
& & 2016 & N/A & $0.0069(0.0002)$ & N/A & $0.0054(0.0002)$ \\
& WCA & 2014 & $0.0051(0.0002)$ & $0.0061(0.0003)$ & $0.0033(0.0001)$ & $0.0057(0.0002)$ \\
& 03 & 2015 & $0.0037(0.0001)$ & $0.0071(0.0004)$ & $0.0077(0.0002)$ & $0.0062(0.0002)$ \\
& & 2016 & N/A & $0.0110(0.0005)$ & N/A & $0.0051(0.0002)$ \\
& WCA & 2014 & $0.0041(0.0001)$ & $0.0056(0.0002)$ & $0.0034(0.0001)$ & $0.0058(0.0002)$ \\
Intermediatenyyyyy & 02 & 2015 & $0.0035(0.0001)$ & $0.0065(0.0002)$ & $0.0031(0.0001)$ & $0.0048(0.0002)$ \\
& & 2016 & N/A & $0.0057(0.0002)$ & N/A & $0.0056(0.0002)$ \\
& SRS & 2014 & $0.0095(0.0003)$ & $0.0079(0.0005)$ & $0.0034(0.0003)$ & $0.0064(0.0003)$ \\
& 07 & 2015 & $0.0076(0.0003)$ & $0.0074(0.0003)$ & $0.0034(0.0001)$ & $0.0052(0.0003)$ \\
& & 2016 & N/A & $0.0058(0.0003)$ & N/A & $0.0053(0.0002)$ \\
& WCA & 2014 & $0.0148(0.0007)$ & $0.0056(0.0002)$ & $0.0037(0.0003)$ & $0.004(0.0002)$ \\
Long & 2015 & $0.0085(0.0003)$ & $0.0068(0.0004)$ & $0.0069(0.0002)$ & $0.0051(0.0003)$ \\
& 04 & 2016 & N/A & $0.0061(0.0003)$ & N/A & $0.0060(0.0003)$ \\
& & 2014 & $0.0072(0.0003)$ & $0.0068(0.0003)$ & $0.0035(0.0002)$ & $0.0048(0.0002)$ \\
& WCA & 2015 & $0.0035(0.0001)$ & $0.0072(0.0003)$ & $0.0034(0.0001)$ & $0.0044(0.0002)$ \\
& 05 & 2016 & N/A & $0.0125(0.0006)$ & N/A & $0.0055(0.0002)$ \\
\hline
\end{tabular}


Table 2: Estimates of the age-based instantaneous mortality rate $M$ (individuals day ${ }^{-1}$ ) and standard error for all species collected between 2014 and 2016. Estimates were standardized to daily mortality rates. Data for F. chrysotus and H. formosa in 2016 were not available.

\begin{tabular}{|c|c|c|c|c|c|c|}
\hline \multirow{2}{*}{ Hydroperiod } & \multirow{2}{*}{ Site } & \multirow{2}{*}{ Wateryear } & \multicolumn{4}{|c|}{ Species } \\
\hline & & & F. chrystous & G. holbrooki & H. formosa & L. goodei \\
\hline \multirow{6}{*}{ Short } & & 2014 & $0.028(0.006)$ & $0.032(0.007)$ & $0.029(0.007)$ & $0.028(0.006)$ \\
\hline & TSL & 2015 & $0.019(0.006)$ & $0.018(0.004)$ & $0.027(0.006)$ & $0.022(0.004)$ \\
\hline & & 2016 & N/A & $0.036(0.015)$ & N/A & $0.027(0.003)$ \\
\hline & & 2014 & $0.022(0.005)$ & $0.030(0.004)$ & $0.023(0.006)$ & $0.020(0.004)$ \\
\hline & We & 2015 & $0.022(0.004)$ & $0.032(0.005)$ & $0.032(0.008)$ & $0.021(0.004)$ \\
\hline & & 2016 & N/A & $0.036(0.009)$ & N/A & $0.047(0.007)$ \\
\hline \multirow{6}{*}{ Intermediate } & WCA & 2014 & $0.018(0.003)$ & $0.032(0.003)$ & $0.061(0.008)$ & $0.031(0.003)$ \\
\hline & WCA & 2015 & $0.021(0.004)$ & $0.052(0.009)$ & $0.066(0.011)$ & $0.033(0.004)$ \\
\hline & & 2016 & N/A & $0.037(0.009)$ & N/A & $0.049(0.011)$ \\
\hline & & 2014 & $0.025(0.004)$ & $0.051(0.012)$ & $0.042(0.007)$ & $0.037(0.004)$ \\
\hline & SRS & 2015 & $0.017(0.003)$ & $0.038(0.010)$ & $0.044(0.007)$ & $0.029(0.005)$ \\
\hline & 07 & 2016 & N/A & $0.020(0.008)$ & N/A & $0.035(0.006)$ \\
\hline \multirow{6}{*}{ Long } & & 2014 & $0.030(0.008)$ & $0.048(0.012)$ & $0.075(0.016)$ & $0.038(0.005)$ \\
\hline & weA & 2015 & $0.031(0.007)$ & $0.056(0.019)$ & $0.042(0.013)$ & $0.036(0.006)$ \\
\hline & & 2016 & N/A & $0.061(0.28)$ & N/A & $0.038(0.08)$ \\
\hline & & 2014 & $0.018(0.04)$ & $0.059(0.07)$ & $0.083(0.13)$ & $0.034(0.03)$ \\
\hline & 05 & 2015 & $0.017(0.05)$ & $0.072(0.15)$ & $0.58(0.10)$ & $0.24(0.04)$ \\
\hline & & 2016 & N/A & $0.043(0.09)$ & N/A & $0.40(0.06)$ \\
\hline
\end{tabular}


Table 3: The Coefficient of Variation (CV) of stage-specific mortality $M$ and growth $G$ for the early life stages (birth/hatch) of each species. CV percentages were calculated at $7 \mathrm{~mm}$ (F. chrysotus, G. holbrooki), 6mm (H. Formosa, J. floridae, L. goodei) and 9mm (P. latipinna). The ratio of the CV's $(\mathrm{M} / \mathrm{G})$ was also calculated. All species, sites, and years per hydroperiod classification were averaged together to calculate the mean $\mathrm{CV}$ at each hydroperiod classification $\left({ }^{+} / \mathrm{SE}\right)$. Sample size vary by hydroperiod classification per species ( $\mathrm{n}=4$ to 6 ).

\begin{tabular}{ccccc}
\hline & & \multicolumn{3}{c}{ Hydroperiod Classification } \\
\cline { 3 - 5 } Species & Parameter CV & Short & Intermediate & Long \\
\hline \multirow{3}{*}{ F. chrysotus } & $M$ & 32.42 & 35.08 & 69.36 \\
& $G$ & 36.54 & 37.13 & 45.00 \\
G. holbrooki & Ratio & 0.89 & 0.94 & 1.54 \\
& $M$ & 74.75 & 40.02 & 33.58 \\
& $G$ & 22.71 & 14.92 & 18.16 \\
H. Formosa & Ratio & 3.29 & 2.68 & 1.85 \\
& $M$ & 25.03 & 24.44 & 22.61 \\
J. floridae & $G$ & 22.71 & 4.11 & 21.19 \\
& Ratio & 1.82 & 5.95 & 1.07 \\
L. goodei & $M$ & 53.93 & $\mathrm{~N} / \mathrm{A}$ & 4.66 \\
& $G$ & 50.61 & $\mathrm{~N} / \mathrm{A}$ & 80.85 \\
& Ratio & 1.06 & $\mathrm{~N} / \mathrm{A}$ & 17.35 \\
P. latipinna & $M$ & 47.68 & 27.26 & 90.72 \\
& $G$ & 21.87 & 9.36 & 29.60 \\
& Ratio & 2.18 & 2.91 & 3.06 \\
Hydroperiod & $M$ & 76.01 & 87.49 & 31.43 \\
Mean & $G$ & 43.47 & 73.46 & 19.74 \\
& Ratio & 1.75 & 1.19 & 1.59 \\
\hline \multirow{2}{*}{ Manyyy} & $M$ & $51.64(8.61)$ & $42.86(11.50)$ & $54.76(11.85)$ \\
& $G$ & $31.49(5.8)$ & $27.79(12.73)$ & $23.06(5.48)$ \\
& Ratio & $1.83(0.35)$ & $2.74(0.89)$ & $4.41(2.60)$ \\
\hline
\end{tabular}


Fig. 1. Results from our general linear model (GLM) testing differences in the instantaneous mortality rates $M$ among hydroperiod types for A) Length-based methods and B) Age-based methods. Estimates for age-based methods were standardized to daily mortality rates.

Fig. 2. Average $M^{\prime} / G^{\prime}$ curves as a function of length $(\mathrm{mm})$ for short, intermediate, and long hydroperiod sites. Estimates for G. holbrooki and L. goodei were based on two sites per hydroperiod from 2014-2016 (n=6). Estimates for F. chrysotus and H. formosa were based on two sites per hydroperiod from 2014-2015 $(n=4)$. Shaded regions indicate 95\% confidence intervals. Darkest areas indicate overlap in confidence intervals. Confidence intervals were excluded for intermediate hydroperiod sites because overlap with both long and short hydroperiod curves obscured patterns. Vertical reference lines indicating the size at the transition period were included for each hydroperiod type.

Fig. 3. Relationship between the log-transformed transition age (days) and annual abundance for the pooled data of each species.

Fig. 4. Site-specific relationship between the log-transformed transition age (age $\mathrm{M}^{\prime} / \mathrm{G}^{\prime}=1$ ) and annual abundance for $L$. goodei. Two examples for each hydroperiod type are presented and selected based on sites used for the growth study.

Fig. 5. Results from our general linear model (GLM) testing differences in species A) Annual density, B) Biomass density, C) Age $M / G=1$, and D) Length $M / G=1$ among disturbance regimes. 
Fig. 6. A) Scatter plot demonstrating the relationship between Annual Hydroperiod (disturbance intensity) and the transition age (age $M^{\prime} / G^{\prime}=1$ ). B) Scatter plot demonstrating the relationship between the $\mathrm{CV}$ of Hydroperiod (hydrological variability) and the $\mathrm{CV}$ of the transition period.

Fig. 7. Mean transition age (age $\left.M^{\prime} / G^{\prime}=1\right)$ at each site for each species. The transition period was averaged across 20 years for each site. Sites are arranged from least disturbed (right) to most disturbed (left). 
Fig. 1
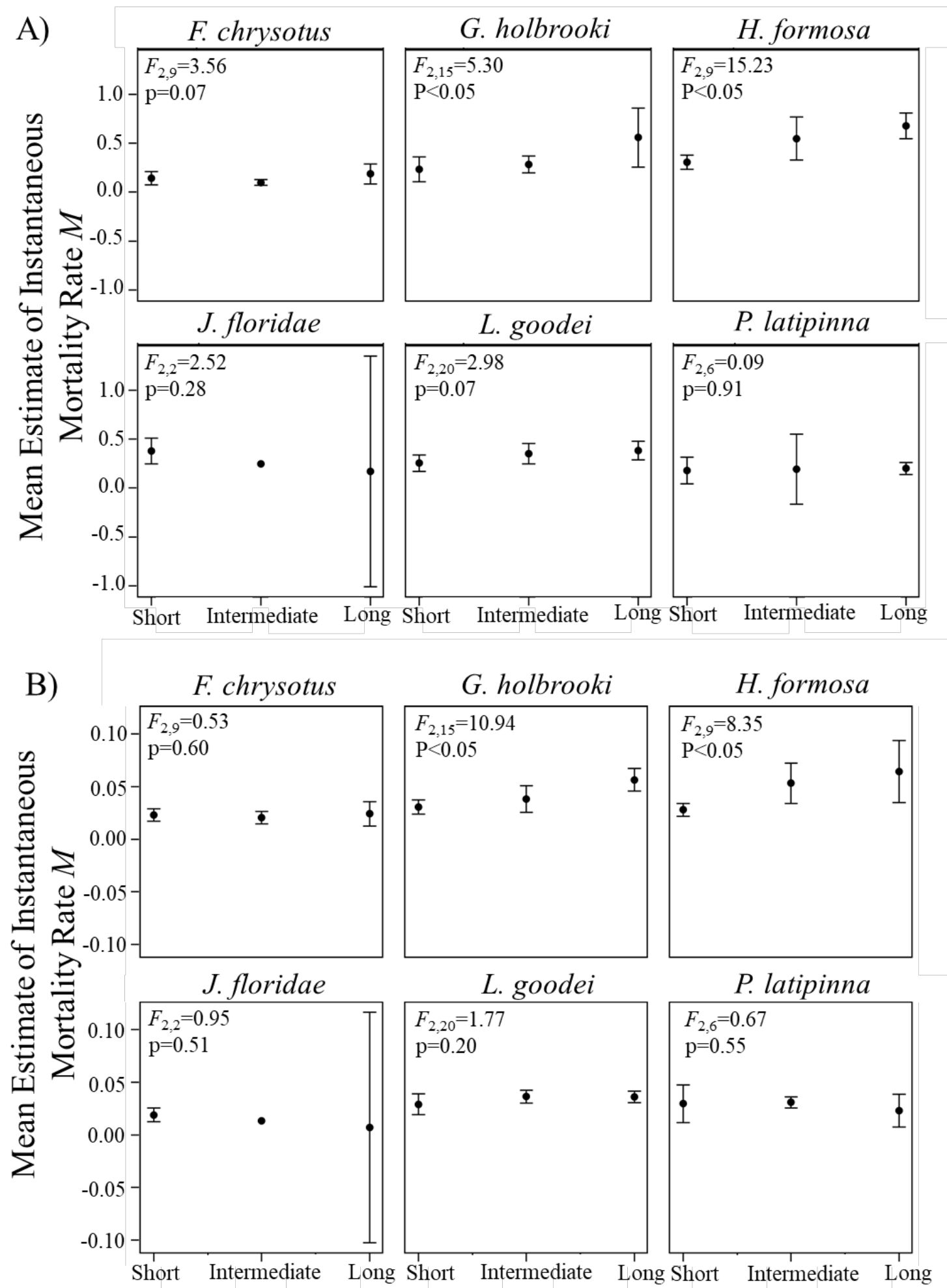
Fig. 2
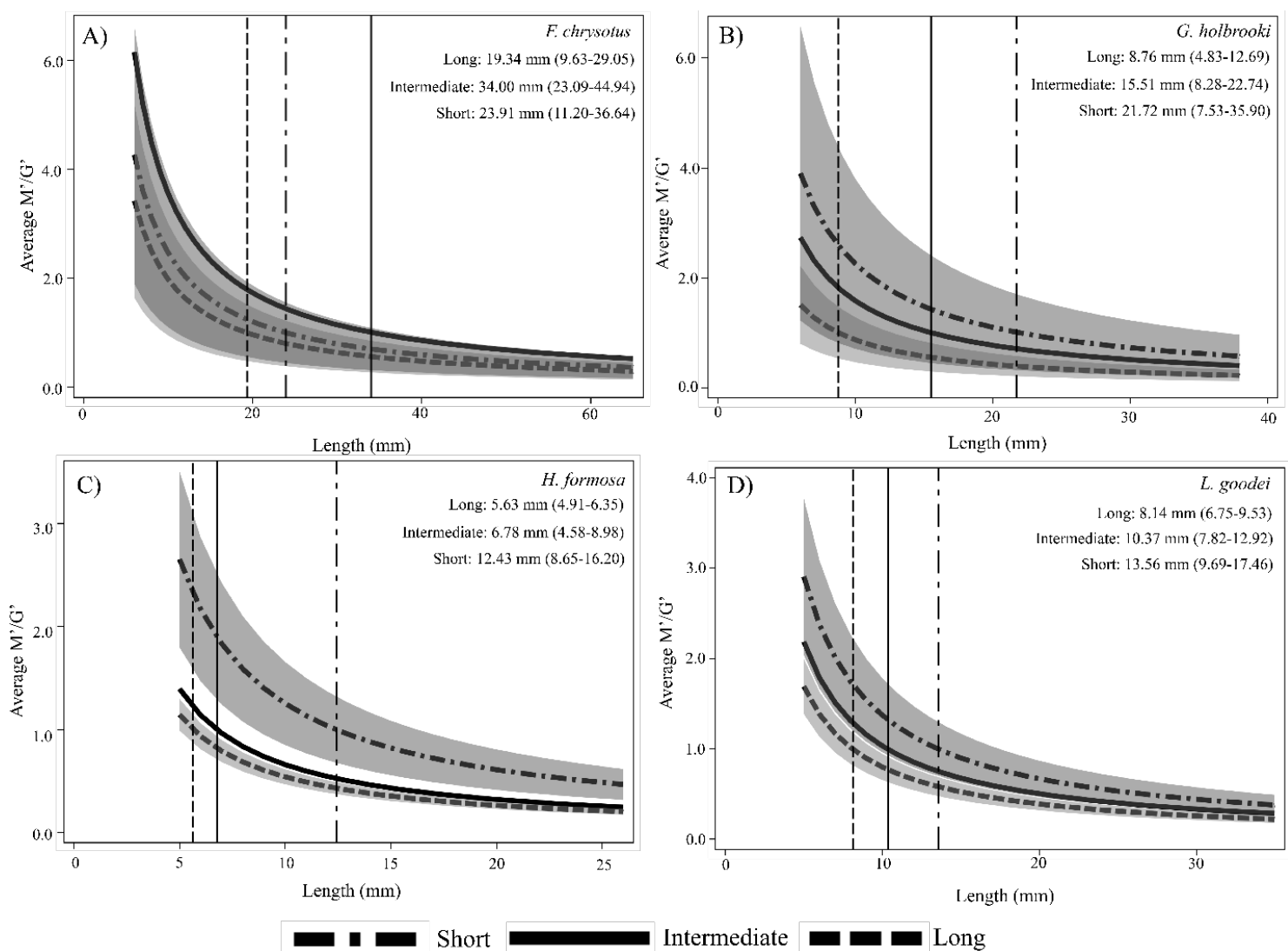
Fig. 3
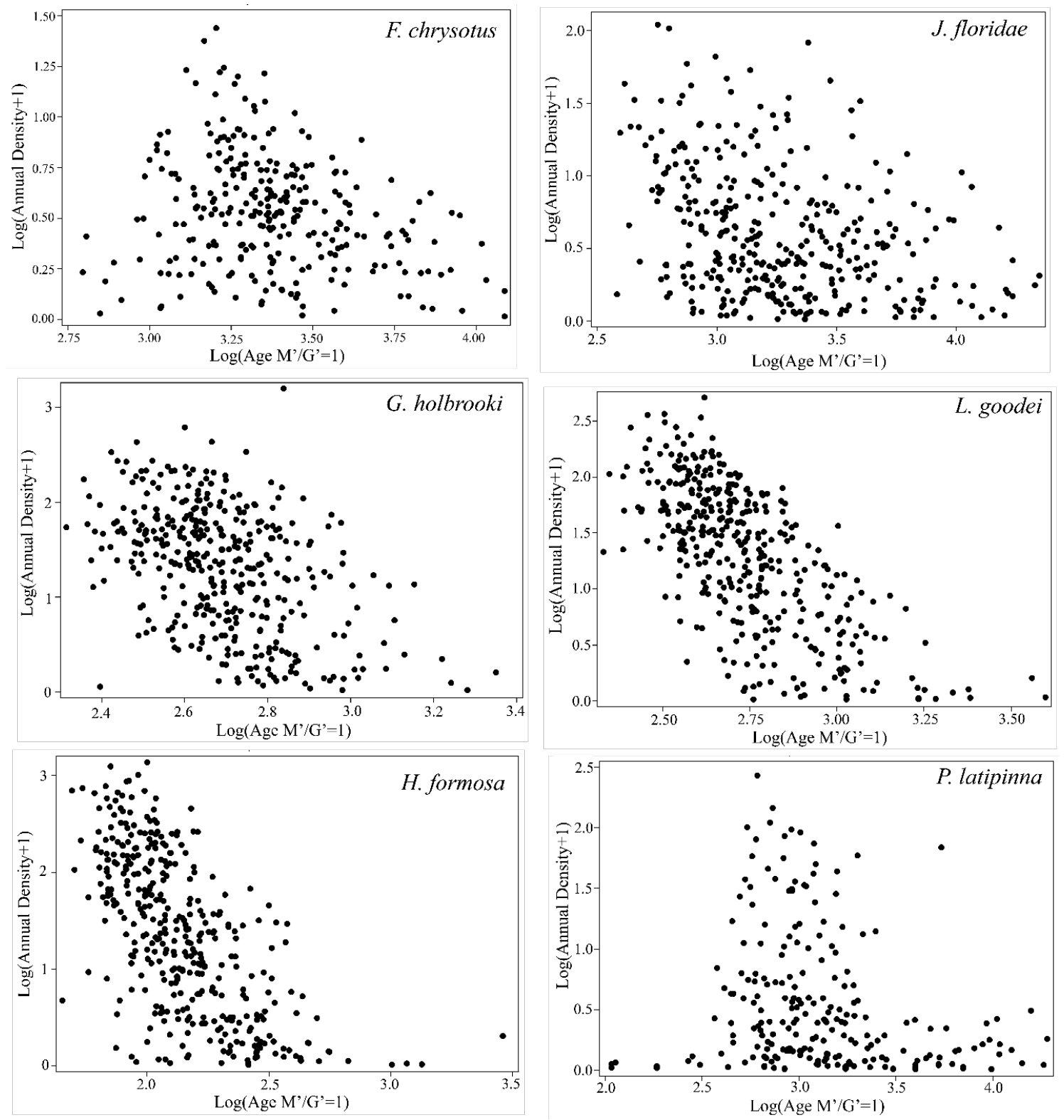
Fig. 4
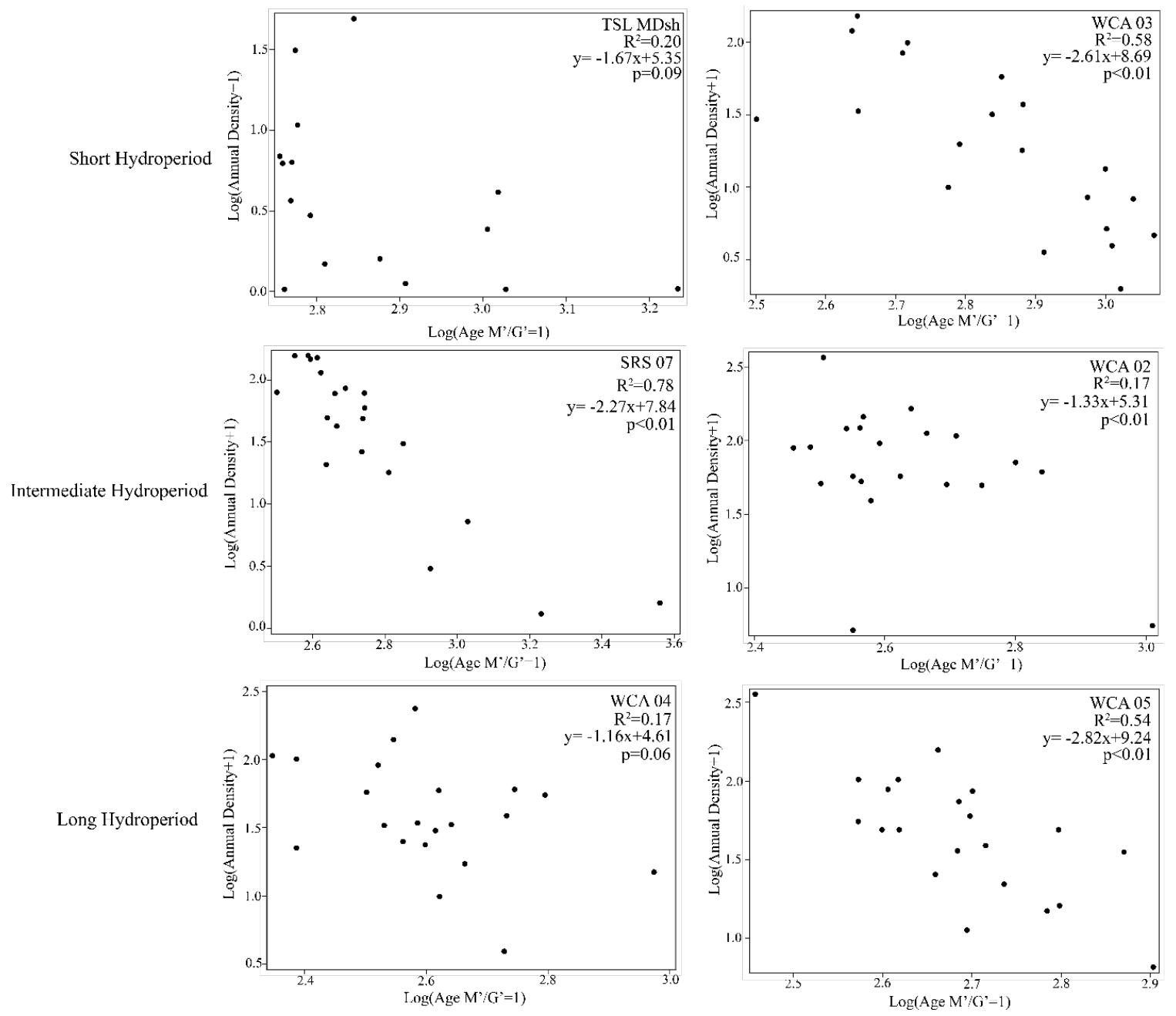
Fig. 5

A)

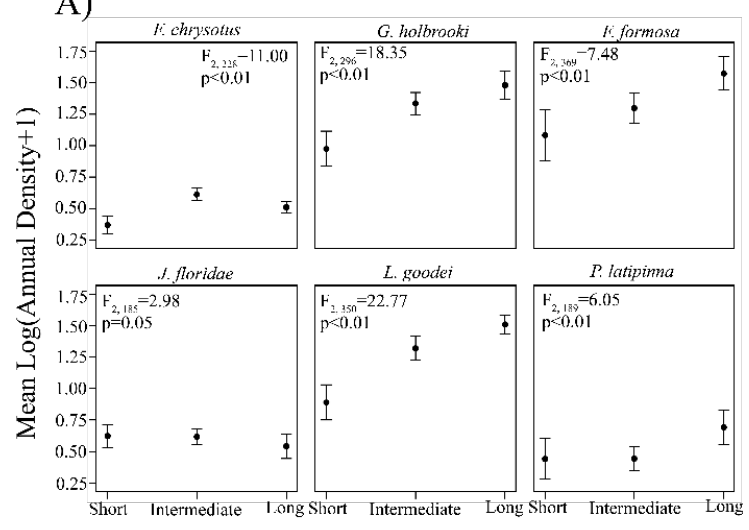

C)

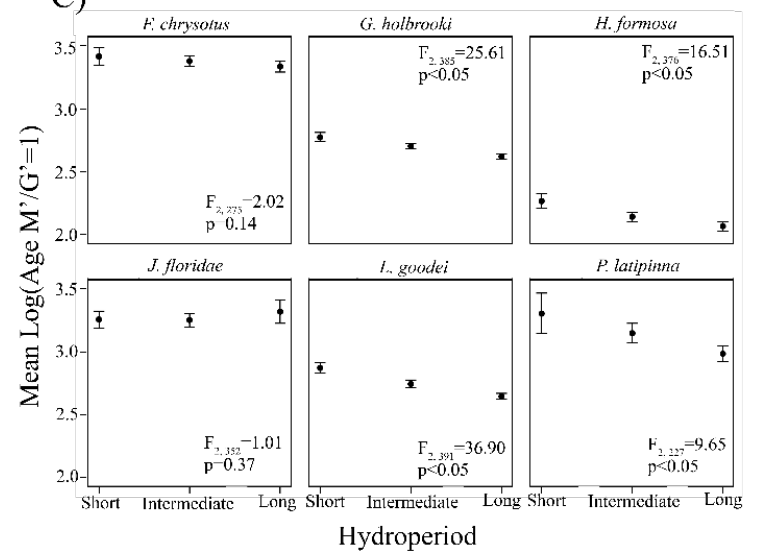

B)

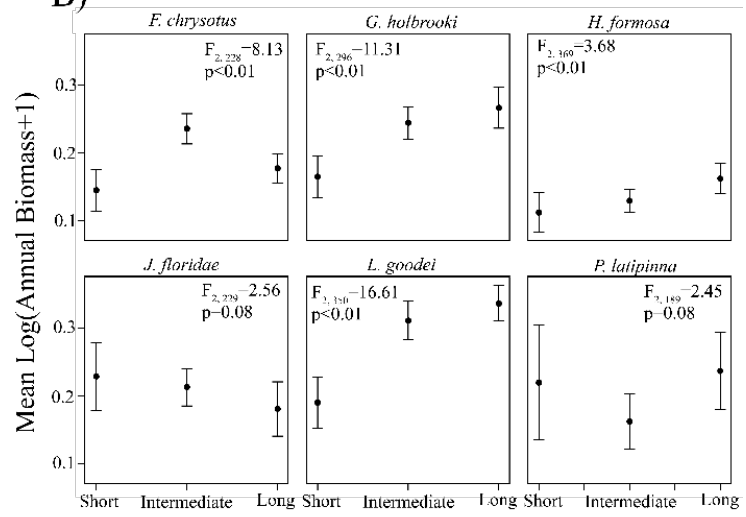

Hydroperiod

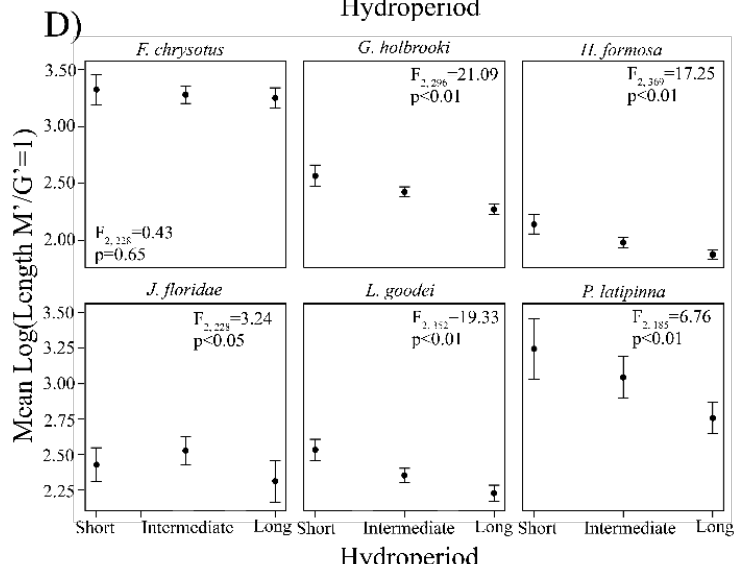

Hydroperiod 
Fig. 6
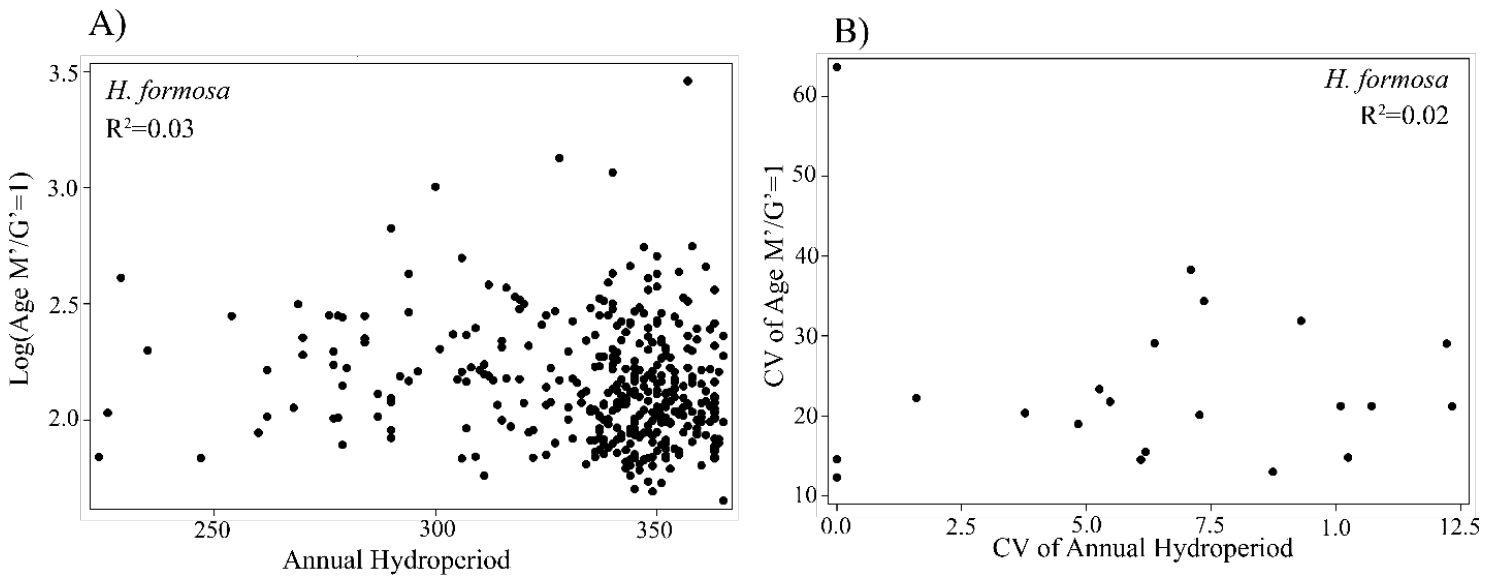
Fig. 7
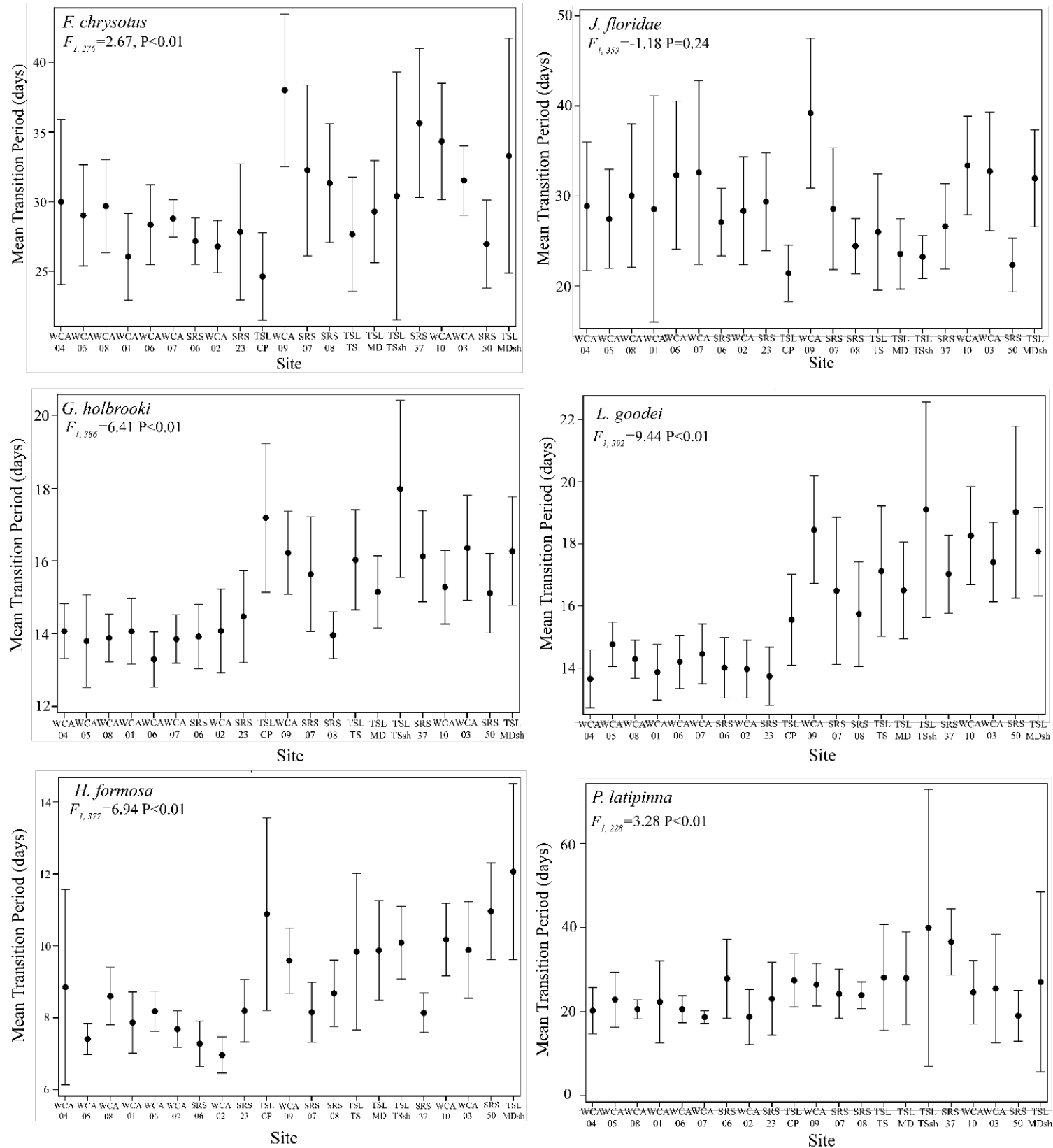
CHAPTER VI

CONCLUSIONS AND FUTURE DIRECTIONS 
Changing hydrology is the major abiotic factor influencing fish populations within seasonally pulsed ecosystems (King et al. 2003, Humphries et al. 2019). Stressful habitats also have adverse effects on survivorship and growth (Rose 1959, Cohen 1966). Identifying how hydrological stress influences these important life history parameters is an important part of understanding how organisms adapt and take advantage of flood pulses. Environmental variability strongly influences the earliest life stages and understanding how these stressful habitats feedback on life history characteristics is vital to understanding recruitment dynamics within floodplains (Fogarty 1993).

Recruitment research has largely focused on testing the presence or absence of certain hypotheses (Gotceitas et al. 1996), identifying the stock-recruitment relationship (Munch et al. 2005), or identifying certain environmental variables which have caused recruitment failure (Myers 1998). Research on recruitment dynamics within floodplain ecosystems have largely focused on fish movement and floodplain utilization during flood pulses (Agostinho et al. 2004, Goss et al. 2013). My dissertation focuses on how site hydrology influences three factor which are crucial to recruitment success: growth, mortality, and dispersal. This study incorporated time series analyses which identified key hydrological variables and how they influenced the drivers of recruitment. Sites within the time series varied greatly in site hydroperiod, depth, and the timing of flooding which was ideal for investigating the effect of these factors on certain life history characteristics.

Chapter II focused on identifying seasonal recruitment within a 20 -year, multi-site time series data set of marsh fish. I first investigated size-selective bias in a 2-mm mesh, 
1- $\mathrm{m}^{2}$ throw trap to determine whether recruits were undersampled. These analyses determined that all juvenile size classes were underrepresented in the time series data; however, adults of all species achieved $100 \%$ selectivity for all size classes. I then applied a cohort analysis to the time series data in order to adjust the data for undersampled individuals. These analyses followed a cohort backward in time to generate a recruit-adjusted dataset. I determined that seasonal recruitment was difficult to detect in the unadjusted data. I found high seasonality within the adjusted data set, with peaks in recruitment typically occurring in October to December (wet season). The adjusted dataset also revealed that depth and days since dry influenced recruit abundance at short and intermediate hydroperiod sites. Depth was the primary hydrological variable which caused changes in recruitment through time at long hydroperiod sites. Identifying size-selective bias and the use of cohort analyses have major implications for identifying seasonal patterns of recruitment and the hydrological factors which influence the timing and abundance of fish species.

Analysis of recruit abundance from the time series data was also used in Chapter III to evaluate the strength of density-dependent recruitment along a hydrological gradient. Multimodel Inference was used to evaluate the strength of evidence for several density-dependent and density-independent stock-recruitment and population dynamics models. These models revealed weak evidence for stock-dependent recruitment mechanisms. However, population dynamics models indicated strong support for density-dependent recruitment. Recruitment from one season to the next was dependent on recruitment from the previous season. Evidence for density-dependence also remained high when seasonal components were included in the model. These determined 
that both the strength of density-dependence $(\beta)$ and the interaction of season with $\beta$ to significantly drive recruitment. I was also able to determine that $\beta$ either decreased or increased with increased hydrological variability depending on the species. Results in this Chapter indicated that hydrology influences the strength of density-dependent recruitment with changes in recruitment dependent on seasonal variation of production from spawning stock.

Chapter IV explicitly examined the dispersal behavior of several marsh fish species in relation to colonization sequence. This chapter sought to describe and identify the colonization sequence (arrival order) of species post-inundation of the floodplain. Using a 20-year time series data set, I was able to document the arrival order of these species and determine the likelihood that each would arrive in any given order. I then quantified each species maximum swimming speed to describe these colonization patterns. I found that high swimming speeds was indicative of early arriving species; whereas, low swimming speeds was indicative of later arrival. I then generated an Agent Based Model to incorporate both swimming speed and directedness from field data. Results from those models indicated that fast moving, directed species were more likely to arrive earlier than slow, non-directed species. Furthermore, arrival probabilities derived from those simulations matched the observed arrival probabilities from the field data. These results indicate that species arrival sequence can be predictable using a simple model which incorporates only two parameters: speed and directedness.

Evidence suggests that mortality is more variable than growth, and my final Chapter focused on identifying how site hydroperiod influenced spatial-temporal trends 
in both growth and mortality rates (Houde 1997). Using a dip net, I collected fish from six sites of varying hydroperiods for three years. Otoliths were extracted from these individuals to reveal species-specific growth rates. Results from those analyses revealed little spatial-temporal variation in growth rates. Furthermore, there was no effect of disturbance intensity on the growth parameter $K$. Methods from Chapter II were then applied to abundance-at-age data to investigate spatial-temporal variation in catch curves. This revealed that mortality rates were more variable than growth rates and were influenced by site hydroperiod. Finally, I calculated the $\mathrm{M}^{\prime} / \mathrm{G}^{\prime}$ ratio and was able to identify the "transition period" $\left(\mathrm{M}^{\prime} / \mathrm{G}^{\prime}=1\right)$. I was able to relate this transition period to changes in species abundance at each site; however, the relationship to species biomass was weak. I was then able to compare annual changes in the timing of the transition period to site-specific hydrology. This analysis determined that the timing of the transition period for high dispersing species was not influenced by hydroperiod. However, the transition period did occur later in life history for species with poor dispersal ability with decreasing hydroperiod. This Chapter determined that hydrology has a larger effect on species-specific mortality rates and emphasizes that even subtle differences in growth rates may have major implications to recruitment variability. Furthermore, hydrology has the largest effect on the transition period for species which have weak colonization potential.

Disturbance frequency and intensity plays a vital role in dispersal, abundance, and community assembly (Ho et al. 2016, Spiller et al. 2018). Recruitment within floodplains is particularly susceptible hydrological disturbance (King et al. 2019). This dissertation supports a growing body of evidence that altered hydrology is the major source of 
reduced recruitment in floodplain ecosystems (King et al. 2003, Humphries et al. 2019).

It also provides evidence that adaptive life history traits (dispersal) can influence recruitment within disturbed ecosystems (Winemiller 2004, Goss et al. 2013). This dissertation thoroughly examined the hydrological effects on species-specific growth, mortality, and dispersal rates within a fluctuating environment. Future research should focus on interannual and inter-seasonal changes in somatic growth and mortality rates of these species. This could lead to the development of predictive models which use sitespecific hydrology data for estimating future recruitment. Data generated form these models could improve restoration efforts for the Everglades and other systems facing intense anthropogenic modification of water bodies.

\section{Literature Cited}

Agostinho, A. A., L. C. Gomes, S. Veríssimo, and E. K. Okada. 2004. Flood regime, dam regulation and fish in the Upper Paraná River: effects on assemblage attributes, reproduction and recruitment. Reviews in Fish Biology and Fisheries 14:11-19.

Cohen, D. 1966. Optimizing reproduction in a randomly varying environment. Journal of theoretical biology 12:119-129.

Fogarty, M. J. 1993. Recruitment in randomly varying environments. ICES Journal of Marine Science 50:247-260.

Goss, C., W. Loftus, and J. Trexler. 2013. Seasonal Fish Dispersal in Ephemeral Wetlands of the Florida Everglades. Wetlands:1-11.

Gotceitas, V., V. Puvanendran, L. L. Leader, and J. A. Brown. 1996. An experimental investigation of the 'match/mismatchl'hypothesis using larval Atlantic cod. Marine Ecology Progress Series 130:29-37.

Ho, A., E. van den Brink, A. Reim, S. Krause, and P. L. Bodelier. 2016. Recurrence and frequency of disturbance have cumulative effect on methanotrophic activity, abundance, and community structure. Frontiers in microbiology 6:1493. 
Houde, E. 1997. Patterns and trends in larval-stage growth and mortality of teleost fish*. J Fish Biol 51:52-83.

Humphries, P., A. J. King, N. McCasker, R. K. Kopf, R. Stoffels, B. P. Zampatti, and A. E. Price. 2019. Riverscape recruitment: a conceptual synthesis of drivers of fish recruitment in rivers. Canadian Journal of Fisheries and Aquatic Sciences.

King, A., C. Doidge, D. Buckle, and K. Tyler. 2019. Preliminary evidence of spawning phenologies of freshwater fish in a wet-dry tropical river: the importance of both wet and dry seasons. Marine and Freshwater Research.

King, A., P. Humphries, and P. Lake. 2003. Fish recruitment on floodplains: the roles of patterns of flooding and life history characteristics. Canadian Journal of Fisheries and Aquatic Sciences 60:773-786.

Munch, S. B., A. Kottas, and M. Mangel. 2005. Bayesian nonparametric analysis of stock recruitment relationships. Canadian Journal of Fisheries and Aquatic Sciences 62:1808-1821.

Myers, R. A. 1998. When do environment-recruitment correlations work? Reviews in Fish Biology and Fisheries 8:285-305.

Rose, S. M. 1959. Population control in guppies. American Midland Naturalist:474-481.

Spiller, D. A., T. W. Schoener, and J. Piovia-Scott. 2018. Recovery of food webs following natural physical disturbances. Annals of the New York Academy of Sciences 1429:100-117.

Winemiller, K. O. 2004. Floodplain river food webs: generalizations and implications for fisheries management. Pages 285-309 in Proceedings of the second international symposium on the management of large rivers for fisheries. Food and Agriculture Organization \& Mekong River Commission, FAO Regional .... 


\section{JOHN VINCENT GATTO}

2008-2011

B.S., Marine Science

University of South Carolina

Columbia, SC

2017

M.S., Biology

Florida International University

Miami, FL

2012-2019

Doctoral Candidate

Florida International University

Miami, FL

PUBLICATIONS, TECHNICAL REPORTS, AND PRESENTATIONS

Gatto, J. V. and J. C Trexler. Speed and Directedness Predict Colonization Sequence Post-Disturbance. Journal of Animal Ecology. In review

Gatto, J. V. and J. C Trexler. 2019. Seasonality of Fish Recruitment in a Pulsed Wetland Ecosystem: Estimation and Hydrological Effects. Environmental Biology of Fishes. 102 (4): 595-613.

Gatto, J. V. and Trexler, J. C. Predicting Sustainable Population Growth by Linking AgeSpecific Mortality and Growth Rate (M'/G') to Biomass in a Fluctuating Environment. American Fisheries Society Annual Meeting, Reno, NV. October 2019 (Oral Presentation in organized session Freshwater Fisheries Management II).

Gatto, J. V. and Trexler, J. C. Predicting Sustainable Population Growth by Linking AgeSpecific Mortality and Growth Rate (M'/G') to Biomass in a Fluctuating Environment. Ecological Society of America Annual Meeting, Louisville, KY. August 2019. (Oral Presentation in organized session Population Dynamics And Regulation).

Gatto, J.V., Trexler, J. C., Newman, S., Saunders, C., \& Cook, M. Evaluating Otolith Microchemistry for Tracking Phosphorus Experienced by Everglades Fish. Greater Everglades Ecosystem Restoration Conference (GEER). Coral Springs, FL. April 2019. (Poster Presentation)

Gatto, J.V. and Trexler, J.C. Using Agent Based Modeling to Predict Recolonization Patterns Following Disturbance. Southeastern Ecology and Evolution Conference (SEEC). University of Miami, Coral Gables, FL. October 2018. (Oral Presentation) 
Gatto, J.V. and Trexler, J.C. Do Changes in Hydrology Influence the Strength of DensityDependent Recruitment in Pulsed Ecosystems? American Fisheries Society Annual Meeting, Atlantic City, NJ. August 2018. (Oral Presentation in organized Symposium Advancing Environmental Flows: Novel Findings, Challenges to Conventional Thinking, and Embracing Uncertainty)

Gatto, J.V. and Trexler, J.C. Using Agent Based Modeling to Predict Recolonization Patterns Following Disturbance. Ecological Society of America Annual Meeting, New Orleans, LA. August 2018. (Oral Presentation in organized session Behavior: Migration And Movement II)

Gatto, J.V. and Trexler, J.C. Detecting Density-Dependent Recruitment in Pulsed Ecosystems. Florida International University Biology Symposium, Miami, FL. February 2018. (Lightning Talk)

Gatto, J.V. and Trexler, J.C. Using Agent Based Modeling to Predict Fish Movement Patterns in the Florida Everglades. American Fisheries Society Annual Meeting, Tampa, FL. August 2017. (Oral Presentation in organized session Fish Movement and Biotelemetry)

Gatto, J.V. and Trexler, J.C. Using Agent Based Modeling to Predict Fish Movement Patterns in the Florida Everglades. Joint Meeting of Herpetologists and Ichthyologists, Austin, TX. July 2017. (Oral Presentation)

Bush, M. R., Gatto, J, Ontkos, A. \& Trexler, J. C. Effects of Hydroscape Modification on Everglades Aquatic Consumers: Evaluating Two Hypotheses. Greater Everglades Ecosystem Restoration Conference, Coral Springs, FL. April 2017. (Oral Presentation in organized session The DPM High-Flow Experiments: Direct Observations to Serve Adaptive Management)

Gatto, J.V. and Trexler, J.C. Using Agent Based Modeling to Predict Fish Movement Patterns in the Florida Everglades. Florida International University Biology Symposium, Miami, FL. February 2017. (Oral Presentation)

Gatto, J.V. and Trexler, J.C. Endurance Tests Explain Recolonization Patterns Following Hydrological Disturbance. Everglades National Park Symposium, Homestead, FL. August 2016. (Invited talk in organized session Restoring an iconic ecosystem?).

Gatto, J.V. and Trexler, J.C. Using Virtual Population Analysis (VPA) to estimate undersampled recruits to improve population dynamics models. Ecological Society of America Annual Meeting, Ft. Lauderdale, FL. August 2016. (Oral Presentation in organized session Population Dynamics: Modeling). 